\title{
DOPAMINERGIC MODULATION OF NEUROPLASTICITY IN HUMANS- CONTRIBUTION OF RECEPTOR SUBTYPES AND DOSAGE
}

\author{
Dissertation \\ for the award of the degree \\ "Doctor of Philosophy" \\ Division of Mathematics and Natural Sciences \\ within the doctoral program Systems Neuroscience \\ of the Georg-August-Universität Göttingen
}

submitted by

Shane Fresnoza

from

Manila, Philippines

Göttingen, 2014 


\section{Doctoral Thesis Committee:}

Prof. Dr. med. Michael A Nitsche (Supervisor, First Referee)

University of Goettingen

Department of Clinical Neurophysiology

Robert-Koch-Straße 40

37075 Göttingen

Prof. Dr. Michael Waldmann (Reviewer)

University of Goettingen

Department of Psychology

Gosslerstr. 14

D-37073 Goettingen

\section{Prof. Dr. Eberhard Fuchs}

German Primate Center

Clinical Neurobiology Laboratory

Kellnerweg 4

37077 Göttingen

Date of thesis submission: 25.07 .2014

Date of oral examination: 04.09 .2014 


\section{Statement of Originality}

I hereby declare that the work entitled, "Dopaminergic modulation of

neuroplasticity in humans-contribution of receptor subtypes and dosage" was independently written and the sources or aids used whether verbatim or in content are properly quoted in the text and references.

Goettingen, July 25, 2014

Shane Matsune Fresnoza 


\section{Declaration of Contribution}

I hereby declare the following contributions I made for the two studies included in the thesis entitled: "Dopaminergic Modulation of Neuroplasticity in HumansContribution of Receptor Subtypes and Dosage".

1. Fresnoza S, Paulus W, Nitsche MA, Kuo M-F (2014) Nonlinear Dose-Dependent Impact of D1 Receptor Activation on Motor Cortex Plasticity in Humans. The Journal of Neuroscience 34(7):2744-2753. Status: Published

Contributions: Participants recruitment and screening, data acquisition, statistical analysis, interpretation of the data, preparations of the articles for submission and revisions of the article.

2. Fresnoza S, Stiksrud E, Klinker F, Liebetanz D, Paulus W, Kuo MF, Nitsche MA (2014) "Dosage-dependent effect of D2 receptor activation on motor cortex plasticity in humans" Status: Accepted for publication (Journal of Neuroscience)

Contributions: Participants recruitment and screening, data acquisition, statistical analysis, interpretation of the data, preparations of the articles for submission and revisions of the article.

Dr. F. Klinker, Dr. E. Stiksrud, Prof. D. Liebetanz and Prof. W. Paulus provided guidance in revision of the articles. Dr. M-F. Kuo and Prof. M. Nitsche contributed to the study design, revising and approval of the final version of the manuscripts.

Shane Matsune Fresnoza

Goettingen, 25.07.2014 


\section{DEDICATION}

I dedicate my doctoral thesis to all the human volunteers who participated in the studies and to all the people suffering from illnesses that might benefit from the results of this work in the future. 


\section{Abbreviations}

ADM -

ADHD-

AMPA -

AP-

CaMKII-

CNS-

COMT-

DC-

EPSP-

FDI-

GABA-

ISI-

IPSP-

L-DOPA-

LTD-

LTP-

M1-

MEP-

MRI-

MT-

NBS- abductor digiti minimi muscle

attention deficit/hyperactivity disorder

$\alpha$-amino-3-hydroxy-5-methyl-4-isoxazolepropionic acid

action potential

calcium/calmodulin dependent kinase

central nervous system

catechol-O-methyltransferase

direct currect

excitatory post synaptic potential

first dorsal interosseus

$\alpha$-amino-3-hydroxy-5-methyl-4-isoxazolepropionic acid

inter-stimulus interval

inhibitory post synaptic potential

L-3,4-dihydroxyphenylalanine

long term depression

long term potentiation

primary motor cortex

motor evoked potential

magnetic resonance imaging

motor threshold

Non-invasive Brain stimulation 
NMDA-

PAS-

PAS10-

PAS25-

PFC-

rTMS-

STDP-

tDCS-

TES-

TMS-
$\mathrm{N}$-methyl-D-aspartate

paired associative stimulation

paired associative stimulation with $10 \mathrm{~ms}$ interstimulus

interval

paired associative stimulation with $25 \mathrm{~ms}$ interstimulus

interval

prefrontal cortex

repetitive transcranial magnetic stimulation

spike-timing dependent plasticity

transcranial direct current stimulation

transcranial electric stimulation

transcranial magnetic stimulation 


\section{Table of Contents}

Table of Contents .............................................................................................................. 1

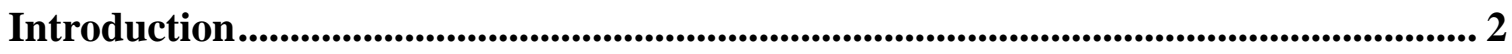

Chapter 1: Plasticity in the central nervous system ................................................ 4

1.1 Mechanisms of functional glutamatergic plasticity..................................................... 8

1.2 Exploring Plasticity in the Human Brain........................................................................ 10

1.2.1 The motor cortex as a model for studying plasticity .................................................... 12

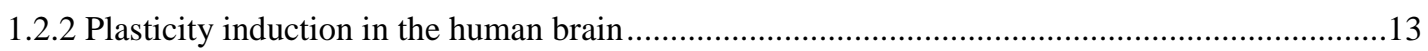

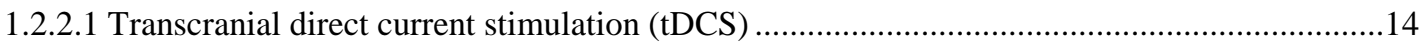

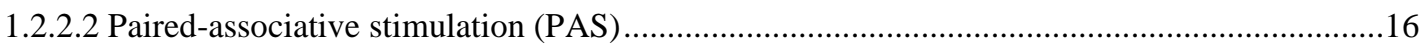

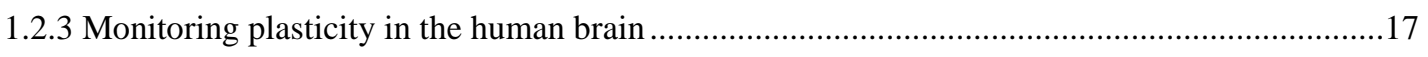

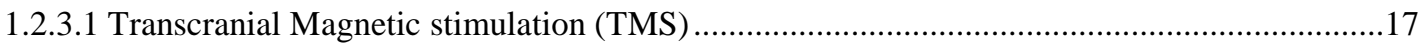

1.3 Dopaminergic modulation of neuroplasticity ........................................................ 18

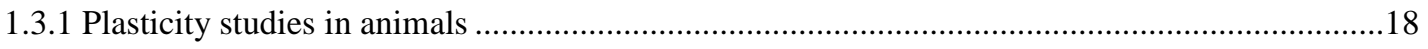

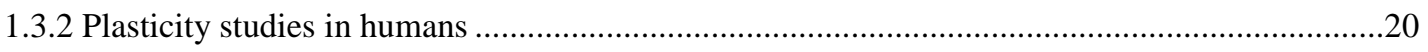

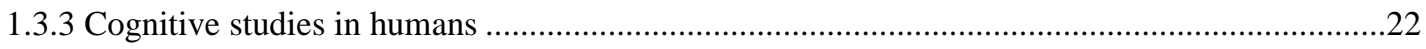

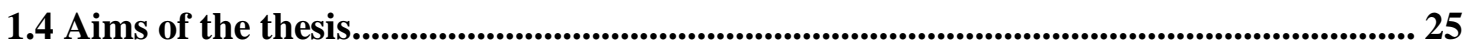

Chapter 2: Original articles and manuscripts......................................................................... 26

2.1 Nonlinear Dose-Dependent Impact of D1 Receptor Activation on Motor Cortex Plasticity in Humans ........................................................................................................................... 27

2.2 Dosage-dependent effect of $\mathrm{D} 2$ receptor activation on motor cortex plasticity in

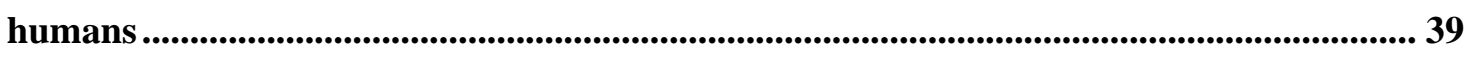

Chapter 3: Summary, Limitations and Conclusions .............................................. 70

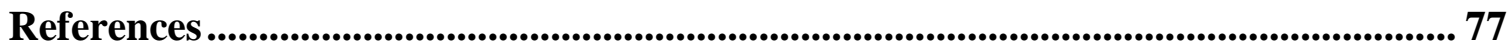

Acknowledgements ........................................................................................................ 94

Curriculum Vitae ................................................................................................................ 96 


\section{Introduction}

From infancy up to adulthood and beyond, the brain reacts adaptively to the continuously changing environment. This capacity is termed "plasticity" and describes the ability of the brain to develop, react to environmental demands by producing proper behavior and repair itself after a disease or injury. Neuroplastic modifications of brain structure and functions are also thought to be important physiologic mechanisms of learning skills and remembering events in our life. Two functional changes taking place at the glutamatergic but also other synapses, namely long term potentiation (LTP) and long term depression (LTD), are considered as synaptic correlates of learning and memory processes (Jay, 2003). Pioneering attempts to study and understand the basic mechanisms of LTP and LTD induction and expression were conducted in slice preparations and in vivo animal studies. However, over the last decades, non-invasive brain stimulation (NBS) techniques such as transcranial magnetic stimulation (TMS), transcranial direct current stimulation (tDCS) and paired associative stimulation (PAS) (Barker et al., 1985; Nitsche and Paulus, 2000; Stefan et al., 2000) emerged, which allow the induction and exploration of plasticity which share some properties with plasticity induced in animal models also in humans. Recently, combining these techniques with central nervous system (CNS) active drugs and imaging techniques (Ziemann, 2004; Ko et al., 2013; Saiote et al., 2013) has given us additional opportunities to study mechanisms and effects of cortical plasticity in the intact human brain.

Neuroplasticity is influenced by substances termed neuromodulators. Among these neuromodulators, dopamine has received the most attention since the discovery that L-3,4-dihydroxyphenylalanine (L-DOPA), the synthetic precursor of dopamine, can 
alleviate the motor symptoms of Parkinson's disease (Abbott, 2010), and that antagonizing dopamine receptor subtypes can relieve positive symptoms of schizophrenia (Seeman, 1987). In physiological and cognitive studies in animals, a complex, heterogeneous, sometimes opposing pattern of effects of alteration of dopaminergic activity emerges, depending on dosage, affected receptor subtypes, and basal brain activity (Seamans and Yang, 2004). The results of human electrophysiological studies improved our knowledge about the impact of dopamine on neuroplasticity (Kuo et al., 2008; Monte-Silva et al., 2009; Nitsche et al., 2009; Monte-Silva et al., 2010; Thirugnanasambandam et al., 2011), however, it is still far from being complete. Specifically, the impact of dopamine receptor subtypes on neuroplasticity in humans was not explored systematically so far. Given the presumed relevance of neuroplasticity for cognition and behavior in health and disease, improving this knowledge might enhance our understanding of respective processes.

In this project we were interested to explore the dosage-dependent, specific effects of dopamine receptor subtype activation on functional plasticity of the human brain. The first chapter will give an introduction into the basic concept of plasticity, its relation to cognitive processes, and modulation by dopamine, and the techniques of inducing and evaluating plasticity in humans. The second chapter contains the main component of the thesis; each subchapter consists of published projects or projects accepted for publication. Finally, the last chapter will discuss the main findings of the present work, including limitations, and future directions for research. 


\section{Chapter 1: Plasticity in the central nervous system}

Plasticity can be defined as any enduring change of cortical properties, either morphological or functional (Donoghue, 1995). Plasticity can occur at different levels of the central nervous system, from a single neuron, to synaptic levels and up to subcortical/cortical networks (Figure 1). An example for macroscopic structural changes is the increase of finger representations of the motor cortex of monkeys and rats observed after grasping training (Kleim et al., 1996; Nudo et al., 1996; Kleim et al., 1998). In humans, parts of the brain involved in skill training and learning were also shown to gain volume (Kami et al., 1995; Pascual-Leone, 1995). TMS mapping and magnetic resonance imaging (MRI) revealed an increase in gray matter volume and cortical representations in some brain areas of professional musicians (Elbert et al., 1995; Sluming et al., 2002; Gaser and Schlaug, 2003), mathematicians (Aydin et al., 2007) and athletes (Tyč et al., 2005; Park et al., 2009) whereas among dancers a decrease in gray and white matter volume was evident (Hänggi et al., 2010). Injuries can also lead to structural brain changes, the loss of afferent input is followed by neuroplastic alterations of cortical functions, e.g. re-organization of somatosensory cortex representation maps after limb amputation (Borsook et al., 1998), or of the visual cortex in blind patients (Pascual-Leone and Torres, 1993; Boven et al., 2000). Additionally, brain lesions are followed by structural and functional plastic changes (Carmichael, 2003; Schaechter et al., 2006) of both, the injured and non-injured motor cortex (Nudo et al., 2003).

Most kinds of neuroplastic processes seem to improve adaption to environmental or internal changes and cause beneficial effects like skill enhancement or recovery from brain injury (Peterson, 2012). On the other hand, plasticity in the brain can be also 
maladaptive, when it leads to behavioral loss or even the development of disease symptoms (May, 2011). For instance, the age-related decline in the efficiency of plasticity in humans (Freitas et al., 2011) might explain the accompanying cognitive decline at least partially. Human plasticity studies also revealed aberrant plasticity mechanisms in conditions like autism (Oberman et al., 2012; Jung et al., 2013), Alzheimer's disease (Battaglia et al., 2007; Koch et al., 2011; Koch et al., 2012) and schizophrenia (Fitzgerald et al., 2004; Frantseva et al., 2008; McClintock et al., 2011). Thus, naturally occurring plasticity in the human brain has been implied to be of profound importance for a multitude of normal, but also pathological brain functions.

At the synaptic level, plasticity is accomplished by structural and functional reorganization of the respective connections via the strengthening or weakening of synapses (Citri and Malenka, 2007). Structural remodeling includes changes in synapse morphology (Lamprecht and LeDoux, 2004; Barnes and Finnerty, 2010; Foscarin et al., 2012), such as the experience-dependent stabilization and destabilization or formation and elimination of synapses in mice's barrel cortex (Trachtenberg et al., 2002; Holtmaat et al., 2006; Knott et al., 2006) and injury-induced axonal sprouting in the motor cortex of squirrel monkeys (Dancause et al., 2005). The experimental work of the thesis will focus on another type of plasticity termed "functional plasticity" of the glutamatergic synapse, the main excitatory synapse in the human brain. It is accomplished by the increase or decrease of the efficiency of an already existing synapse. With regard to the duration of the effects, the first 60 minutes of functional plasticity are referred to as "early" phase and the longer lasting protein-synthesis-dependent part (duration of hours or up to weeks or months) is called the "late" phase (Malenka and Bear, 2004). Another 
important feature of functional plasticity is its direction. For long term synaptic plasticity, which has received the most attention due to its possible role in memory and learning processes, long term potentiation (LTP), which refers to enhanced cortical excitability, and long term depression (LTD), which is a long-lasting reduction of excitability of the target synaptic connections, can be discerned. LTP and LTD are presumably expressed in all excitatory brain circuits as well as at the inhibitory GABAergic synapse (Kano, 1995; Malenka and Bear, 2004; Rueda-Orozco et al., 2009).

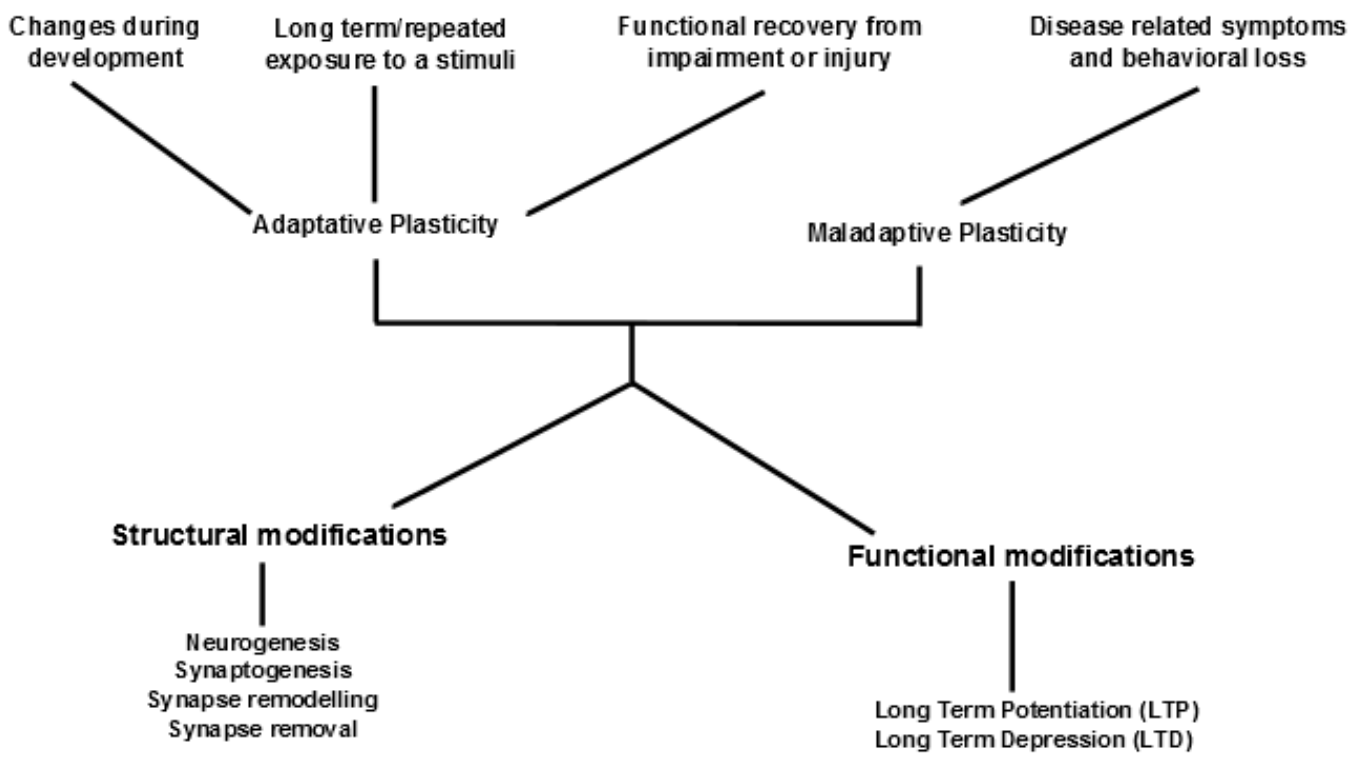

Figure 1. Schematic diagram of different types of plasticity which lead to structural and functional changes at the level of the synapses. (Adapted from Trojan and Pokorny, Physiological research / Academia Scientiarum Bohemoslovaca, 1999). 
Plasticity is thought to be the underlying mechanism of learning and memory. The Hebbian theory was the first to offer an explanation on how neurons adapt during a learning process. According to this concept, strengthening of a synapse occurs when two neurons are active at the same time (Hebb, 1988). The LTP induced at glutamatergic synapses in the hippocampus of the anaesthetized rabbit via repetitive stimulation at high frequency of the perforant path leading to strengthening of the synapse between perforant path and granule cells (target cells) of the dentate gyrus (Bliss and Gardner-Medwin, 1973; Bliss and Lømo, 1973) satisfies the criteria proposed by Hebb making it a viable model of long term memory storage (Bliss and Collingridge, 1993; Bliss and Cooke, 2011). LTD on the other hand, first demonstrated in rat hippocampal slices in vitro and in the dentate gyrus of anaesthetized rats (Lynch et al., 1977; Levy and Steward, 1979), also exhibits properties like occurrence (that is, LTD can be induced experimentally in the neural circuits that are relevant for a specific cognitive function), necessity (that is blocking LTD disrupts the respective function), and sufficiency (that is, induction of LTD produces behavior similar to the function) that suggest it has a role in learning and memory too (Collingridge et al., 2010). Subsequently, LTP- and LTD-like plasticity was also induced electrophysiologically in many other cortical areas like the barrel (Fox, 2002), visual (Kirkwood and Bear, 1994; Heynen and Bear, 2001), auditory (Pereda et al., 1998; Newton and Sur, 2005), the somatosensory and motor cortex (CastroAlamancos et al., 1995), suggesting that plasticity is an ubiquitary mechanism of the CNS. In accordance with electrophysiological studies, experience-induced anatomical changes in the brain have been shown also in animal (Rioult-Pedotti et al., 1998a; Trachtenberg et al., 2002; Gruart et al., 2006; Holtmaat et al., 2006; Whitlock et al., 
2006) and human studies (Draganski et al., 2004; May, 2011). Furthermore, a study that showed that the suppression of LTP after learning can erase a previously learned skill strengthened the idea that LTP maintenance is necessary for memory maintenance as well (Bliss et al., 2006).

Therefore, exploring the mechanisms of neuroplasticity in humans is relevant for improving our comprehension of brain physiology in health and disease, as well as understanding the neural basis of learning and memory mechanism in humans.

\subsection{Mechanisms of functional glutamatergic plasticity}

Plasticity of the glutamatergic system is accomplished primarily via calciumpermeable NMDA (N-methyl D-aspartate) receptors (Malenka and Bear, 2004; Bliss and Collingridge, 2013). Dependent on the amount of calcium influx into the subsynaptic neuron, both, LTP, and LTD, can be induced (Lisman, 2001). It has been demonstrated that a strong calcium increase results in LTP, and a weak elevation of calcium concentration triggers LTD (Hansel et al., 1996; Yang et al., 1999; Cormier et al., 2001) (see figure 2).

When the postsynaptic membrane is significantly depolarized via presynaptic glutamate release, and consecutive opening of $\alpha$-amino-3-hydroxy-5-methyl-4isoxazolepropionic acid (AMPA) receptors, which have sodium channel properties, the voltage-dependent block of the NMDA receptor by magnesium is relieved allowing calcium to enter the postsynaptic dendritic spines, soma or the axon. This rise in postsynaptic calcium, if sufficiently large, triggers the activation of intracellular 
signaling cascades that include several protein kinases, most notably the calcium/calmodulin dependent kinase (CaMKII) (Lynch et al., 1983; Malenka et al., 1988; Malenka et al., 1999; Malenka, 1999 ; Lisman et al., 2002). Activation of these kinases results in insertion of AMPA receptors in the postsynaptic plasma membrane, therefore resulting in larger depolarization of the postsynaptic neuron following a given presynaptic glutamate release, and thus enhanced efficacy of the respective synaptic connection (Malenka et al., 1999; Malenka and Bear, 2004). LTD on the other hand is thought to result from a smaller rise in postsynaptic calcium (Lisman, 1989; Artola and Singer, 1993; Hansel et al., 1997; Nishiyama et al., 2000). This triggers a different subset of calcium-dependent intracellular signaling molecules than those required for LTP, including serine/threonine phosphatases which dephosphorylate critical synaptic substrates, including the AMPA receptor, which de-activates the latter. The depression of synaptic strength in case of LTD is additionally due to the removal of synaptic AMPA receptors via dynamin- and clathrin-dependent endocytosis (Malenka and Bear, 2004). For intermediate calcium concentrations, the existence of a zone between LTP and LTD, called the " no man's land", was reported, which does not result in any plasticity (Cho et al., 2001; Lisman, 2001). Moreover, calcium levels above the threshold for LTP induction might prevent plasticity probably due to the activation of hyperpolarizing potassium channels (Misonou et al., 2004). 


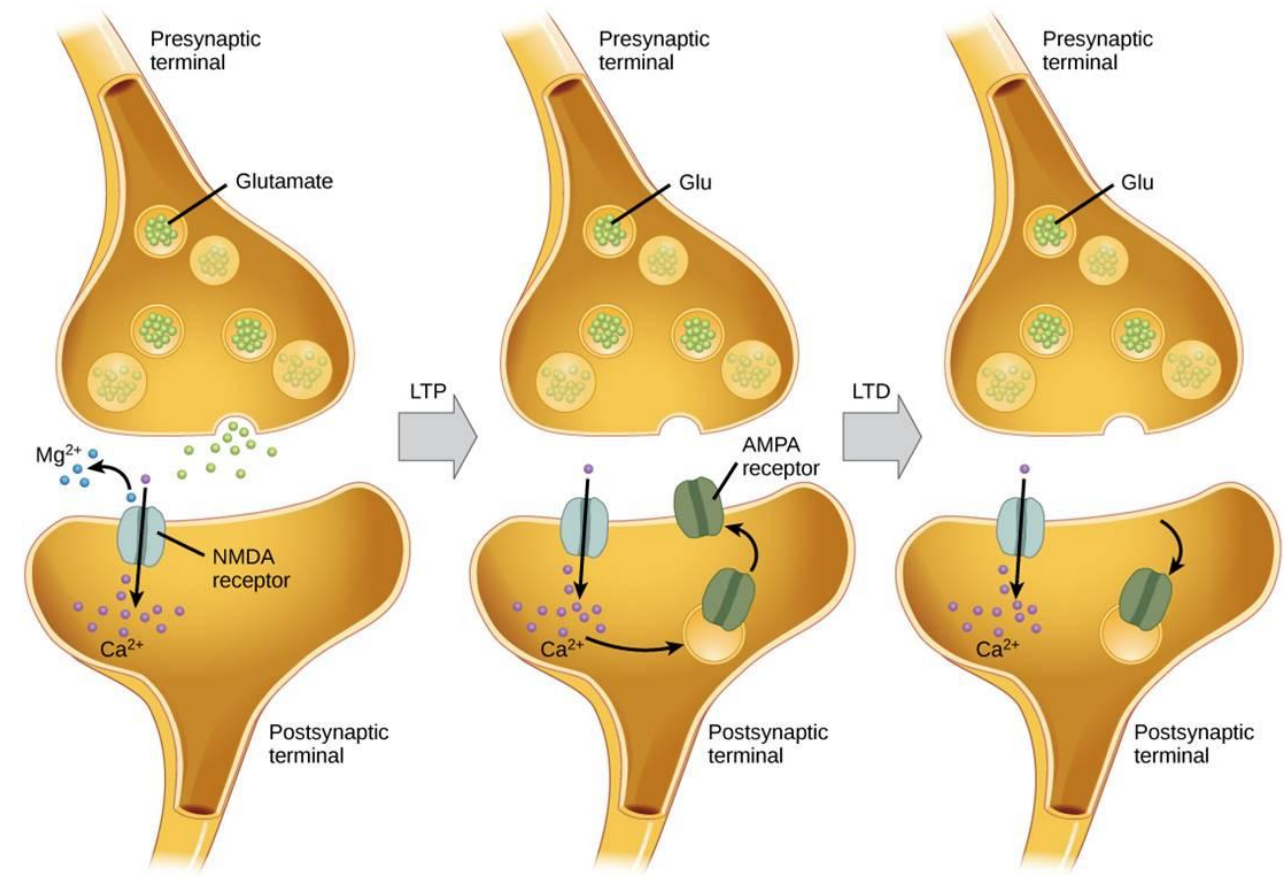

Figure 2. Schematic illustration of LTP and LTD at the glutamatergic synapse. The level of calcium influx into the postsynaptic membrane determines the direction of plasticity. Strong calcium increase leads to cascades of events resulting in the insertion of AMPA receptors in the postsynaptic membrane which causes strengthening or potentiation of synaptic strength (LTP). Weak calcium increase leads to the removal of AMPA receptors from the postsynaptic membrane causing synaptic weakening or depression (LTD). (Adapted from Hauser, L. 2013. Derived copy of Biology 102. OpenStax-CNX, July 15, 2013. http://cnx.org/content/col11541/1.1/.).

\subsection{Exploring Plasticity in the Human Brain}

Our knowledge about plasticity in the human brain is still far from being complete. A limited set of studies explored LTP at the cellular level. It could be shown in vitro in hippocampal and temporal cortex tissues of epileptic patients that LTP can be induced also in the human brain via stimulation techniques which were developed in animal 
experimentation (Chen et al., 1996a; Beck et al., 2000; Cooke and Bliss, 2006). This approach is however restricted, because respective brain material is rare, and because of missing spontaneous activity, and disease-related alteration of cortical architecture, the results might not easily be transferred to the healthy human brain in vivo. During the last decades, however, technological advances in the field of non-invasive brain stimulation (NBS) techniques emerged allowing the controlled induction of prolonged cortical excitability alterations, as well as the monitoring of respective effects in awake human subjects. These include transcranial magnetic stimulation (TMS), repetitive transcranial magnetic stimulation (rTMS), transcranial direct current stimulation (tDCS) and paired associative stimulation (PAS) (Barker et al., 1985; Nitsche and Paulus, 2000; Stefan et al., 2000; Nitsche and Paulus, 2001; Huang et al., 2005) (Figure 3). In accordance with the functional relevance of plasticity, these techniques can also alter behavior and cognitive functions non-invasively in both healthy and patient populations (Fregni et al., 2006; Salatino et al., 2013; Park et al., 2014). In the present work we will focus on tDCS and PAS as means for inducing plasticity; and single pulse TMS to measure the increase and decrease in excitability of neurons in the human motor cortex.
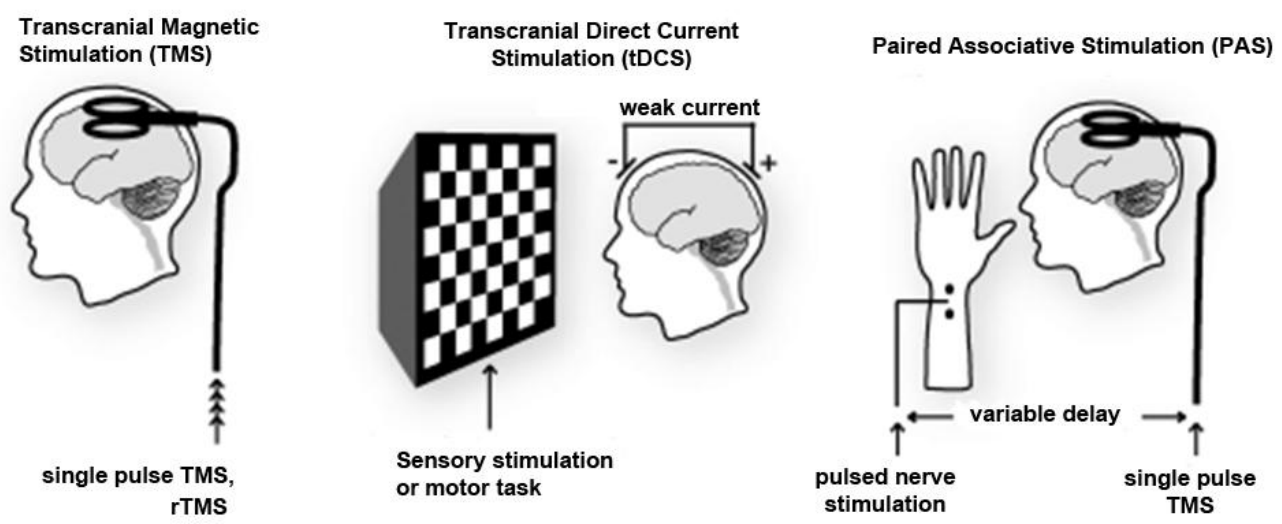
Figure 3. Non-invasive Brain Stimulating Techniques: Single pulse transcranial magnetic stimulation (TMS) can be used for monitoring excitability changes in the motor cortex. Repetitive transcranial magnetic stimulation (rTMS), transcranial direct current stimulation (tDCS) and paired associative stimulation (PAS) are mainly used to induce LTP and LTD-like plasticity in the motor cortex. (Figure adapted and modified from Bliss and Cooke, Clinics, 2011).

\subsubsection{The motor cortex as a model for studying plasticity}

Although the primary motor cortex (M1) was for a long time perceived solely as an effector area for the initiation of movements, plasticity of this region is well documented (Pascual-Leone et al., 2005), and in accordance with recently published studies this area is more actively involved in motor learning and memory formation than previously thought (Rioult-Pedotti et al., 2000; Muellbacher et al., 2002; Nitsche et al., 2003b). Thus this region is principally well suited to study plasticity and physiological cognitive/behavioral interactions in the human brain. It is furthermore well suited to serve as a model system because of the following reasons: First, the anatomical, physiological and functional properties of the human motor cortex are well established. It consists of six layers of cells with layer 5 as the descending output layer containing the giant Betz cells. Cells of the primary motor cortex (M1) are the most excitable and encode for movement force and control (Pruszynski et al., 2007). The horizontal connections within the primary motor cortex (M1) are suggested to have a capacity for long-lasting synaptic modification, such as strengthening of horizontal cortical connections following motor 
skill learning (Kleim et al., 1998; Rioult-Pedotti et al., 1998b; Sanes and Donoghue, 2000). Second, its location at the cerebral surface, which holds true especially for the hand area, makes it an accessible target for non-invasive brain stimulation techniques. Finally, excitability, and activity of this area can be easily monitored via TMS/MRI to explore global corticospinal excitability, and specific transmitter/neuronal systems (Rothwell, 1993; Ziemann, 2004).

\subsubsection{Plasticity induction in the human brain}

Prior to the invention of transcranial electrical stimulation (TES) by Morton and Merton in 1980, most of the techniques developed were applied for therapeutic purposes

only, and not intended for research. TES was the first non-invasive technique suited for stimulating neurons of the intact human brain (Merton and Morton, 1980). It uses suprathreshold low frequency high-intensity pulses, and is painful, making its application as an experimental technique problematic. In 1985, Barker and colleagues introduced a new non-invasive brain stimulation technique, called Transcranial Magnetic Stimulation (TMS) (Barker et al., 1985). This technique later gave rise to the development of rTMS, another technique for inducing plasticity, which is however beyond the scope of this thesis. In the experiments included in the present thesis, we used paired associative stimulation (PAS), which combines peripheral nerve stimulation with single pulse TMS, which induces an associative kind of plasticity (Stefan et al., 2000), and tDCS, which uses subthreshold electrical stimulation to induce changes of cortical excitability (Nitsche and Paulus, 2000). 


\subsubsection{Transcranial direct current stimulation (tDCS)}

The fact that tonic application of relatively weak direct currents can induce neuronal excitability and activity alterations in animals was first demonstrated in the 1960's. It was observed that applying positive polarizing currents in vitro and in vivo causes an increase in the frequency of spontaneous neuronal spiking, whereas negative polarizing currents reduce neuronal firing compared to baseline values (Creutzfeldt et al., 1962; Bindman LJ, 1964; Purpura and McMurtry, 1965). The effects during stimulation are due to direct current (DC)-induced subthreshold changes of the resting membrane potential (Bindman LJ, 1964; Purpura and McMurtry, 1965). Later experiments revealed that after effects, which can last for many hours after the end of stimulation for a few minutes, depend on protein synthesis (Gartside, 1968), alter intracellular cAMP concentration (Hattori et al., 1990), and intracellular calcium concentration and gene expression mediated by NMDA receptors (Islam et al., 1995a; Islam et al., 1995b). Therefore, the after-effects depend on plasticity mechanisms similar to those obtained in LTP and LTD induced by more "classic" stimulation protocols (Islam et al., 1995a). In 2000, Nitsche and Paulus published a study in which they could show that transcranial direct current stimulation induces similar effects on motor cortex excitability in awake humans (Nitsche and Paulus, 2000). Analogous to the effect of polarizing currents observed in animals studies (Bindman LJ, 1964; Purpura and McMurtry, 1965), if applied for 13 minutes, anodal stimulation with an intensity of $1 \mathrm{~mA}$ (milliampere) induces a prolonged increase of cortical excitability, whereas cathodal tDCS for 9 minutes induces opposite effects (Nitsche and Paulus, 2001; Nitsche et al., 2003a; Nitsche et al., 2008). Furthermore, similar to the results obtained in animal experiments, the primary effects of 
tDCS depend on shifts of membrane polarization hence, the voltage-gated calcium channel blocker flunarizine and Na-channel blocker carbamazipine abolished the effects of depolarizing anodal stimulation, but had no impact on membrane-hyperpolarizing cathodal stimulation. Furthermore the NMDA receptor antagonist dextromethorphan and GABAA receptor agonist lorazepam had no effect during stimulation, in accordance with a primary effect of tDCS on neuronal membranes, but not synapses (Nitsche et al., 2003c; Nitsche et al., 2004b). The after effects on the other hand, which usually last for 1 hour, and thus are in the range of early LTP/LTD, are both NMDA- and calcium channeldependent (Liebetanz et al., 2002; Nitsche et al., 2003c; Nitsche et al., 2004a) suggesting similar mechanisms as shown for glutamatergic LTP and LTD induced in animal models (Malenka and Bear, 2004). The weak subthreshold direct current applied over the scalp stimulates underlying cortical neurons tonically but nonspecifically, thus the effect is not focal (Nitsche and Paulus, 2000). Evidence exists that the plastic changes in the human motor cortex induced by tDCS are predominantly cortical rather than subcortical (Nitsche and Paulus, 2000; Nitsche et al., 2005; Miranda et al., 2006; Wagner et al., 2007).

TDCS can also modulate cognitive functions (for a review see, (Kuo and Nitsche, 2012). Anodal tDCS at the motor cortex applied during performance improved motor sequence learning (Nitsche et al., 2003b) and enhanced motor skill learning (Reis et al., 2009). Stimulation at the motor cortex and visual cortex of healthy subjects also improved performance in the learning phase of a visuo-motor coordination task (Antal et al., 2004). Additionally, temporal lobe stimulation with anodal tDCS reduced false memories in healthy subjects, while it improved recognition memory and working memory in Alzheimer's and Parkinson's disease patients respectively (Boggio et al., 
2006; Boggio et al., 2009b; Boggio et al., 2009a). The enhancing effect of anodal tDCS on learning can be hypothetically explained by the synergistic effects of tDCS-induced, and learning-generated LTP on task-dependent cortical networks (Stagg and Nitsche, 2011).

\subsubsection{Paired-associative stimulation (PAS)}

PAS is a technique which combines stimulation of somatosensory afferents of a mixed peripheral nerve with motor cortex TMS (Stefan et al., 2000; Stefan et al., 2002; Wolters et al., 2003). In the "classic" protocol, a peripheral electrical stimulus with an intensity set to $300 \%$ of the sensory perceptual threshold is applied to a peripheral nerve. This is combined with a suprathreshold TMS pulse to the contralateral motor cortex with an ISI of 10 or $25 \mathrm{~ms}$ at a frequency of $0.05 \mathrm{~Hz}$ for 30 minutes (Stefan et al., 2000; Wolters et al., 2003). Like tDCS, the effect of PAS on the motor cortex are localized intracortically (Müller-Dahlhaus et al., 2010), however, PAS induces phasic suprathreshold synaptic activation. The physiological mechanism behind PAS is based on the principles of spike timing-dependent plasticity (STDP) initially observed in animal studies (Gustafsson et al., 1987; Markram et al., 1997; Bi and Poo, 1998; Debanne et al., 1998). Similar as in STDP, neuroplastic excitability alterations induced by PAS critically depend on the interstimulus interval (ISI) between the peripheral nerve stimulus and the TMS pulse. An interval of 10ms (PAS10) (Wolters et al., 2003) results in an excitability reduction, while an interval of 25ms (PAS25) increases excitability, longer ISI (100, 525 and $5000 \mathrm{~ms})$ however, have no effect (Stefan et al., 2000). In PAS10, the afferent inputs elicited by median nerve stimulation reaches the motor cortex after the TMS pulse, causing an asynchronous activation of the motor cortex. In accordance, in animal models, an action 
potential (AP) preceding an excitatory post synaptic potential (EPSP) induces calciumdependent NMDA receptor inactivation which induces LTD (Zucker, 1999). In PAS25, the afferent input precedes the TMS pulse causing a synchronous activation of the motor cortex. Again in accordance, back-propagated APs triggered by large EPSPs or by other inputs enhance calcium influx through NMDA receptors causing LTP in animal models (Zucker, 1999). PAS is thought to induce LTP-like or LTD-like plasticity at glutamatergic synapses. The NMDA receptor blocker dextromethorphan blocks both LTP and LTD-like plasticity induced by PAS (Stefan et al., 2002; Wolters et al., 2003) while nimodipine, an L-type voltage-gated calcium channel blocker, prevents the LTD-like effect of PAS10 (Wolters et al., 2003). This suggests that the mechanism of PAS shows some similarities with cellular STPD. The proposed plastic effect of PAS are largely restricted to synapses connecting the sensory and motor cortex (Stefan et al., 2000), hence compared to tDCS its effect is more specific or focal.

\subsubsection{Monitoring plasticity in the human brain}

\subsubsection{Transcranial Magnetic stimulation (TMS)}

TMS is based on the principles of electromagnetic induction. The magnetic field generated by the coil induces a secondary electric current in a postero-anterior direction in the underlying cortex, which depolarizes cortical neurons, which in turn activates the respective pyramidal tract neurons, causing a motor evoked potential (MEP) (Di Lazzaro et al., 1998). MEP latency reflects central nervous system (CNS) conduction time in the corticospinal tract, whereas the size of the MEP amplitude reflects corticospinal excitability (Rothwell, 1993). Comparing the changes in MEP amplitudes before and after intervention thus provides a measure of excitability alterations induced by the 
respective intervention. Other TMS protocols like double pulse or paired pulse TMS protocols allow the specific exploration of excitatory and inhibitory intracortical systems (Kujirai et al., 1993; Tokimura et al., 1996; Ziemann et al., 1996).

\subsection{Dopaminergic modulation of neuroplasticity}

Neuromodulators are transmitters that can alter plasticity but are not essential for its occurrence (Malenka and Bear, 2004). They induce little or no change in basal neuronal activity, but potentiate or attenuate responses evoked by other transmitter substances (Barchas et al., 1978). Dopamine is one of the major neuromodulators in the brain and exerts its action by binding to specific receptors at the postsynaptic and presynaptic membrane (Vallone et al., 2000). The five dopamine receptors are grouped into two subfamilies depending on their signaling, physiological and pharmacological properties (Kebabian and Calne, 1979; Sokoloff and Schwartz, 1995; Beaulieu and Gainetdinov, 2011). The D1 and D5 receptors belong to the D1-like, while, D2, D3 and D4 receptors constitute the D2-like receptor family.

\subsubsection{Plasticity studies in animals}

In electrophysiological studies in animals, dopamine application results in both, inhibitory and excitatory responses in neurons of the prefrontal and motor cortices, although inhibitory responses predominate (Bernardi et al., 1982; Bradshaw et al., 1985; Sawaguchi et al., 1986; Awenowicz and Porter, 2002). These cellular effects are reflected by the impact of dopamine on plasticity, showing both facilitatory as well as inhibitory effects on LTP and LTD (Jay, 2003), in accordance with the assumption that dopamine is not a driver, but a modulator of synaptic plasticity. In general, the impact of dopamine 
on neuronal excitability/plasticity is complex and depends on receptor subtype, dosage or level of stimulation, and the kind of plasticity being induced (Jay, 2003; Seamans and Yang, 2004).

With regard to the contribution of dopaminergic receptor subtypes, is was shown that D1 receptors have an enhancing effect on NMDA and GABAergic synaptic currents (Seamans and Yang, 2004), and a positive impact on LTP and LTD. Animal experiments are in favor for a supportive role of the D1 receptor for LTP induction in the PFC (Gurden et al., 2000; Huang et al., 2004) striatum (Kerr and Wickens, 2001; Centonze et al., 2003) and hippocampus (Otmakhova and Lisman, 1996; Bailey et al., 2000). Activation of the D1 receptors also enhances LTD in the striatum (Calabresi et al., 1992; Calabresi et al., 2000) however, reversal of LTD into a transient potentiated state in the hippocampus of the rat was reported in another study (Mockett et al., 2007). In contrast, the D2 receptor has a reducing effect on NMDA and GABAergic synaptic currents as revealed by electrophysiological studies in the striatum and prefrontal cortex (PFC) (Tseng and O'Donnell, 2004). Compared to the D1-mediated impact, D2 receptor activation resulted in mixed effects, causing LTP enhancement in-vitro/in-vivo in the hippocampus and in the basolateral amygdala-dentate gyrus pathway (Frey et al., 1989; Manahan-Vaughan and Kulla, 2003; Abe et al., 2008), LTD enhancement in-vitro at the prefrontal cortex and striatum (Otani et al., 1998; Spencer and Murphy, 2000; Centonze et al., 2001; Tang et al., 2001), but also diminishing effects on LTD and LTP were reported (O'Donnell and Grace, 1994; Chen et al., 1996a). An impact of dopamine on cognitive functions, which can be assumed to base on the physiological effects of the substance, was first observed in the pioneering work of Brozoski and colleagues. They 
observed impaired performance of a delayed response task following dopamine depletion in the PFC of monkeys (Brozoski et al., 1979). Succeeding studies across different animal species suggest a non-linear dopaminergic dose-response relationship (Murphy et al., 1996; Arnsten, 1997; Arnsten and Goldman-Rakic, 1998; Mizoguchi et al., 2000). For the dosage-dependent impact of dopamine receptor subtypes on cognition, a dosagedependency of D1 receptor-mediated effects was first studied in recordings of PFC neurons of animals engaged in a working memory task. The results of respective studies confirm that activation or inhibition of the D1 receptor has a dosage dependent non-linear effect on neuronal firing, and performance (Williams and Goldman-Rakic, 1995; Cai and Arnsten, 1997; Zahrt et al., 1997; Seamans et al., 1998; Goldman-Rakic et al., 2000; Floresco and Phillips, 2001; Sawaguchi, 2001; Lidow et al., 2003; Vijayraghavan et al., 2007; Kroener et al., 2009). Specifically, in these studies too much or too little D1 receptor stimulation impaired performance, and reduced firing rates, whereas optimal stimulation enhanced firing rates and improved cognitive performance (Williams and Goldman-Rakic, 1995; Murphy et al., 1996; Seamans and Yang, 2004). An inverted Ushaped effect of D2-like receptors stimulation is not well explored in cognitive studies in animals. However, a behavioral study in rats revealed such an effect on yawning (Collins et al., 2005).

\subsubsection{Plasticity studies in humans}

Plasticity research in the human brain aimed to disentangle the role of dopamine has been initiated some years ago. Two electrophysiological studies explored the dosagedependency of global dopamine activation on functional glutamatergic plasticity. Here an 
inverted U-shaped impact of non-specific dopaminergic stimulation was demonstrated. Low and high doses of L-dopa abolished or impaired plasticity, whereas under medium dosage plasticity was preserved except for the anodal tDCS LTP-like after-effect which was reversed into inhibition (Monte-Silva et al., 2010; Thirugnanasambandam et al., 2011). With regard to the contribution of dopaminergic receptor subtypes to these effects, electrophysiological studies concerning the impact of D1-like receptor stimulation are rare due to the lack of selective agonists and antagonists available for human use. In motor cortex plasticity studies, using an indirect approach by relatively enhancing D1 receptor activation by D2 receptor block abolished LTP and LTD-like plasticity, but adding L-DOPA under D2 receptor block, which should result in a relatively specific activation of D1-like receptors, re-established both types of plasticity (Nitsche et al., 2009), suggesting a crucial function of D1 receptor activation for plasticity induction. D2 receptor activity seems to be also relevant for plasticity induction in the human brain, since D2 receptor block by sulpiride abolishes different kinds of plasticity in the human motor cortex (Nitsche et al., 2006; Monte-Silva et al., 2009; Nitsche et al., 2009; MonteSilva et al., 2011). A study using the D2/D3 agonist ropinirole showed a non-linear effect of D2-like receptor activation on human motor cortex plasticity (Monte-Silva et al., 2009). However, ropinirole is a predominant D3 receptor agonist with a greater affinity for the D3 receptor (Coldwell et al., 1999). In animals, an opposing effect of D2 and D3 receptor activation on physiologic processes in the brain was observed (Collins et al., 2005; Collins et al., 2007; Collins et al., 2009). Therefore this study was not suited to elucidate the specific contribution of D2 receptor activation on plasticity in humans. 


\subsubsection{Cognitive studies in humans}

Many domains of cognitive functions in humans such as learning and memory formation, behavioral flexibility, and attention are critically dependent on dopaminergic activity, particularly of the prefrontal cortex and striatum (Nieoullon, 2002; D’Ardenne et al., 2012; Klanker et al., 2013; Costa et al., 2014). Hereby, the specific effects seem to depend on receptor subtypes, concentration, the type of task, baseline performance and stage/phase of learning process (Kimberg et al., 1997; Cools and D'Esposito, 2011).

In healthy individuals, global/non-specific dopaminergic activation with 100mg L-dopa was shown to enhance the speed, overall success, and long-term retention of word learning (Knecht et al., 2004) and enhance motor learning in the elderly (Flöel et al., 2005). This beneficial effect on learning was also observed in acute and chronic stroke patients (Scheidtmann et al., 2001; Rösser et al., 2008). With regard to the contribution of dopamine receptor subtypes, like in plasticity studies in humans, the impact of D2 receptors is better explored compared to that of D1-like receptors. To date, only 2 clinical studies have used selective D1 agonists and antagonists to explore their impact on cocaine abuse (Haney et al., 1999; Haney et al., 2001), however, the bioavailability of these agents was low (Breitenstein et al., 2006). In one study, the D1 agonist AB-431 did not affect the frequency of cocaine smoking, however, it dose-dependently decreased the subjective effect of cocaine (Haney et al., 1999). The D1 antagonist ecopipam on the other hand significantly decreased cocaine craving in the presence of placebo cocaine while it increased cocaine self-administration in the presence of active cocaine (Haney et al., 2001). With regard to D2-like receptor involvement in cognitive processes, some more studies, however with heterogeneous results, have been conducted. The D2-like 
agonist bromocriptine was shown to have a facilitating effect on visuospatial working memory (Luciana et al., 1992; Luciana and Collins, 1997; Luciana et al., 1998; Mehta et al., 2001), but this effect was not observed in other studies (Kimberg et al., 1997; Müller et al., 1998; Gibbs and D'Esposito, 2005). D2 receptor antagonists like sulpiride also resulted in mixed outcomes, showing negative (Mehta et al., 1999; Mehta et al., 2004) and no effect on working memory performance (Mehta et al., 2005). Dosage-dependent non-linear effects, which might contribute to these heterogeneous effects, have not been explored in humans directly so far. However, some dosage-dependent effects might be present. This assumption is suggested by genetic studies showing that a polymorphism of the catechol-O-methyltransferase (COMT), an enzyme that metabolizes dopamine, determines working memory performance. Carriers of the Met-allele (low COMT activity, higher dopamine level in the PFC) are performing better than Val-allele carriers (high COMT activity, low dopamine level in the PFC) in a working memory task (Egan et al., 2001; Rosa et al., 2010). However, other studies suggest that there is no homogeneous effect of the COMT polymorphism on cognition (Barnett et al., 2007). Moreover, the effect, if present, might be task-dependent (Cools et al., 2001; Kimberg and D'Esposito, 2003; Cools and D'Esposito, 2011). It was argued that the impact of dopamine on cognitive processes might be determined by the respective cognitive demand. Tasks which require flexible manipulation of neural information/representation would demand cognitive flexibility (de-focusing effect) via D2 receptor-mediated processes, whereas tasks requiring stable maintenance of information/representation would require cognitive stability (focusing effect) via a D1 receptor-mediated process (Costa et al., 2014). This hypothesis was conceptualized by the computational model put 
forward by Durstewitz and colleagues. In this model, a D1-dominated state favors cognitive stability by focusing on high activity states and increasing the threshold for noise, a D2-dominated state would allow cognitive flexibility via updating information by transition from different low activity states (Durstewitz et al., 2000; Seamans and Yang, 2004).

Evidence for such a task-dependent effect of dopaminergic modulation of cognition was observed in both healthy subjects and patients. Performance of healthy subjects taking the D2 receptor blocker sulpiride was impaired in a set switching task which involved cognitive flexibility, but improved in a delayed response task which requires cognitive stability (Mehta et al., 2004). Similar effects were also observed in an fMRI study involving healthy subjects. Here, after the intake of the D2 agonist bromocriptine, an improvement in switching performance, which was accompanied by a drug-induced modulation of activity in the putamen (D2 dominant area) during learning was observed, whereas lateral frontal (D1 dominant area) activity was unaltered. However, lateral frontal activity, but not striatal activity was modulated by bromocriptine during distraction, which might require more stable information processing in the presence of noise (Cools et al., 2007). This latter study also suggests that dopaminergic modulation of learning is not only influenced by task demands, but might depend also on the specific phase of task. Further support for this hypothesis originates from animal studies (Ichihara et al., 1988; Sigala et al., 1997; Puig and Miller, 2012), however, empirical evidence is still limited. 


\subsection{Aims of the thesis}

The general aim of the thesis is to explore the influence of dopamine on neuroplasticity in humans. Specifically, the two projects are designed to explore the effect of dopamine receptor subtypes on human motor cortical plasticity.

Project I- This project specifically aims to define the contribution of D1-like receptors on motor cortex plasticity with specific regard to a dosage-dependency of the effect, as well as its impact on focal and non-focal plasticity. This project challenges the unavailability of a specific D1 agonist suitable for application in humans by using an indirect approach of activating D1-like receptors via combination of global dopamine enhancement with D2 receptor block.

Project II- This project aims to identify the specific dosage-dependent role of D2 receptor stimulation on motor cortex plasticity. By using a D2 agonist, we discern the impact of specific D2 receptor activation from the result of an earlier study which used a mixed D2/D3 agonist (Monte-Silva et al., 2009). 


\section{Chapter 2: Original articles and manuscripts}

This chapter contains the two published papers included in the thesis. The first study focuses on the dose-dependent effect of the dopamine D1 receptor on focal and non-focal plasticity in healthy human subjects. The second study explores the specific dose-dependent effect of D2 receptor activation also on focal and non-focal plasticity in healthy human subjects with the specific aim of disentangling this effect observed from results of a previous study which used a mixed D2/D3 receptor agonist.

I- $\quad$ Fresnoza S, Paulus W, Nitsche MA, Kuo M-F (2014) Nonlinear Dose-Dependent Impact of D1 Receptor Activation on Motor Cortex Plasticity in Humans. The Journal of Neuroscience 34(7):2744-2753 (Published)

II- $\quad$ Fresnoza S, Stiksrud E, Klinker F, Liebetanz D, Paulus W, Kuo M-F, Nitsche MA (2014) Dosage-dependent effect of D2 receptor activation on motor cortex plasticity in humans. The Journal of Neuroscience (Accepted) 


\subsection{Nonlinear Dose-Dependent Impact of D1 Receptor Activation on Motor Cortex Plasticity in Humans}

Studies exploring the impact of the D1-like receptors on plasticity are rare in humans due to the lack of D1-selective agents available for application in humans. Data from electrophysiological studies in animals suggest a "focusing effect" of D1 receptor activation by suppressing irrelevant neuronal activity, increasing signal-to-noise ratio (Williams and Goldman-Rakic, 1995; Vijayraghavan et al., 2007). Cognitive studies in animals suggest that an optimum concentration of dopamine is needed for such a focusing effect, since too much or too little D1 receptor stimulation impaired, whereas medium/optimal dosage facilitated performance in a working memory task (Seamans and Yang, 2004). In humans, a similar focusing effect of dopamine on neuroplasticity was initially revealed by electrophysiological studies on human motor cortex plasticity. Global dopamine activation with 100mg L-dopa reversed the non-focal excitability enhancing effect of anodal tDCS into inhibition, but stabilized the PAS-induced synapsespecific excitability increase (Kuo et al., 2008). Moreover, a non-linear dosage dependent impact of global dopamine receptor activation was observed in motor cortex plasticity studies in humans. Too much or little dopamine receptor stimulation impaired or abolished, whereas medium/optimal stimulation preserved plasticity induced by tDCS and PAS except for the effect on anodal tDCS, which was reversed into inhibition in line with the previous result of Kuo and colleagues in 2008 (Monte-Silva et al., 2010; Thirugnanasambandam et al., 2011). These previous human studies however, did not account for a specific dosage dependent effect of D1 receptor stimulation observed in animal studies. Here, using an indirect approach by blocking the D2 receptors with 
sulpiride and enhancing D1 receptor activity by different doses of L-dopa shows that too much and too little activation inversed, inhibited or abolished plasticity induced by tDCS and PAS, whereas under medium dosage, the excitability increase induced by anodal tDCS and excitatory PAS was preserved. For the excitability-diminishing effect of cathodal tDCS and inhibitory PAS, the effect was abolished and trendwise reversed under the medium dosage. Thus, D1 receptor activation also has a non-linear dosage dependent effect on motor cortex plasticity, however a focusing effect was not observed in this study. The present study also revealed that D1-like receptor stimulation seems to favor the excitability-enhancing effect of anodal tDCS and excitatory PAS to a certain degree compared to the excitability-diminishing plasticity inducing protocols. 


\title{
Nonlinear Dose-Dependent Impact of D1 Receptor Activation on Motor Cortex Plasticity in Humans
}

Shane Fresnoza, Walter Paulus, Michael A. Nitsche,* and Min-Fang Kuo*

Department of Clinical Neurophysiology, Georg-August-University, 37075 Grttingen, Germany

\begin{abstract}
The neuromodulator dopamine plays an important role in synaptic plasticity. The effects are determined by receptor subtype specificity, concentration level, and the kind of neuroplasticity induced. D1-like receptors have been proposed to be involved in cognitive processes via their impact on plasticity. Cognitive studies in humans and animals revealed a dosage-dependent effect of D1-like receptor activation on task performance. In humans, D1-like receptor activation re-establishes plasticity under D2 receptor block. However, a dosagedependent effect has not been explored so far. To determine the impact of the amount of D1-like receptor activation on neuroplasticity in humans, we combined sulpiride, a selective D2 receptor antagonist, with the dopamine precursor L-DOPA (25, 100, and $200 \mathrm{mg})$ or applied placebo medication. The impact on plasticity induced by anodal and cathodal transcranial direct current stimulation (tDCS) was compared with the impact on plasticity induced by excitatory and inhibitory paired associative stimulation (PAS) at the primary motor cortex of healthy humans. Stimulation-generated cortical excitability alterations were monitored by transcranial magnetic stimulation-induced motor-evoked potential amplitudes. D1-like receptor activation produced an inverted U-shaped dose-response curve on plasticity induced by both facilitatory tDCS and PAS. For excitability-diminishing tDCS and PAS, aftereffects were abolished or converted trendwise into facilitation. These data extend findings of dose-dependent inverted U-shaped effects of D1 receptor activation on neuroplasticity of the motor cortex.
\end{abstract}

Key words: dopamine; dopamine receptors; neuroplasticity; paired associative stimulation; transcranial direct current stimulation; transcranial magnetic stimulation

\section{Introduction}

Dopamine improves learning and memory formation in humans and animals (Floresco and Phillips, 2001; Knecht et al., 2004; Floel et al., 2005). Dopamine's impact on neuroplasticity might help to explain these effects. Dopamine enhances long-term potentiation (LTP) and long-term depression (LTD) in animals, and LTP-/LTD-like plasticity in humans (Otani et al., 1998; Bailey et al., 2000). Moreover, impaired cognitive functions (Dubois and Pillon, 1996; Grace et al., 1998) and deficient plasticity (Ueki et al., 2006; Hasan et al., 2012), like those in Parkinson's disease and schizophrenia, are caused by dopaminergic dysfunction.

The dopaminergic impact on plasticity is complex and depends on dosage, kind of plasticity induction, and receptor subtypes. In humans, the dopaminergic impact on plasticity has been explored by noninvasive brain stimulation techniques, such as transcranial direct current stimulation (tDCS), and paired associative stimulation (PAS). tDCS induces polarity-dependent plasticity of the glutamatergic system not restricted to specific

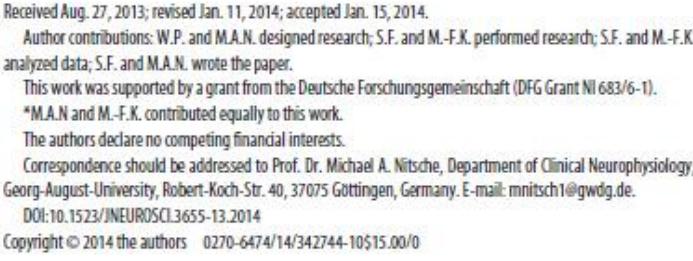

neuronal subgroups (Nitsche et al., 2008; Stagg and Nitsche, 2011). PAS induces neuron-specific glutamatergic plasticity of somatosensory-motor cortical connections, and the direction of plasticity depends on the synchrony of stimulation (Stefan et al., 2000, 2002; Wolters et al., 2003).

Dopamine has a nonlinear dose-dependent effect on neuroplasticity in humans (Monte-Silva et al., 2010; Thirugnanasambandam et al., 2011). Accordingly in animal experiments both insufficient and excessive dopamine impairs cognitive functions, while medium dopaminergic activity improves it (Brozoski et al., 1979; Murphy et al., 1996; Arnsten, 1997). Furthermore, dopamine receptor subtypes have discernable effects on neuroplasticity. D2-like receptor stimulation revealed opposing results on LTP and LTD in animals (Chen et al., 1996; Otani et al., 1998; Manahan-Vaughan and Kulla, 2003), hinting for additional dosage-dependency, which is supported by results of experiments in humans (Monte-Silva et al., 2009). In contrast, D1-like receptor activation enhanced LTP and LTD in animal experiments (Bailey et al., 2000; Gurden et al., 2000; Huang et al., 2004), with the exception of one study, where LTD was reversed into a transient potentiated state (Mockett et al., 2007). Furthermore, the D1 receptor is relevant for learning processes (Piri et al., 2013; Pina and Cunningham, 2014). Because of the close connection between learning and plasticity, a better understanding of dosagedependency of D1 receptor activation on plasticity would be useful in exploring the physiological basis of the D1 receptor's contribution to learning and memory formation (Rioult-Pedotti 
et al., 1998). However, so far, this issue has not been sufficiently explored. Since nonlinear effects of D1 activation on other cognitive processes, like working memory, are well known (Williams and Castner, 2006; Vijayraghavan et al., 2007) and associated with respective effects on cortical activity, similar mechanisms might be involved in how D1 receptors affect plasticity.

We explored dosage-dependent effects of D1-like receptor activation on plasticity of the primary motor cortex induced by tDCS and PAS. Because no selective D1 receptor agonist is available for human use, we blocked D2-like receptors with $400 \mathrm{mg}$ of the D2 receptor antagonist sulpiride, and enhanced global dopaminergic activity with 25,100 , and $200 \mathrm{mg}$ of L-DOPA. We hypothesized that D1-like receptor activation has a nonlinear effect on plasticity.

\section{Materials and Methods}

Subjects. Twelve right-handed, healthy subjects participated in each experiment [tDCS experiment: seven males, five females; age, $27.58 \pm 4.01$ years (mean $\pm \mathrm{SD}$ ); PAS experiment: seven males, five females; age, $26.91 \pm 4.23$ years $($ mean \pm SD) $]$. Subjects had no history of acute or chronic medical diseases, had no metallic or electric implants in the body, and did not take medication during the study or $\leq 2$ weeks before participating in the study. Only one occasional smoker (male) participated in the study, and participants denied the use of any recreational drug. Alcohol intake was not allowed $\geq 1 \mathrm{~d}$ before the experiment and coffee on the day of the experiment until the second day. Pregnancy was ruled out by a pregnancy test. Written informed consent was obtained from each subject before participation. The study was approved by the Ethics Committee of the University of Göttingen and conforms to the Declaration of Helsinki.

Monitoring of corticospinal excitability. Corticospinal excitability was monitored by peak-to-peak amplitudes of motor-evoked potentials (MEPs) induced by transcranial magnetic stimulation (TMS) of the motor cortex representation of the right abductor digiti minimi muscle (ADM). Single-pulse TMS generated by a Magstim 200 magnetic stimulator (Magstim) at a frequency of $0.25 \mathrm{~Hz}$ via a figure-eight magnetic coil (diameter of one winding, $70 \mathrm{~mm}$; peak magnetic field, 2.2 tesla) was used to determine optimal coil position, which was defined as the site where stimulation consistently resulted in the largest MEP amplitudes. The coil was held tangentially on the scalp at an angle of $45^{\circ}$ to the midsagittal plane with the handle pointing laterally and posteriorly. Electromyographic (EMG) recording was obtained from the right ADM with $\mathrm{Ag}-\mathrm{AgCl}$ electrodes attached in a belly-tendon montage. Signals were filtered ( $30 \mathrm{~Hz}-2 \mathrm{kHz}$ ), amplified (Digitimer 360, Digitimer), and then stored on computer via a Power 1401 data acquisition interface (Cambridge Electronic Design). Analysis was performed using Signal Software (Cambridge Electronic Design). TMS intensity was adjusted to elicit baseline MEPs of averaged $1 \mathrm{mV}$ peak-to-peak MEP amplitude and was kept constant for the poststimulation assessment unless adjusted (see below).

Plasticity induction by $t D C S$ (Experiment 1). For tDCS, we used a battery-driven constant current stimulator (NeuroConn) with a maximum output of $4.5 \mathrm{~mA}$. We used two saline-soaked surface sponge electrodes each measuring $7 \times 5 \mathrm{~cm}$ to deliver the current. To achieve a functionally monopolar stimulation over the primary motor cortex, an enlarged return electrode could have been used (Nitsche et al., 2007). To keep the experimental design identical to those of former studies of our group (Kuo et al., 2008; Monte-Silva et al., 2009, 2010; Nitsche et al., 2009; Thirugnanasambandam et al., 2011), and because the size of the return electrode seems to have no impact on resulting motor cortex plasticity (Nitsche et al, 2007), we did not use such a large return electrode. The stimulating electrode was positioned over the cortical representational area of the right ADM in the motor cortex. The return electrode was positioned above the right supraorbital area. A current strength of $1 \mathrm{~mA}$ was administered for $13 \mathrm{~min}$ for anodal tDCS and $9 \mathrm{~min}$ for cathodal tDCS. This current induces cortical excitability alterations lasting for $\sim 1 \mathrm{~h}$ after the end of stimulation (Nitsche and Paulus, 2001; Nitsche et al., 2003a).
Plasticity induction by PAS (Experiment 2). Peripheral nerve stimulation with a Digitimer D185 stimulator (Digitimer) delivered an electrical pulse to the right ulnar nerve at the wrist level (cathode proximal) with an intensity three times higher than the sensory perceptual threshold (square waveform of $50 \mu$ s duration) combined with single-pulse TMS. Peripheral nerve stimulation was followed by the TMS stimulus with interstimulus intervals of 10 (inhibitory PAS: PAS10) or $25 \mathrm{~ms}$ (excitatory PAS: PAS25). Ninety pairs of stimuli were administered at a frequency of $0.05 \mathrm{~Hz}$ for $30 \mathrm{~min}$, which induces cortical excitability enhancement (PAS25) or reduction (PAS10) for $\sim 1 \mathrm{~h}$ after stimulation (Stefan et al., 2000, 2002; Wolters et al., 2003).

Pharmacological Intervention. Ninety minutes before the start of the plasticity-inducing protocols, the subjects received at each experimental session low $(25 \mathrm{mg})$, medium $(100 \mathrm{mg})$, or high $(200 \mathrm{mg})$ dosages of L-DOPA in fixed combination with the dopamine decarboxylase inhibitor benserazide (one-fourth the dose of L-DOPA) in combination with sulpiride $(400 \mathrm{mg})$, or a placebo medication. At the time of plasticity induction, the drugs have reached peak plasma concentrations and have prominent effects in the CNS (Flöel et al., 2005; Kuo et al,, 2008). These dosages of L-DOPA were used since in previous experiments they were shown to induce nonlinear effects on tDCS-induced and PAS-induced plasticity (Monte-Silva et al., 2010; Thirugnanasambandam et al., 2011). To prevent systemic side effects of $\mathrm{L}-\mathrm{DOPA}$, such as nausea and vomiting, subjects also received $20 \mathrm{mg}$ of the peripheral-acting dopaminergic antagonist domperidone three times per day for $2 \mathrm{~d}$ before the experiment and also $2 \mathrm{~h}$ before L-DOPA intake. Twenty milligrams of domperidone alone exerts no effects on motor cortical excitability (Grundey et al., 2013).

Experimental procedures. We conducted a double-blinded, randomized, and placebo-controlled study. Experimental sessions (eight sessions per subject; each subject participated in Experiment 1 or 2) were separated by an interval of $\geq 1$ week to avoid interference effects. Each subject was seated on a reclining chair with head and arm support, and was asked to relax, but to keep their eyes open during the course of the experiment. EMG electrodes were placed at the right ADM using a belly-tendon montage. The motor cortex hotspot of the ADM representation was determined by TMS and marked with a skin marker. This was also done for the EMG electrodes to ensure their constant positioning throughout the experiment. Then the TMS intensity that resulted in a MEP amplitude of $\sim 1 \mathrm{mV}$ was identified. At least $25 \mathrm{MEPs}$ were recorded as Baseline 1 with this stimulus intensity. Immediately after the baseline measurement, the participants received placebo medication or a combination of 25,100 , or $200 \mathrm{mg}$ of L-DOPA together with $400 \mathrm{mg}$ of sulpiride. After $90 \mathrm{~min}$, another set of $25 \mathrm{MEPs}$ (Baseline 2) was obtained to check for any druginduced change of MEP amplitudes. If Baseline 2 differed relevantly $(<0.2$ or $>0.2 \mathrm{mV})$ from Baseline 1, TMS intensity was readjusted to produce stable MEP amplitudes of $\sim 1 \mathrm{mV}$ (Baseline 3 ). Then anodal tDCS (13 min), cathodal tDCS ( 9 min), PAS25, or PAS10 was applied. Following intervention, $25 \mathrm{MEPs}$ were recorded at time points of $0,5,10$, $15,20,25,30,60,90$, and $120 \mathrm{~min}$ on the same day, and then again on the same evening, the next morning, the next afternoon, and the next evening (Fig. 1).

Data analysis and statistics. The individual MEP amplitude means of Baselines 1,2, and 3 and all time points after plasticity induction were calculated. Postintervention MEP amplitudes were normalized to Baseline 2 only if Baseline 2 did not differ significantly from Baseline 1. Baseline 3 was used for normalization in those subjects where stimulation intensity had been adjusted. Then normalized MEP amplitudes from all subjects were pooled together sessionwise by calculating the grand average across subjects for each condition and time point. After checking for normal distribution (Shapiro-Wilk test), a repeatedmeasures ANOVA was performed for the time bins up to the next evening measurement after tDCS (Experiment 1) and PAS (Experiment 2), with the repeated-measure factors time course, direction of plasticity (anodal and cathodal tDCS, PAS25, and PAS10), drug dosage (25, 100, $200 \mathrm{mg}$ of L-DOPA and placebo), the between-subjects factor stimulation paradigm (tDCS and PAS), and the dependent-variable MEP amplitude. Mauchly's test of sphericity was checked and Greenhouse-Geisser correction applied when necessary. If the ANOVA yielded significant results, 


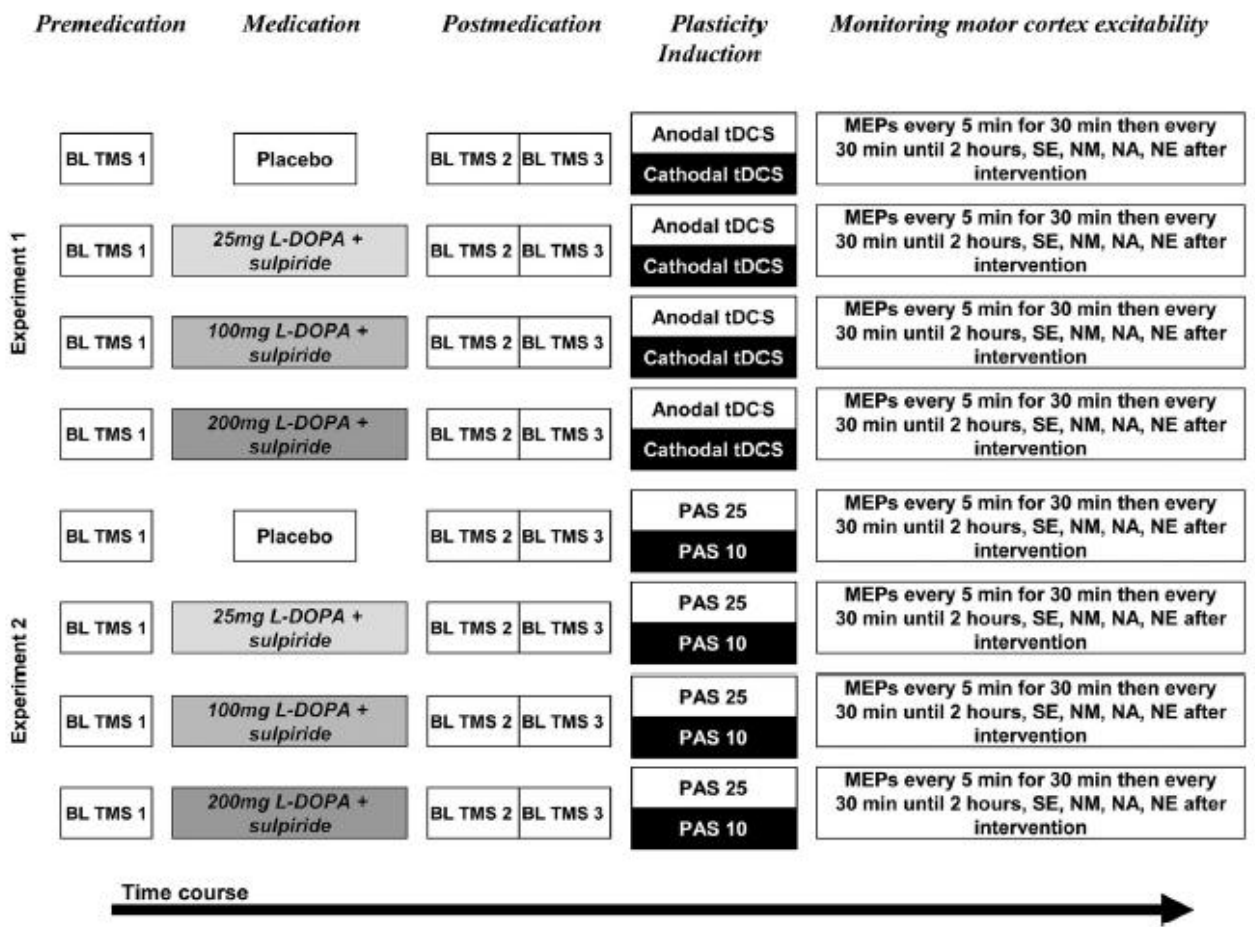

Figure 1. Course of the experiments. MEPs selicited by single-pulse TMS over the motor hot spot of the right ADM were recorded at $1 \mathrm{mV}$ intensity before drug intake [Baseline 1(BL TMS 1)]. Ninety minutes after drug intake, Baseline 2 (BLTMS2) was recorded to look for an effect of the drug on cortical excitability. In case of any MEP alterationsfrom Baseline 1, Baseline3 (BL TMS3) was recorded by adjusting the stimulator output to obtain a mean MEP amplitude of $1 \mathrm{mV}$. Then tDCS (anodal or cathodal) or PAS (excitatory or inhibitory) were administered, immediately followed by MEP after-measurements that covered 120 min. Additional after-measurements were performed at the same evening (SE), and the morning (NM), afternoon (NA), and evening (NE) of the second day following plasticity induction.

post hoc comparisons (paired, two-tailed Student's $t$ tests, $p<0.05$, not adjusted for multiple comparisons) were performed to compare (1) the mean MEP amplitudes at all time points after $\mathrm{tDCS}$ or PAS versus Baseline 2 or 3 and (2) the mean MEP amplitude obtained at a specific time point for the various drug conditions against the respective placebo medication condition. Baselines 1,2, and $3 \mathrm{MEP}$ amplitudes were compared with test for any drug influence alone on cortical excitability, and to exclude baseline differences between medication/stimulation conditions before plasticity induction. Furthermore, we pooled standardized MEP amplitudes for the first $30 \mathrm{~min}$ after plasticity induction, and performed Student's $t$ test (paired samples, two-tailed, $p<0.05$ ) to compare the respective placebo medication conditions with the MEP amplitudes under real stimulation for all plasticity induction protocols.

\section{Results}

One hour after oral intake of $200 \mathrm{mg}$ of L-DOPA together with $400 \mathrm{mg}$ of sulpiride, three subjects experienced mild nausea. One subject vomited. The symptoms diminished after $10-15 \mathrm{~min}$. All subjects completed the respective session. No side effects were reported under both low and medium dosages of the drugs. The remaining subjects tolerated the drugs well.

Peak-to-peak amplitudes of baseline MEPs were not affected by the drugs ( $p \geq 0.05$, Student's paired, two-tailed $t$ test; Table 1 ), and baseline MEP amplitudes and percentage of maximal stimulator output to achieve baseline amplitudes of $\sim 1 \mathrm{mV}$ did not differ between sessions (Student's $t$ test, paired, two-tailed, $p>0.05$; Table 1). The Shapiro-Wilk test indicated that the data were normally distributed (all $p>0.05$ ). The ANOVA revealed significant effects of time course ( $\mathrm{df}=14, F=2.706, p=0.001$, $\left.\eta^{2}=0.197\right)$, drug dosage $\times$ direction of plasticity $(\mathrm{df}=3, F=$ $16.900, p<0.001, \eta^{2}=0.606$ ), direction of plasticity $\times$ time course ( $\mathrm{df}=14, F=3.642, p<0.001, \eta^{2}=0.249$ ), and drug dosage $\times$ direction of plasticity $\times$ time course $(\mathrm{df}=42, F=$ 3.424, $p<0.001, \eta^{2}=0.237$; Table 2).

Dose-dependent effect of D1 receptor activation on tDCS-induced neuroplasticity

Under placebo medication, anodal tDCS increased excitability compared with baseline significantly for $\leq 30 \mathrm{~min}$ after stimulation, while cathodal tDCS significantly decreased excitability for $2 \mathrm{~h}$ (Fig. $2 A, B$ ). Low-dosage L-DOPA abolished any excitability enhancement accomplished by anodal tDCS, compared with the respective baselines. A trend for enhanced MEP amplitudes can be identified for cathodal tDCS under lowdosage L-DOPA relative to baseline values, which resulted in significant differences versus the respective placebo medication condition. Under medium dosage of L-DOPA, anodal tDCS resulted in an excitability enhancement, which was significant 15 and $30 \mathrm{~min}$ after stimulation relative to baseline, as shown by the post hoc $t$ tests, but not at the other time points, probably because of relatively large variability of the results. This excitability enhancement did not differ significantly from the respective placebo medication condition. For cathodal tDCS, medium dosage L-DOPA abolished any MEP alterations relative to baseline (Fig. $2 A, B$ ). High-dosage medication resulted in similar effects as low-dosage medication on tDCSgenerated excitability alterations. For anodal tDCS, MEP 
Table 1. Peak-to-peak MEP amplitudes and TMS Intensity before and after application of $\mathrm{L}$-DOPA combined with sulplride

\begin{tabular}{|c|c|c|c|c|c|c|}
\hline L-DOPA plus $400 \mathrm{mg}$ sulpiride & $\begin{array}{l}\text { Baseline } 1 \\
\text { MEP (mV) }\end{array}$ & $\mathrm{MSO}(\%)$ & $\begin{array}{l}\text { Baseline 2 } \\
\text { MEP (mV) }\end{array}$ & MSO (\%) & $\begin{array}{l}\text { Baseline 3 } \\
\text { MEP (mV) }\end{array}$ & MSO (\%) \\
\hline Anodal; $25 \mathrm{mg}$ & $1.075 \pm 0.04$ & $47.2 \pm 1.7$ & $1.066 \pm 0.10$ & $47.2 \pm 1.7$ & $1.134 \pm 0.10$ & $46.3 \pm 2.0$ \\
\hline tDCS; $100 \mathrm{mg}$ & $1.154 \pm 0.02$ & $47.1 \pm 1.8$ & $1.077 \pm 0.08$ & $47.1 \pm 1.8$ & $1.091 \pm 0.11$ & $51.3 \pm 5.9$ \\
\hline tDCS; $200 \mathrm{mg}$ & $1.197 \pm 0.10$ & $48.0 \pm 2.1$ & $1.094 \pm 0.10$ & $48.0 \pm 2.1$ & $1.140 \pm 0.12$ & $53.0 \pm 3.5$ \\
\hline Cathodal; $25 \mathrm{mg}$ & $1.143 \pm 0.04$ & $49.0 \pm 1.9$ & $1.097 \pm 0.08$ & $49.0 \pm 1.9$ & $1.031 \pm 0.05$ & $52.0 \pm 3.6$ \\
\hline tDCs; $100 \mathrm{mg}$ & $1.134 \pm 0.10$ & $48.4 \pm 1.8$ & $1.234 \pm 0.05$ & $48.4 \pm 1.8$ & $1.208 \pm 0.01$ & $49.0 \pm 2.5$ \\
\hline tDCs;200 mg & $1.114 \pm 0.03$ & $48.0 \pm 2.1$ & $1.054 \pm 0.05$ & $48.0 \pm 2.1$ & $1.047 \pm 0.10$ & $55.0 \pm 3.5$ \\
\hline PAS25; $25 \mathrm{mg}$ & $1.042 \pm 0.03$ & $42.4 \pm 1.6$ & $1.140 \pm 0.05$ & $42.4 \pm 1.6$ & $1.140 \pm 0.05$ & $42.4 \pm 1.6$ \\
\hline PAS25; $100 \mathrm{mg}$ & $1.165 \pm 0.03$ & $42.0 \pm 1.8$ & $1.070 \pm 0.06$ & $42.0 \pm 1.8$ & $1.105 \pm 0.02$ & $42.0 \pm 2.7$ \\
\hline PAS $25 ; 200 \mathrm{mg}$ & $1.144 \pm 0.03$ & $44.0 \pm 1.7$ & $1.353 \pm 0.10$ & $44.0 \pm 1.7$ & $1.121 \pm 0.04$ & $47.0 \pm 2.9$ \\
\hline PAS10; $25 \mathrm{mg}$ & $1.108 \pm 0.04$ & $44.0 \pm 2.2$ & $1.038 \pm 0.04$ & $44.0 \pm 2.2$ & $1.101 \pm 0.00$ & $47.0 \pm 4.6$ \\
\hline PAS10; $100 \mathrm{mg}$ & $1.094 \pm 0.10$ & $44.0 \pm 1.9$ & $1.032 \pm 0.11$ & $44.0 \pm 1.9$ & $1.105 \pm 0.07$ & $44.0 \pm 1.6$ \\
\hline PAS $10 ; 200 \mathrm{mg}$ & $1.121 \pm 0.04$ & $42.3 \pm 2.4$ & $0.996 \pm 0.13$ & $42.3 \pm 2.4$ & $1.104 \pm 0.03$ & $43.0 \pm 6.1$ \\
\hline
\end{tabular}

Shown are the mean +1 - standard error of mean (SEM) of MEP ampitudes and stimulation intensities [percentage of maximum stimulator output (MSO)] of Baselines 1,2, and 3. There was no significant difference between these parameters arooss the different conditions (Student's ttest, paired, 2-tailed, $p>0.05$ ).

Table 2. Results of the ANOVA conducted for tDCS and PAS

\begin{tabular}{lrrrl}
\hline & df & Fvalue & $p$ value & $\mathrm{n}^{2}$ \\
\hline Stimulation & 1 & 0.077 & 0.786 & 0.007 \\
Dosage & 3 & 0.075 & 0.973 & 0.007 \\
Polarity & 1 & 4.114 & 0.067 & 0.272 \\
Time course & 14 & 2.706 & $0.001^{*}$ & 0.197 \\
Stimulation $\times$ dosage & 3 & 1.014 & 0.399 & 0.084 \\
Stimulation $\times$ polarity & 1 & 0.761 & 0.402 & 0.065 \\
Dosage $\times$ polarity & 3 & 16.900 & $<0.001^{*}$ & 0.606 \\
Stimulation $\times$ dosage $\times$ polarity & 3 & 0.249 & 0.862 & 0.022 \\
Stimulation $\times$ time course & 14 & 0.374 & 0.980 & 0.033 \\
Dosage $\times$ time course & 42 & 1.300 & 0.105 & 0.106 \\
Stimulation $\times$ dosage $\times$ time & 42 & 0.663 & 0.949 & 0.057 \\
$\quad$ course & & & & \\
Polarity $\times$ time course & 14 & 3.642 & $<0.001^{*}$ & 0.249 \\
Stimulation $\times$ polarity $\times$ time & 14 & 0.420 & 0.967 & 0.037 \\
$\quad$ course & & & & \\
Dosage $\times$ polarity $\times$ time course & 42 & 3.424 & $<0.001^{*}$ & 0.237 \\
Stimulation $\times$ dosage $\times$ polarity $\times$ & 42 & 0.538 & 0.992 & 0.047 \\
$\quad$ time course & & & & \\
\end{tabular}

The ANOVA encompasses the time course of the MEP measures up to evening after stimulation. Asterisks indicate significant results $(p<0.05)$. df, Degrees of freedom; $n^{2}$, partial eta squared (measure of effect size).

amplitudes did not differ from baseline values, but were significantly reduced relative to placebo medication $0,5,10,20$, and $120 \mathrm{~min}$ after tDCS (Student's $t$ test, paired, two-tailed, $p \leq 0.05)$. For cathodal tDCS, excitability was trendwise enhanced relative to baseline, and significantly different from cathodal tDCS-generated excitability reductions under placebo medication (Fig. $2 A, B$ ). For anodal tDCS, pooled MEP amplitudes $60 \mathrm{~min}$ after stimulation were significantly reduced compared with placebo medication under both lowdosage and high-dosage L-DOPA, while no reduction was observed under medium dosage (Fig. 4A). For cathodal tDCS, the conversion into excitation under low and high dose, and the reduction of the excitability diminution under medium dose, were significant (see Fig. 4A). No significant effects where found on the second day (see Fig. $4 B$ ). In summary, L-DOPA combined with sulpiride dosage-dependently modified tDCS-induced excitability changes depending on stimulation polarity: whereas low and high dosages of L-DOPA together with sulpiride diminished and abolished anodal tDCS-induced facilitatory neuroplasticity, medium dosage preserved it; the cathodal tDCS-induced aftereffects were converted into facilitation under low and high dosage, and were abolished under the medium dosage.
Dose-dependent effect of D1 receptor activation on

PAS-induced neuroplasticity

Under placebo medication, PAS25 increased excitability significantly compared with baseline until $90 \mathrm{~min}$, whereas PAS10 decreased excitability for $1 \mathrm{~h}$ (see Fig. $3 A, B$ ). For excitatory PAS, low-dosage L-DOPA did not result in significant excitability alterations relative to baseline. However, inhibitory PAS enhanced MEP amplitudes significantly relative to baseline values $20 \mathrm{~min}$ after PAS. MEP amplitudes differed significantly from those under placebo medication, as shown by the results of the post hoc tests. Under medium-dosage L-DOPA, excitatory PAS resulted in a significant excitability enhancement versus baseline values for $\leq 30$ min after stimulation, which did not differ from PAS25 effects under placebo medication. In contrast, MEP amplitudes after PAS 10 were only significantly different from baseline values after $15 \mathrm{~min}$, resulting in respective significant differences in relation to the placebo medication condition (Fig. $3 A, B$ ). Highdosage L-DOPA prevented aftereffects of PAS25 and PAS10 relative to baseline excitability; consequently MEP amplitudes differed significantly from those under placebo medication (Fig. $3 A, B)$. Pooled MEP values for the first $60 \mathrm{~min}$ after inhibitory PAS were all significantly larger compared with the placebo medication condition, whereas for PAS25, MEP amplitudes were significantly less enhanced compared with placebo medication. However, in the latter condition, medium dosage of L-DOPA resulted in a clear enhancement of MEP amplitudes in relation to baseline (Fig. 4A). The effect of L-DOPA on PAS25 was still significant compared with placebo on the second day, however less clear than immediately after stimulation (Fig. 4B). To summarize the effect of D1 receptor activation by L-DOPA combined with sulpiride on PAS-induced plasticity, a dosage-dependent effect was observed depending on the type of stimulation: whereas low and high dose of L-DOPA abolished PAS25-induced neuroplasticity, medium dosage preserved it. On the other hand, the PAS10-induced aftereffects were abolished or trendwise facilitated under all dosages.

\section{Discussion}

The results show a nonlinear dosage-dependency of D1-like receptor activation on motor cortex plasticity. For facilitatory tDCS and excitatory PAS, low and high activation of D1-like receptors impaired plasticity, while moderate activation preserved it. For excitability-diminishing plasticity, D1-like receptor activation reversed all aftereffects of PAS trendwise into facilitation, whereas for tDCS, high and trendwise low D1-like receptor activation converted the excitability diminution into facilitation, while under medium dosage the inhibitory aftereffects were abolished. 

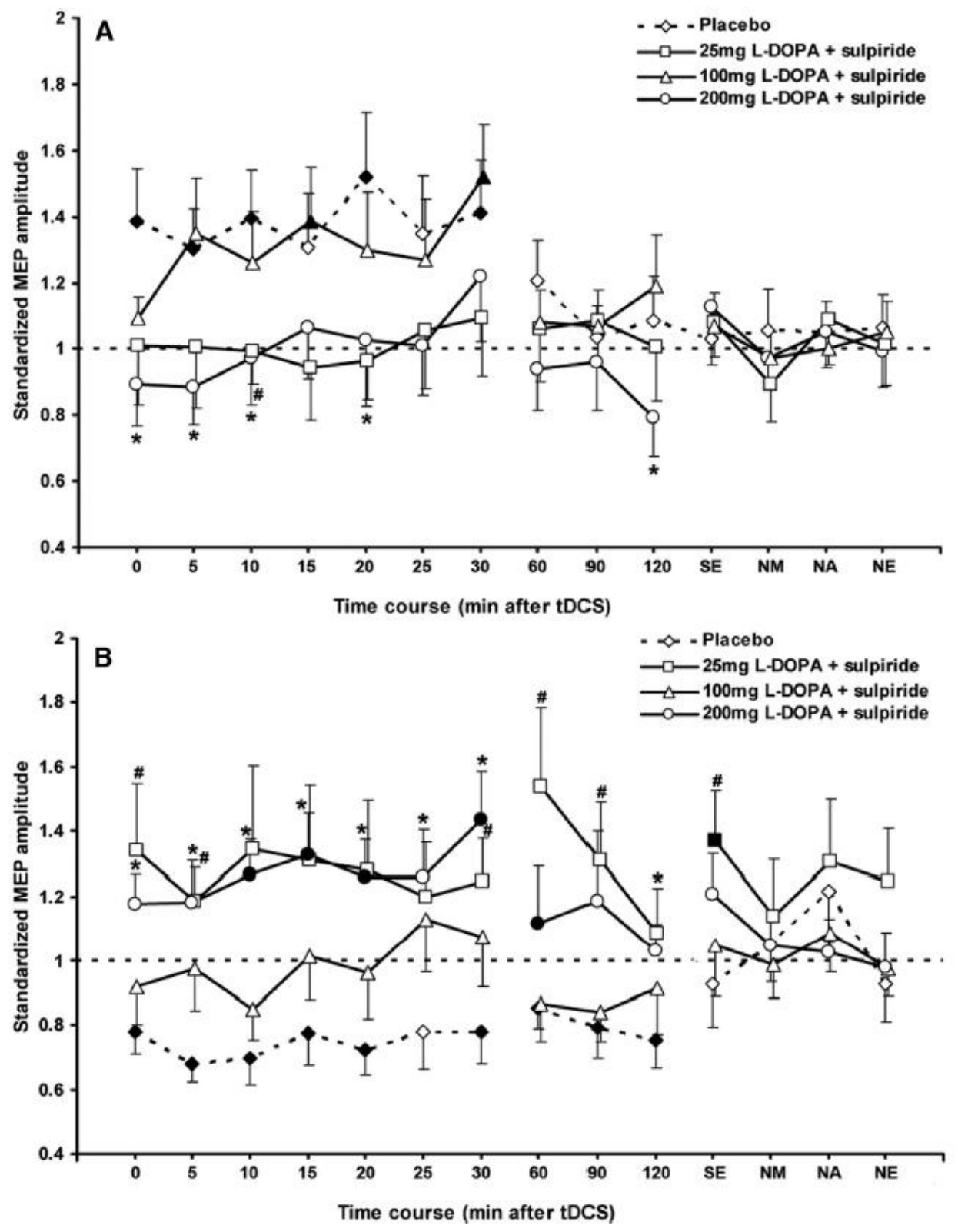

Flgure 2. Dose-dependent effect of D1-like receptor activation on plasticity induced by anodal and cathodal tDCS (Experiment 1). The X-axis displays the time points (in minutes) of after-measurements during the experiment. MEP amplitudes standardized to the corresponding baseline values (mean \pm SEM) are plotted on the $y$-axis. The graphs show that under placebo medication, anodal tDCS induces an excitability enhancement lasting for $\sim 30$ min, whereas cathodal tDCS diminishes excitability for $>1 \mathrm{~h}$ following stimulation. $A_{f}$ Low-dose (25 mg) and high-dose (200 mg) I-DOPA impaired and abolished the aftereffects of anodal tDCS respectively, whilemedium-dose $(100 \mathrm{mg}) \mathrm{L}-\mathrm{DOPA}$ together with sulpinide preserved the anodal tDCS-generated aftereffects. $B_{,}$Low-dose and high-dose L-DOPA resulted in trendwise facilitation of the cathodal tDCS-generated aftereffects, while undermedium dose the aftereffectswere abolished. Filled symbols indicatestatistically significant deviations of the post-tDCS MEP values compared with baseline. $\#,{ }^{*}$, Significant differences of the real medication compared with the placebo medication conditions at the same time points after plasticity induction (Student's $t$ test, paired, 2 -tailed, $p \leq 0.05$ ). SE, Same evening; NM, nextmoming; NA, next aftemoon; NE, next evening. Error bars show SE of mean (SEM). \#, 25 mg of L-DOPA. *, 200 mg of L-DOPA.

D1-like receptor stimulation effects on excitatory stimulation paradigms

D1-like receptor activation causes a dose-dependent inverted U-shaped effect on LTP-like plasticity induced by anodal tDCS and PAS25. Too much or too little D1-receptor activation by
L-DOPA under D2 receptor block suppresses the induction of plasticity, while under medium D1-like receptor activation plasticity was preserved. These effects of D1-like receptor activity on LTP-like plasticity extend previous results of our group. Here D2 receptor block alone abolished facilitatory tDCS-induced plastic- 

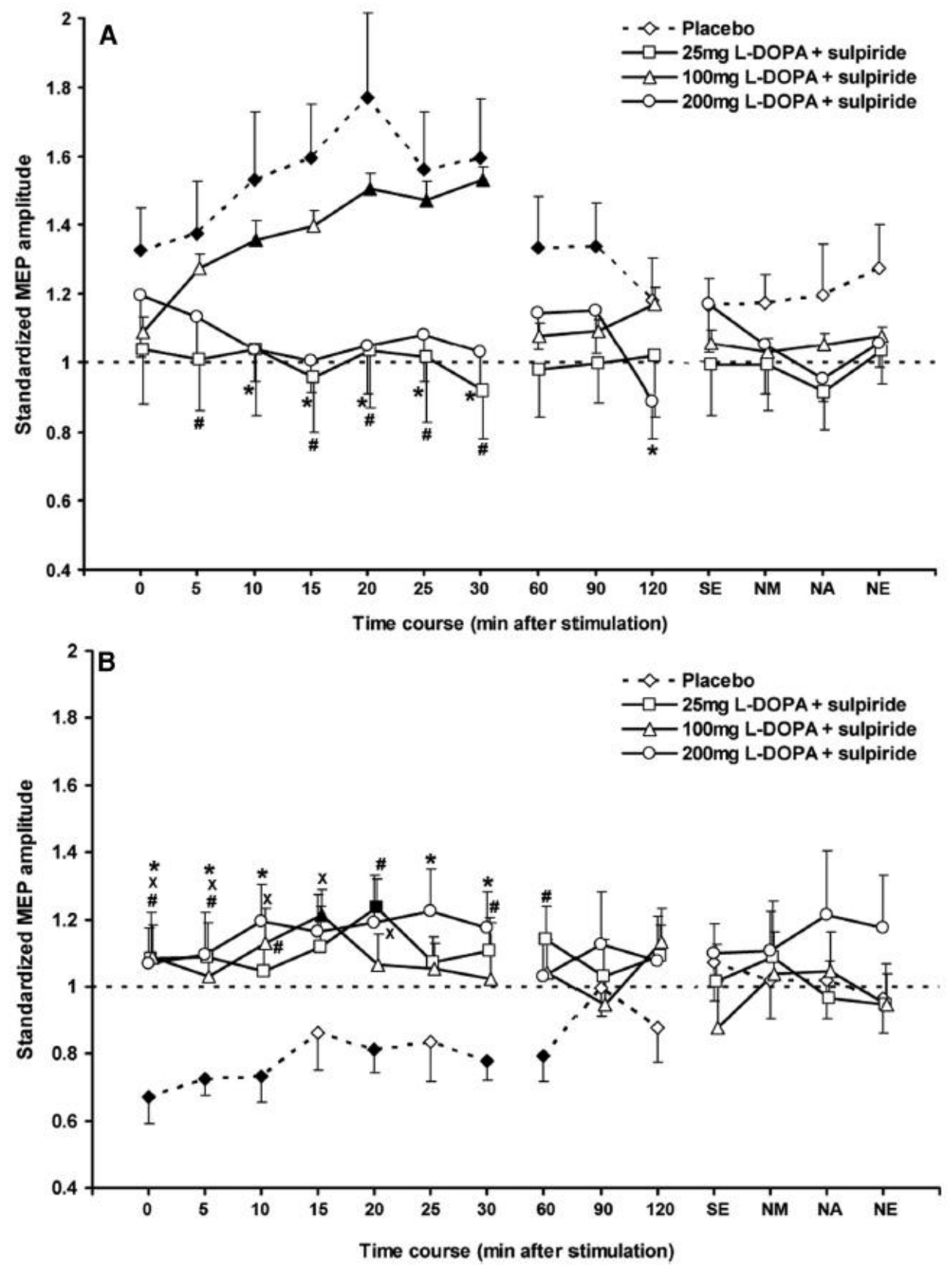

Flgure 3. Dose-dependenteffects of D1-like receptor activation on plasticity induced by PAS25 and PAS10 (Experiment 2). Thex-axis displays the time points (in minutes) of after-measurements during the experiment. MEP amplitudes standardized to the corresponding baseline values (mean \pm SEM) are plotted on the $y$-axis. The graphs show that under placebo medication, excitatory PAS (PAS25) induces an excitability enhancement lasting for $\sim 60 \mathrm{~min}$, whereas inhibitory PAS (PAS10) diminishes excitability for $>1 \mathrm{~h}$ following stimulation. A, Low-dose (25 mg) and high-dose (200 $\mathrm{mg}$ ) L-DOPA applied together with sulpiride abolish the aftereffects of PAS25, whereas medium-dose (100 mg) L-DOPA with sulpiride preserved it. $B$, Low-dose ( $25 \mathrm{mg}$ ), medium-dose (100 mg), and high-dose (200 mg) I-DOPA with sulpiride trendwise converted the PAS10 aftereffects into facilitation. Filled symbols indicate statistically significant deviations of the post-PAS MEP values compared with baseline. $\#, X$, *, Significant differences of the real medication compared with the placebo medication conditions at the same time points after plasticity induction (Student's $t$ test, paired, 2-tailed, $p \leq 0.05$ ). SE, Same evening; NM, next morning; NA, next afternoon; NE, next evening. Error bars show SEM. $\#, 25 \mathrm{mg}$ of L-DOPA.X, $100 \mathrm{mg}$ of $\mathrm{L}-\mathrm{DOPA}$. *, $200 \mathrm{mg}$ of L-DOPA. 
A

A Day 1: Until 60 min after stimulation
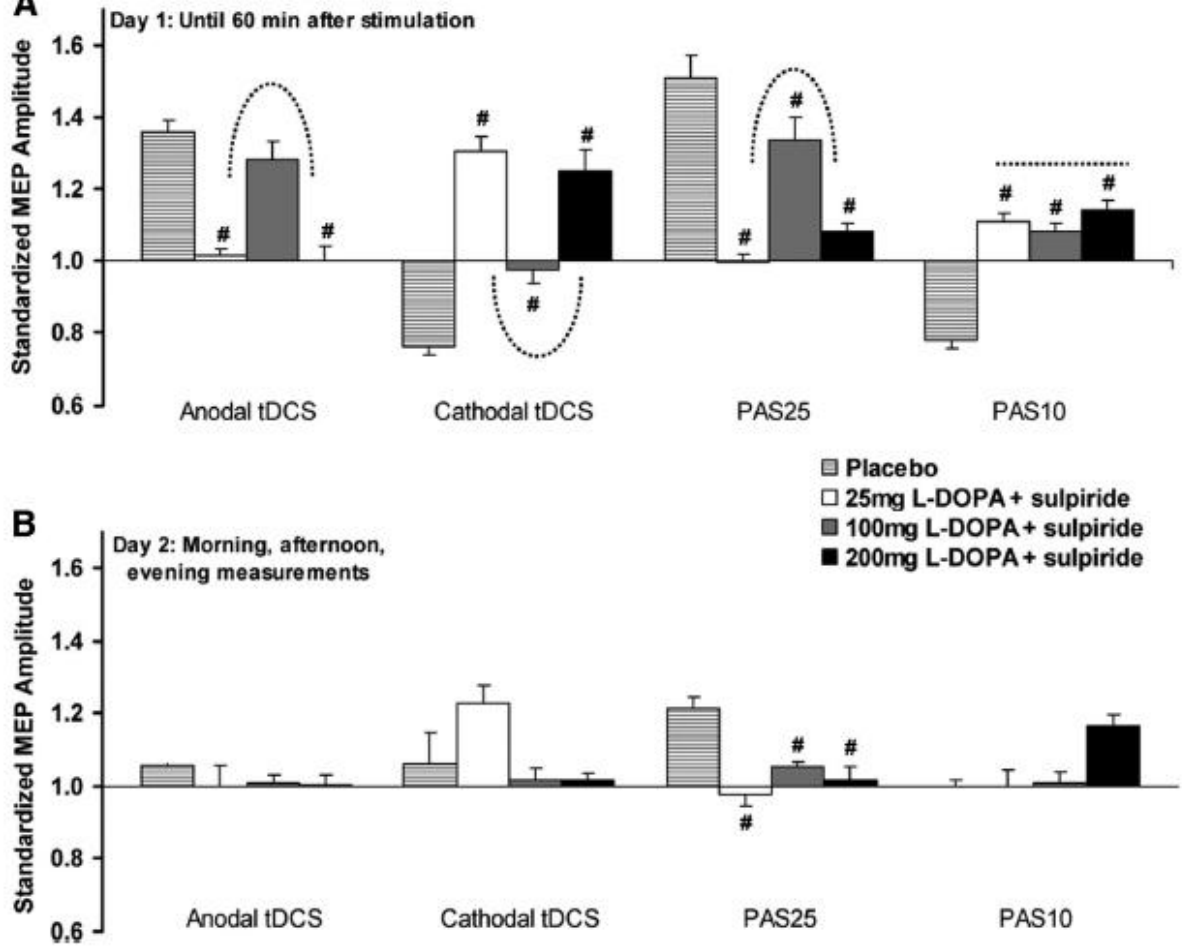

Flgure 4. Dose-dependent effects of D1 receptor activation on plasticity induced by tDCS and PAS. A, B, Shown are baseline-standardized MEP amplitudes \pm SEM pooled for 60 min after anodal/cathodal tDCS and PAS25/PAS10 $(\boldsymbol{A})$ and the second-day measurements $(\boldsymbol{B})$. D1 receptor activation by L-DOPA under D2 receptor block by sulpiride has inverted U-shaped effects on neuroplasticity induced by anodal tDCS, cathodal tDCS, and excitatory PAS. High-dose or low-dose L-DOPA with sulpiride impaired, abolished, or reversed plasticity. No dose-dependent alterations on inhibitory PAS-induced aftereffects were observed (A). The aftereffect of PAS25 was still significant on the second day $(\boldsymbol{B})$. $\#$, Significant differences of the real medication compared with placebo medication (Student's t test, paired, 2-tailed, $p \leq 0.05$ ).

ity, which was however re-established by a medium dose (100 $\mathrm{mg}$ ) of L-DOPA (Nitsche et al., 2006, 2009). The results of the present study suggest that an optimal level of D1-like receptor activation is required for the induction of LTP-like plasticity in the human motor cortex. This correlates with findings from single-cell recordings of the prefrontal cortex of monkeys (Vijayraghavan et al., 2007), and cognitive task performance in awake behaving animals (Cai and Arnsten, 1997; Zahrt et al., 1997; Granon et al., 2000). Vijayraghan and colleagues observed that the same group of PFC neurons dose-dependently respond to a D1 receptor agonist (SKP81297) during the delay period of a spatial working memory task. Low $(10 \mathrm{nA})$ and high dosage $(40 \mathrm{nA})$ marginally reduced neuronal firing rates and significantly suppressed delay-related activity of neurons that fire to preferred directions respectively, whereas moderate levels $(15 \mathrm{nA})$ led to an enhancement in spatial tuning of mnemonic activity. Behaviorally, performance was improved by relatively low doses of selective D1 agonists, but larger doses impaired performance (Cai and Arnsten, 1997; Zahrt et al., 1997). The results of the present study imply that D1 receptor activation has similar nonlinear dosagedependent effects on plasticity, which might affect learning and memory formation.

With regard to involved mechanisms, we can only speculate at present. However, three facts suggest that the glutamatergic and GABAergic systems are relevant (Durstewitz and Seamans, 2008): (1) tDCS as well as PAS induce plasticity of glutamatergic synapses (Stefan et al., 2002; Nitsche et al., 2003b, 2004; Wolters et al., 2003); (2) tDCS alters GABAergic activity (Stagg et al., 2009); and (3) D1 and D2 receptors have a specific impact on NMDA and GABAergic receptors. D2 receptors inhibit glutamatergic and GABAergic activity (Seamans and Yang, 2004) such that their block by sulpiride will enhance activity of both systems. D1 receptors enhance glutamatergic and GABAergic activity. However, only in highly active neurons is the impact on glutamate larger than that on GABA (Seamans and Yang, 2004). Thus, for low-dosage L-DOPA under sulpiride, synergistic strengthening of GABAergic activity by D2 receptor block and D1 receptor enhancement might abolish glutamatergic tDCS-induced and PAS-induced plasticity. Alternatively, the activation of presynaptic D1 autoreceptors, which reduce dopamine release in animal experiments, might have abolished plasticity (Pennartz et al., 1992; Momiyama et al., 1996), or the minor D1 receptor activation might not have been sufficient to overcome the plasticityabolishing effect of D2 receptor block accomplished by sulpiride (Nitsche et al., 2006).

For the medium dosage, enhanced D1-like receptor activation preserved the excitatory effect of anodal tDCS and PAS25. This is probably due to the predominant NMDA receptor-enhancing effect of optimal D1-like receptor stimulation (Seamans and Yang, 2004). The reason high-dosage L-DOPA abolished both the effects of anodal tDCS and PAS25 may be traced to (1) excessive activation of glutamatergic receptors, which can activate hyper- 
polarizing potassium channels (Misonou et al., 2004) and thus be detrimental for LTP induction; or to (2) D1-induced enhancement of GABA-evoked currents (Flores-Hernandez et al., 2000).

D1-like receptor stimulation effects on inhibitory stimulation paradigms

The effect of D1-like receptor activation on LTD-like plasticity, similar to the effect on LTP-like plasticity, follows an inverted U-shaped curve, but not in such a clear, unambiguous way. D1 receptor activation dose-dependently abolished or trendwise converted LTD-like plasticity. With respect to the medium dosage, these effects are not in full accordance with those found in a previous study, where $100 \mathrm{mg}$ of L-DOPA combined with sulpiride only trendwise reduced the effects of cathodal tDCS, and had no impact on PAS10-generated plasticity (Nitsche et al., 2009). This might be due to differences in baseline dopamine concentration between subjects (Cools and D'Esposito, 2011) or to other factors, like genetic polymorphisms. However, the results of the present study agree in principle with those of an animal slice experiment, where LTD was transiently converted into a potentiation via D1-like receptor activation (Mockett et al., 2007).

With regard to putative mechanisms, again predominant GABA receptor activation or activation of D1 autoreceptors under low-dosage medication might have abolished plasticity induction. For the medium and high L-DOPA dosages, a shift to predominant glutamatergic receptor activation accomplished by more efficient D1 receptor activation might have resulted in intracellular calcium concentrations too large to elicit LTD-like plasticity, but too low to induce LTP-like plasticity (Lisman, 2001). Generally, D2 receptor block might have favored a D1-like receptor "biased" system, which favors facilitation. This is in accordance with electrophysiological recordings from $\mathrm{D} 2$ receptordeficient mice, where conversion of LTD to LTP occurs (Cepeda et al., 2001). However, future studies should explore mechanisms of action more directly.

\section{General remarks}

For tDCS and PAS, D1 receptor activation has a specific effect on plasticity, which is discernable from that of D2 (Monte-Silva et al., 2009) and global dopamine activation (Monte-Silva et al., 2010; Thirugnanasambandam et al., 2011). Neither D2 nor D1 activation alone can explain all global dopamine effects. A focusing effect on facilitatory plasticity (i.e., a strengthening of synaptic subgroup-specific LTP-like plasticity, but conversion of nonspecific LTP-like plasticity) was only accomplished by medium-dosage global dopaminergic stimulation, but not by selective D1-like or D2-like activation. Here, synergistic activities of the respective receptor subtypes might be needed. The nonlinear effects of D1 receptor stimulation on facilitatory plasticity might help explain its impact on cognitive performance, especially with regard to learning and memory formation. Low and high receptor activation might reduce performance via its compromising effect on plasticity, whereas optimal activation should preserve it. This hypothesis awaits testing in future studies. However, respective nonlinear effects of D1 receptor stimulation have been demonstrated for their impact on working memory and acute neuronal activity. Targeting the D1 receptors for improving cognitive functions could be an alternative treatment for Parkinson's disease (Cools, 2006), where dopamine depletion and excess cause deficits (Gotham et al., 1988). Likewise, in schizophrenia, where a relationship between prefrontal dopamine function and the integrity of working memory has been proposed, targeting D1 receptors might be relevant (Goldman-Rakic et al., 2004). Some limitations of our study should be mentioned. With regard to the mechanistic explanation of the results, the proposed modes of action are speculative at present. Furthermore, the indirect approach we had to choose for the activation of D1 receptors bears the risk that the activation of receptors other than D1 receptors (e.g., D3, D4, and D5 receptors) by L-DOPA contributed to the results. A primary involvement of D3 receptors is improbable. The predominant D3 receptor agonist ropinirole had different effects in another study (Monte-Silva et al., 2009), and not only D2, but also D3 receptors are blocked by sulpiride. Furthermore, individual differences in baseline dopamine level might limit comparability of results obtained with different subject groups. This might explain minor deviations of the results of the present study, compared with previous ones. However, our subject group was fairly homogenous and demographic characteristics were comparable to those of the subjects in the other studies (Kuo et al., 2008; Nitsche et al., 2009; Monte-Silva et al., 2010; Thirugnanasambandam et al., 2011). The results of the present study might not, however, be completely transferable to groups with other demographic characteristics. In older subjects, baseline dopamine is lower, which might affect the dosage-dependency of the effects (Floel et al., 2008). Blinding might have been compromised in four subjects suffering from mild nausea or vomiting after high-dose 1-DOPA in single sessions. Multiple sessions, blinded tDCS and PAS protocols, medication, and identical aftermeasurement durations in all conditions should have guaranteed blinding of most of the participants. Finally, we did not obtain drug plasma levels, which would have enabled exploration of dosage-dependent and gene polymorphism-dependent effects of the medication in greater detail (Witte and Floel, 2012; Witte et al., 2012; Kristin et al., 2013). Further studies are needed to explore the specific contribution of D1-like receptor stimulation on cognition in humans. Given the prominent effects of D1-like receptor activation on plasticity in humans, an important impact of this receptor on cognition in humans can be expected.

\section{References}

Arnsten AFT (1997) Catecholamine regulation of the prefrontal cortex. J Psychopharmacology 11:151-162. CrossRef

Bailey CH, Giustetto M, Huang YY, Hawkins RD, Kandel ER (2000) Is heterosynaptic modulation essential for stabilizing Hebbian plasticity and memory? Nat Rev Neurosci 1:11-20. CrossRef Medline

Brozoski TJ, Brown RM, Rosvold HE, Goldman PS (1979) Cognitive deficit caused by regional depletion of dopamine in prefrontal cortex of rhesus monkey. Science 205:929-932. CrossRef Medline

Cai JX, Arnsten AF (1997) Dose-dependent effects of the dopamine D1 receptor agonists A77636 or SKF81297 on spatial working memory in aged monkeys. J Pharmacol Exp Ther 283:183-189. Medline

Cepeda C, Hurst RS, Altemus KL, Flores-Hernández J, Calvert CR, Jokel ES, Grandy DK, Low MJ, Rubinstein M, Ariano MA, Levine MS (2001) Facilitated glutamatergic transmission in the striatum of D2 dopamine receptor-deficient mice. J Neurophysiol 85:659-670. Medline

Chen Z, Ito K, Fujii S, Miura M, Furuse $\mathrm{H}$, Sasaki $\mathrm{H}$, Kaneko $\mathrm{K}$, Kato $\mathrm{H}$, Miyakawa H (1996) Roles of dopamine receptors in long-term depression: enhancement via D1 receptors and inhibition via D2 receptors. Receptors Channels 4:1-8. Medline

Cools R (2006) Dopaminergic modulation of cognitive functionimplications for L-DOPA treatment in Parkinson's disease. Neurosci Biobehav Rev 30:1-23. CrossRef Medline

Cools R, D'Esposito M (2011) Inverted-U-shaped dopamine actions on human working memory and cognitive control. Biol Psychiatry 69:el13e125. CrossRef Medline

Dubois B, Pillon B (1996) Cognitive deficits in Parkinson's disease. J Neurology 244:2-8. CrossRef

Durstewitz D, Seamans JK (2008) The dual-state theory of prefrontal cortex dopamine function with relevance to catechol-O-methyltransferase ge- 
notypes and schizophrenia. Biol Psychiatry 64:739-749. CrossRef Medline

Floel A, Breitenstein C, Hummel F, Celnik P, Gingert C, Sawaki L, Knecht S, Cohen LG (2005) Dopaminergic influences on formation of a motor memory. Ann Neurol 58:121-130. CrossRef Medline

Floel A, Vomhof P, Lorenzen A, Roesser N, Breitenstein C, Knecht S (2008) Levodopa improves skilled hand functions in the elderly. Eur J Neurosci 27:1301-1307. CrossRef Medline

Floresco SB, Phillips AG (2001) Delay-dependent modulation of memory retrieval by infusion of a dopamine $D_{1}$ agonist into the rat medial prefrontal cortex. Behav Neurosci 115:934-939. CrossRef Medline

Flores-Hernandez J, Hernandez S, Snyder GL, Yan Z, Fienberg AA, Moss SJ, Greengard P, Surmeier DJ (2000) D1 dopamine receptor activation reduces $\mathrm{GABA}(\mathrm{A})$ receptor currents in neostriatal neurons through a PKA/DARPP-32/PP1 signaling cascade. J Neurophysiol 83:2996-3004. Medline

Goldman-Rakic PS, Castner SA, Svensson TH, Siever LJ, Williams GV (2004) Targeting the dopamine D1 receptor in schizophrenia: insights for cognitive dysfunction. Psychopharmacology 174:3-16. Medline

Gotham AM, Brown RG, Marsden CD (1988) 'Frontal' cognitive function in patients with Parkinson's disease 'on' and 'off' levodopa. Brain 111: 299-321. CrossRef Medline

Grace AA, Gerfen CR, Aston-Jones G (1998) Catecholamines in the central nervous system. Overview. Adv Pharmacol 42:655-670. CrossRef Medline

Granon S, Passetti F, Thomas KL, Dalley JW, Everitt BJ, Robbins TW (2000) Enhanced and impaired attentional performance after infusion of D1 dopaminergic receptor agents into rat prefrontal cortex. J Neurosci 20: 1208-1215. Medline

Grundey J, Freznosa S, Klinker F, Lang N, Paulus W, Nitsche MA (2013) Cortical excitability in smoking and not smoking individuals with and without nicotine. Psychopharmacology 229:653-664. CrossRef Medline

Gurden H, Takita M, Jay TM (2000) Essential role of D1 but not D2 receptors in the NMDA receptor-dependent long-term potentiation at hippocampal-prefrontal cortex synapses in vivo. J Neurosci 20:RC106. Medline

Hasan A, Nitsche MA, Herrmann M, Schneider-Axmann T, Marshall L, Gruber O, Falkai P, Wobrock T (2012) Impaired long-term depression in schizophrenia: a cathodal tDCS pilot study. Brain Stimul 5:475-483. CrossRef Medline

Huang YY, Simpson E, Kellendonk C, Kandel ER (2004) Genetic evidence for the bidirectional modulation of synaptic plasticity in the prefrontal cortex by DI receptors. Proc Natl Acad Sci U SA 101:3236-3241. CrossRef Medline

Knecht S, Breitenstein C, Bushuven S, Wailke S, Kamping S, Floel A, Zwitserlood P, Ringelstein EB (2004) Levodopa: faster and better word learning in normal humans. Ann Neurol 56:20-26. CrossRef Medline

Kristin MP-F, Brian M, Daniel A, Babak S, Steven CC (2013) Genetic variation in the human brain dopamine system influences motor learning and its modulation by L-Dopa. PLoS One 8:e61197. CrossRef Medline

Kuo MF, Paulus W, Nitsche MA (2008) Boosting focally-induced brain plasticity by dopamine. Cereb Cortex 18:648-651. CrossRef Medline

Lisman JE (200I) Three Ca2 + levels affect plasticity differently: the LTP zone, the LTD zone and no man's land. J Physiol 532:285. CrossRef Medline

Manahan-Vaughan D, Kulla A (2003) Regulation of depotentiation and long-term potentiation in the dentate gyrus of freely moving rats by dopamine D2-like receptors. Cereb Cortex 13:123-135. CrossRef Medline

Misonou H, Mohapatra DP, Park EW, Leung V, Zhen D, Misonou K, Anderson AE, Trimmer JS (2004) Regulation of ion channel localization and phosphorylation by neuronal activity. Nat Neurosci 7:711-718. CrossRef Medline

Mockett BG, Guévremont D, Williams JM, Abraham WC (2007) Dopamine D1/D5 receptor activation reverses NMDA receptor-dependent longterm depression in rat hippocampus. J Neurosci 27:2918-2926. CrossRef Medline

Momiyama T, Sim JA, Brown DA (1996) Dopamine D1-like receptormediated presynaptic inhibition of excitatory transmission onto rat magnocellular basal forebrain neurones. J Physiol 495:97-106. Medline

Monte-Silva K, Kuo MF, Thirugnanasambandam N, Liebetanz D, Paulus W, Nitsche MA (2009) Dose-dependent inverted U-shaped effect of dopa- mine (D2-like) receptor activation on focal and nonfocal plasticity in humans. J Neurosci 29:6124-6131. CrossRef Medline

Monte-Silva K, Liebetanz D, Grundey J, Paulus W, Nitsche MA (2010) Dosage-dependent non-linear effect of L-dopa on human motor cortex plasticity. J Physiol 588:3415-3424. CrossRef Medline

Murphy BL, Arnsten AF, Goldman-Rakic PS, Roth RH (1996) Increased dopamine turnover in the prefrontal cortex impairs spatial working memory performance in rats and monkeys. Proc Natl Acad Sci US A 93:1325-1329. CrossRef Medline

Nitsche MA, Paulus W (2001) Sustained excitability elevations induced by transcranial DC motor cortex stimulation in humans. Neurology 57: 1899-1901. CrossRef Medline

Nitsche MA, Nitsche MS, Klein CC, Tergau F, Rothwell JC, Paulus W (2003a) Level of action of cathodal DC polarisation induced inhibition of the human motor cortex. Clin Neurophysiol 114:600-604. CrossRef Medline

Nitsche MA, Fricke K, Henschke U, Schlitterlau A, Liebetanz D, Lang N, Henning S, Tergau F, Paulus W (2003b) Pharmacological modulation of cortical excitability shifts induced by transcranial direct current stimulation in humans. J Physiol 553:293-301. CrossRef Medline

Nitsche MA, Liebetanz D, Schlitterlau A, Henschke U, Fricke K, Frommann $\mathrm{K}$, Lang N, Henning S, Paulus W, Tergau F (2004) GABAergic modulation of DC stimulation-induced motor cortex excitability shifts in humans. Eur J Neurosci 19:2720-2726. CrossRef Medline

Nitsche MA, Lampe C, Antal A, Liebetanz D, Lang N, Tergau F, Paulus W (2006) Dopaminergic modulation of long-lasting direct current-induced cortical excitability changes in the human motor cortex. Eur J Neurosci 23:1651-1657. CrossRef Medline

Nitsche MA, Doemkes S, Karakose T, Antal A, Liebetanz D, Lang N, Tergau F, Paulus W (2007) Shaping the effects of transcranial direct current stimulation of the human motor cortex. J Neurophysiol 97:3109-3117. CrossRef Medline

Nitsche MA, Cohen LG, Wassermann EM, Priori A, Lang N, Antal A, Paulus W, Hummel F, Boggio PS, Fregni F, Pascual-Leone A (2008) Transcranial direct current stimulation: state of the art 2008. Brain Stimul 1:206223. CrossRef Medline

Nitsche MA, Kuo MF, Grosch J, Bergner C, Monte-Silva K, Paulus W (2009) D1-receptor impact on neuroplasticity in humans. J Neurosci 29:26482653. CrossRef Medline

Otani S, Blond O, Desce JM, Crépel F (1998) Dopamine facilitates longterm depression of glutamatergic transmission in rat prefrontal cortex. Neuroscience 85:669-676. CrossRef Medline

Pennartz CM, Dolleman-Van der Weel MJ, Kitai ST, Lopes da Silva FH (1992) Presynaptic dopamine Dl receptors attenuate excitatory and inhibitory limbic inputs to the shell region of the rat nucleus accumbens studied in vitro. J Neurophysiol 67:1325-1334. Medline

Pina M, Cunningham C (2014) Effects of dopamine receptor antagonists on the acquisition of ethanol-induced conditioned place preference in mice. Psychopharmacology (Berl) 231:459-468. CrossRef Medline

Piri M, Rostampour M, Nasehi M, Zarrindast MR (2013) Blockade of the dorsal hippocampal dopamine Dl receptors inhibits the scopolamineinduced state-dependent learning in rats. Neuroscience 252:460-467. CrossRef Medline

Rioult-Pedotti MS, Friedman D, Hess G, Donoghue JP (1998) Strengthening of horizontal cortical connections following skill learning. Nat Neurosci 1:230-234. CrossRef Medline

Seamans JK, Yang CR (2004) The principal features and mechanisms of dopamine modulation in the prefrontal cortex. Prog Neurobiol 74:1-58. CrossRef Medline

Stagg CJ, Nitsche MA (2011) Physiological basis of transcranial direct current stimulation. Neuroscientist 17:37-53. CrossRef Medline

Stagg CJ, Best JG, Stephenson MC, O'Shea J, Wylezinska M, Kincses ZT, Morris PG, Matthews PM, Johansen-Berg H (2009) Polarity-sensitive modulation of cortical neurotransmitters by transcranial stimulation. J Neurosci 29:5202-5206. CrossRef Medline

Stefan K, Kunesch E, Cohen LG, Benecke R, Classen J (2000) Induction of plasticity in the human motor cortex by paired associative stimulation. Brain 123:572-584. CrossRef Medline

Stefan K, Kunesch E, Benecke R, Cohen LG, Classen J (2002) Mechanisms of enhancement of human motor cortex excitability induced by interventional paired associative stimulation. J Physiol 543:699-708. CrossRef Medline 
Thirugnanasambandam N, Grundey J, Paulus W, Nitsche MA (2011) Dosedependent nonlinear effect of $\mathrm{L}$-dopa on paired associative stimulationinduced neuroplasticity in humans. J Neurosci 31:5294-5299. CrossRef Medline

Ueki Y, Mima T, Kotb M, Sawada H, Saiki H, Ikeda A, Begum T, Reza F, Nagamine T, Fukuyama H (2006) Altered plasticity of the human motor cortex in Parkinson's disease. Ann Neurol 59:60-71. CrossRef Medline

Vijayraghavan S, Wang M, Birnbaum SG, Williams GV, Arnsten AF (2007) Inverted-U dopamine D1 receptor actions on prefrontal neurons engaged in working memory. Nat Neurosci 10:376-384. CrossRef Medline

Williams GV, Castner SA (2006) Under the curve: critical issues for elucidating D1 receptor function in working memory. Neuroscience 139:263276. CrossRef Medline
Witte AV, Floel A (2012) Effects of COMT polymorphisms on brain function and behavior in health and disease. Brain Res Bull 88:418-428. CrossRef Medline

Witte AV, Kurten J, Jansen S, Schirmacher A, Brand E, Sommer J, Floel A (2012) Interaction of BDNF and COMT polymorphisms on pairedassociative stimulation-induced cortical plasticity. J Neurosci 32:45534561. CrossRef Medline

Wolters A, Sandbrink F, Schlottmann A, Kunesch E, Stefan K, Cohen LG, Benecke R, Classen J (2003) A temporally asymmetric Hebbian rule governing plasticity in the human motor cortex. J Neurophysiol 89:23392345. CrossRef Medline

Zahrt J, Taylor JR, Mathew RG, Arnsten AF (1997) Supranormal stimulation of D1 dopamine receptors in the rodent prefrontal cortex impairs spatial working memory performance. J Neurosci 17:8528-8535. Medline 


\subsection{Dosage-dependent effect of D2 receptor activation on motor cortex plasticity in humans}

The impact of D2 receptor stimulation on plasticity (LTP and LTD) and behaviour in animals revealed conflicting findings (Jay, 2003). Enhancing, diminishing or null effects were reported, which might be associated with a non-linear dosage dependent effect of D2 receptor stimulation on respective processes. In humans, D2 receptor agonists and antagonists resulted in comparable heterogeneous effect on cognitive functions (Cools and D'Esposito, 2011), probably also caused by different degrees of receptor activation. Supporting evidence from electrophysiological studies in humans regarding a dosage-dependent effect however is scarce so far. A pioneering study exploring such a dosage-dependent effect of D2 receptor stimulation used the D2/D3 receptor agonist ropinirole. The results of this study show an inverted "U"-shaped doseresponse curve on plasticity for facilitatory tDCS and PAS and for inhibitory tDCS. No dosage-dependent effect was evident for inhibitory PAS (Monte-Silva et al., 2009). However, ropinirole is a mixed agonist with a greater affinity for D3 receptors, which exhibit different, and in some instances opposing effects to those of D2 receptors. In the present study, we specifically targeted the D2 receptors by bromocriptine. The results show that D2 receptor activation has a non-linear dosage dependent effect on focal and non-focal plasticity induced by tDCS and PAS respectively. Low and high dosage impaired or abolished plasticity, whereas under medium dosage the plasticity induced by cathodal tDCS and inhibitory PAS was preserved. In contrast, non-focal excitability enhancement by anodal tDCS was abolished, while the focal excitability enhancement 
induced by excitatory PAS was diminished. Thus D2 receptor stimulation facilitated inhibitory plasticity, but reduced excitatory plasticity. Interestingly, a focusing effect was observed under the D2 receptor stimulation with regard to facilitatory plasticity, but to a minor degree, as compared with global dopamine receptor stimulation. 


\section{Dosage-dependent effect of D2 receptor activation on motor cortex}

\section{plasticity in humans}

Shane Fresnoza ${ }^{1}$, Elisabeth Stiksrud ${ }^{1}$, Florian Klinker ${ }^{1}$, David Liebetanz ${ }^{1}$, Walter

Paulus $^{1}$, Min-Fang Kuo ${ }^{1 *}$, and Michael A. Nitsche ${ }^{1 *}$

1Department of Clinical Neurophysiology, Georg-August-University, Robert-Koch-Strasse 40, 37075 Göttingen

* These co-authors contributed equally

\section{Abstract}

The neuromodulator dopamine plays an important role in synaptic plasticity. The effects depend on receptor subtypes, affinity, concentration level and the kind of neuroplasticity induced. In animal experiments, D2-like receptor stimulation revealed partially antagonistic effects on plasticity, which might be explained by dosage-dependency. In humans, D2 receptor block abolishes plasticity, and the D2/D3, but predominant D3 receptor agonist ropinirol has a dosage-dependent non-linear impact on plasticity. Here we aimed to determine the specific impact of D2 receptor activation on neuroplasticity in humans, because physiological effects of D2, and D3 receptors might differ. Therefore we combined application of the selective D2 receptor agonist bromocriptine $(2.5 \mathrm{mg}$, $10 \mathrm{mg}$ and $20 \mathrm{mg}$, or placebo medication) with anodal and cathodal transcranial direct current stimulation (tDCS), which induces non-focal plasticity, and with paired associative stimulation (PAS) generating of a more focal kind of plasticity in the motor cortex of healthy humans. Plasticity was monitored by transcranial magnetic stimulation (TMS)-induced motor evoked potential amplitudes (MEP). For facilitatory tDCS, 
bromocriptine prevented plasticity induction independent from drug dosage. Its application resulted however, in an inverted U-shaped dose-response curve on inhibitory tDCS, excitability-diminishing PAS and to a minor degree on excitability-enhancing PAS. These data support the assumption that modulation of D2-like receptor activity exerts a non-linear dose-dependent effect on neuroplasticity in the human motor cortex, which differs from predominant D3 receptor activation, and that the kind of plasticity induction procedure is relevant for its specific impact.

\section{Introduction}

Dopamine modulates learning and memory formation. This effect is probably based on its impact on neuroplasticity, such as long term potentiation (LTP) and long term depression (LTD), as observed in animal studies (Jay, 2003). The precise mechanism of the dopaminergic impact on plasticity is complex, and depends on receptor subtype, concentration level and type of plasticity (Seamans and Yang, 2004; Kuo et al., 2008). Therefore, obtaining knowledge about dosage-dependent effects of specific dopamine receptor activation on synaptic plasticity in vivo in humans is critical.

Animal cognitive and human electrophysiological studies revealed non-linear dosage-dependent effects of non-selective and D1-like receptor activation on performance and plasticity (Seamans and Yang, 2004; Monte-Silva et al., 2010; Thirugnanasambandam et al., 2011; Fresnoza et al., 2014). Insufficient or too much dopamine impairs, while an optimum dose facilitates performance (Williams and Goldman-Rakic, 1995). Accordingly, the impact of global dopaminergic and D1 receptor activation on plasticity in humans differs with regard to dosage, plasticity-induction 
procedures and direction of plasticity (facilitatory versus excitability-diminution) (MonteSilva et al., 2010; Thirugnanasambandam et al., 2011; Fresnoza et al., 2014). For the contribution of D2-like receptors however, variable effects on plasticity have been obtained in animal experimentation (Chen et al., 1996b; Otani et al., 1998; ManahanVaughan and Kulla, 2003) and human cognitive studies (Breitenstein et al., 2006; Meintzschel and Ziemann, 2006). The D2/D3 agonist Ropinirole revealed a non-linear dosage-dependent effects on facilitatory, but not inhibitory plasticity in humans (MonteSilva et al., 2009). However, ropinirole predominantly activates D3 rather than D2 receptors (Coldwell et al., 1999). Animal experiments suggest different effects of D2, and D3 receptors on memory consolidation and locomotor activity in rats (facilitation by D2 and inhibition by D3 receptor activation) (Kling-Petersen et al., 1995; Sigala et al., 1997). For neurotensin gene expression in rats, D2 has a negative, while D3 has a positive effect (Diaz et al., 1994). For a full overview of the contribution of dopaminergic receptor subtypes on human brain plasticity, a clarification of the specific effect of D2 receptor activation on plasticity in humans is warranted.

To this aim, we applied transcranial direct current stimulation (tDCS) and paired associative stimulation (PAS) in combination with three doses $(2.5,10,20 \mathrm{mg}$, and placebo) of bromocriptine, a selective D2 receptors agonist. tDCS induces a polaritydependent, non-focal type of glutamatergic plasticity (Nitsche et al., 2008). Anodal stimulation enhances, while cathodal tDCS diminishes excitability of the primary motor cortex. PAS induce focal/synapse-specific glutamatergic plasticity of somatosensorymotor cortical connections. The mechanism resembles to a certain degree spike timingdependent plasticity. The synchrony between motor cortex stimulation and an afferent 
somatosensory stimulus elicited by peripheral nerve stimulation determines the effect direction (Stefan et al., 2000; Stefan et al., 2002; Wolters et al., 2003).

We hypothesized that specific D2 receptor activation has a non-linear impact on plasticity, which depends on the kind of plasticity induction protocol.

\section{Materials and Methods}

Subjects. Twelve right-handed, healthy subjects participated in each experiment [tDCS experiment: 7 males, 5 females, age $27.92 \pm 1.60$ years (mean \pm SD) and PAS experiment: 7 males, 5 females, age $28.42 \pm 1.08$ years (mean \pm SD)]. Subjects with a history of medical diseases, metallic or electric implants in the body, intake of medication during or up to 2 weeks before participating in the study, and smokers and recreational drug users were excluded. Pregnancy was ruled out by a pregnancy test. Subjects gave written informed consent prior to participation. The study was approved by the Ethics Committee of the University of Göttingen and conforms to the Declaration of Helsinki.

Monitoring of corticospinal excitability. The peak-to-peak amplitudes of motor evoked potentials (MEP) induced over the motor cortex representation of the right abductor digiti minimi muscle (ADM) by TMS was used to monitor corticospinal excitability. Initially, single-pulse TMS generated by a Magstim 200 magnetic stimulator (Magstim Company) at a frequency of $0.25 \mathrm{~Hz}$ via a figure of eight magnetic coil (diameter of one winding = $70 \mathrm{~mm}$, peak magnetic field $=2.2$ tesla) was used to determine optimal coil position, defined as the site where stimulation resulted in the largest MEP amplitudes. The coil was held tangentially to the scalp at an angle of $45^{\circ}$ to the midsagittal plane with the handle pointing laterally and posteriorly generating an anterior-posterior current direction in the brain. Electromyographic (EMG) recording was obtained from the right 
$\mathrm{ADM}$ with $\mathrm{Ag}-\mathrm{AgCl}$ electrodes attached in a belly-tendon montage. Signals were filtered (30 Hz to $2 \mathrm{kHz}$ ), amplified (Digitimer 360, Digitimer Ltd, Welwyn Garden City, Herts, UK), and then stored on a computer via a Power 1401 data acquisition interface (Cambridge Electronic Design Ltd, Cambridge, UK). Analysis was carried out using Signal Software (Cambridge Electronic Design). TMS intensity was adjusted to elicit baseline MEPs of averaged $1 \mathrm{mV}$ peak-to-peak MEP amplitude and was kept constant for the post-stimulation assessment unless adjusted (see below).

Nonfocal plasticity induction by tDCS (experiment 1). A battery-driven constant current stimulator (NeuroConn GmbH, Ilmenau, Germany) with a maximum output of $4.5 \mathrm{~mA}$ was used for tDCS via a pair of saline-soaked surface sponge electrodes each measuring $7 \times 5 \mathrm{~cm}$. We positioned one electrode over the motor cortex representation area of the right $\mathrm{ADM}$, and the other above the right supra-orbital area. A current strength of $1 \mathrm{~mA}$ was administered for 13 min for anodal tDCS and 9 min for cathodal tDCS, which induce cortical excitability alterations lasting for about 1 hour after the end of stimulation (Nitsche et al., 2008).

Focal plasticity induction by PAS (experiment 2). A single TMS pulse with the stimulation intensity resulting in an MEP amplitude of approximately $1 \mathrm{mV}$ was combined with a peripheral nerve stimulus (Digitimer D185 stimulator, Digitimer Ltd, Hertfordshire, England), which delivered an electrical pulse to the right ulnar nerve at the

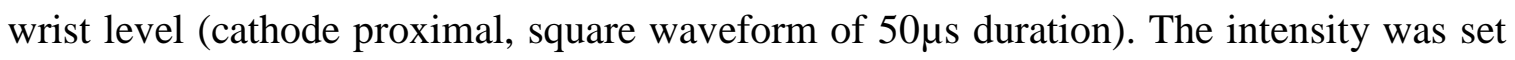
to three times higher than the individual sensory perceptual threshold. Peripheral nerve stimulation was followed by the TMS stimulus with interstimulus intervals (ISI) of $10 \mathrm{~ms}$ 
(inhibitory PAS: PAS10) for LTD-like plasticity or $25 \mathrm{~ms}$ (excitatory PAS: PAS25) for LTP-like plasticity induction. For PAS10, the somatosensory stimulus reaches the motor cortex relevantly earlier than the TMS stimulus applied over the motor cortex, while PAS25 results in synchronous arrival of the somatosensory and TMS stimulus at this area. Ninety pairs of stimuli were administered at a frequency of $0.05 \mathrm{~Hz}$ for $30 \mathrm{~min}$ (Stefan et al., 2000; Stefan et al., 2002; Wolters et al., 2003).

Pharmacological Intervention. Two hours before the start of the plasticity-inducing protocols, the participants received low $(2.5 \mathrm{mg})$, medium $(10 \mathrm{mg})$ or high $(20 \mathrm{mg})$ dosages of bromocriptine or placebo medication at each experimental session. These dosages cause systemic changes of cortical activity and performance (Kimberg et al., 2001; Franken et al., 2008). To prevent systemic side effects of bromocriptine like nausea and vomiting, subjects received $20 \mathrm{mg}$ of the peripheral acting dopaminergic antagonist domperidone three times per day for two days prior to the experiment and also 2 hours before bromocriptine intake. $20 \mathrm{mg}$ domperidone alone exerts no effects on motor cortical excitability (Grundey et al., 2013).

Experimental procedures. The experiment was conducted in a double-blinded, randomized and placebo-controlled design. Each subject participated in 8 sessions (experiment 1 or 2) separated by an interval of at least 1 week to avoid interference effects. Subjects were seated on a reclining chair with head and arm support, and were asked to relax, but maintain their eyes open during the course of the experiment. EMG electrodes were placed at the right $\mathrm{ADM}$ using a belly-tendon montage. To ensure consistency, a skin marker was placed on the position of the EMG electrodes and motor cortex hotspot as identified by TMS. Then the TMS intensity which resulted in a MEP 
amplitude of about $1 \mathrm{mV}$ was identified (SI1mV). At least 25 MEPs were recorded as baseline 1 with this stimulus intensity. Immediately after the baseline measurement, the participants received placebo medication or $2.5,10$ or $20 \mathrm{mg}$ bromocriptine. After 2 hours, another set of 25 MEPs (baseline 2) was obtained to check for any drug-induced change of MEP amplitudes. If baseline 2 differed relevantly $(0.2 \mathrm{mV})$ from baseline 1 , TMS intensity was re-adjusted to produce stable MEP amplitudes of about $1 \mathrm{mV}$ (baseline 3). Then anodal tDCS (13min), cathodal tDCS (9 min), PAS25, or PAS10 was applied. Following intervention, 25 MEPs were recorded at the time points of $0,5,10$, $15,20,25,30,60,90$, and $120 \mathrm{~min}$, same day evening, next morning, next afternoon and next evening (Figure 1). Based on the results of previous studies, significant after effects at the post-intervention days could not be ruled out. This warrants the long-term monitoring of excitability in the present experiment (Kuo et al., 2008; Monte-Silva et al., 2009; Monte-Silva et al., 2010; Thirugnanasambandam et al., 2011).

Data analysis and statistics. The individual MEP amplitude means of baselines 1,2 , and 3 and all time points after plasticity induction were calculated. Post-intervention MEP amplitudes were normalized to baseline 2 only if baseline 2 did not differ significantly from baseline 1, otherwise baseline 3 was used for normalization. Normalized MEP amplitudes were pooled together session-wise by calculating the grand average across subjects for each condition and time point. After checking for normal distribution (Shapiro-Wilk Test), a mixed linear model analysis (SPSS 21, SPSS Inc. Chicago, Illinois) with subject as the random-effect covariate was applied with the MEP amplitude (as measured over time from baseline up to the next evening) as the dependent variable. Stimulation (tDCS and PAS), polarity (anodal and cathodal tDCS; PAS25 and PAS10), 
drug dosage $(2.5,10,20 \mathrm{mg}$ of bromocriptine and placebo) time and the respective interactions were treated as fixed-effect covariates. We used the partial eta squared $\left(\eta^{2}\right)$ calculated from an univariate ANOVA model to obtain effects sizes, since linear mixed models do not provide respective values. Fisher's LSD post hoc tests (paired, two-tailed, $\mathrm{p}<0.05$ ), which do not correct for multiple comparisons, were performed to compare (1) the mean MEP amplitudes at all time points after tDCS or PAS versus baseline 2 or 3 and (2) the mean MEP amplitude obtained at a specific time point for the various drug conditions against the respective placebo medication condition. Baseline 1, 2 and 3 MEP amplitudes were compared to test for any drug influence alone on cortical excitability, and to exclude baseline differences between medication/stimulation conditions. Furthermore, we performed the same mixed linear model analysis with subjects as random factor for the standardized MEP amplitudes pooled for the first $60 \mathrm{~min}$ after plasticity induction. Then a Fisher's LSD post hoc test (paired, two-tailed, $\mathrm{p}<0.05$ ) was used to compare the first 60 minutes MEP amplitude of the respective placebo medication conditions with the first 60 minutes MEP amplitudes under real medication for all plasticity induction protocols.

\section{Results}

With regard to side effects, two hours after oral intake of $20 \mathrm{mg}$ bromocriptine, 3 subjects experienced dizziness, nausea and vomiting, while hypotension was observed in one subject. 1 session had to be cancelled. Under low dosage, one subject experienced dizziness and one hypotension, under medium dosage only one subject developed 
dizziness. All symptoms were fully reversible and the remaining subjects tolerated the drugs well.

Baseline peak-to-peak MEP amplitudes and baseline TMS intensity in percentage of maximal stimulator output were not affected by the drug, and did not differ between conditions ( $P \geq 0.05$, Student's paired, two-tailed $t$ test; see Table 1$)$.

The data were normally distributed (Shapiro-Wilk test, all $\mathrm{p}>0.05$ ). Results of the mixed linear model analysis revealed significant effects of drug dosage $(\mathrm{df}=3, \mathrm{~F}=$ $\left.20.015, p=<.001, \eta^{2}=.020\right)$, polarity $\left(\mathrm{df}=1, \mathrm{~F}=139.812, p=<.001, \eta^{2}=.046\right)$, time course $\left(\mathrm{df}=14, \mathrm{~F}=1.947, p=.015, \mathrm{\eta}^{2}=.010\right)$, and significant interactions stimulation $\mathrm{x}$ dosage $\left(\mathrm{df}=3, \mathrm{~F}=4.337, \mathrm{p}=.005, \mathrm{\eta}^{2}=.004\right)$, dosage $x$ polarity $(\mathrm{df}=3, \mathrm{~F}=75.237, p=$ $\left.<.001, \eta^{2}=.073\right)$, stimulation $\mathrm{x}$ dosage $\mathrm{x}$ polarity $\left(\mathrm{df}=3, \mathrm{~F}=5.111, p=.002, \eta^{2}=.005\right)$,

polarity $x$ time course $\left(\mathrm{df}=14, \mathrm{~F}=6.701, p=<.001, \eta^{2}=.032\right)$, and drug dosage $\mathrm{x}$ polarity $x$ time course $\left(\mathrm{df}=42, \mathrm{~F}=3.361, p=<.001, \eta^{2}=.047\right)$, (see Table 2$)$. Further analysis of the MEP amplitudes for the first 60 minutes after stimulation using a mixed linear model with subjects as random factor revealed significant main effects of stimulation $(\mathrm{df}=1, \mathrm{~F}=4.594, p=.032)$, drug dosage $(\mathrm{df}=3, \mathrm{~F}=18.018, p=<.001)$, polarity ( $\mathrm{df}=1, \mathrm{~F}=172.777, p=<.001)$, and significant interactions stimulation $\mathrm{x}$ dosage $(\mathrm{df}=3, \mathrm{~F}=3.070, p=.027)$, polarity $x$ dosage $(\mathrm{df}=3, \mathrm{~F}=86.633, p=<.001)$ and stimulation $\mathrm{x}$ dosage $\mathrm{x}$ polarity interactions $(\mathrm{df}=3, \mathrm{~F}=3.484, p=<.015)$.

\section{Dose-dependent effect of D2 receptor activation on tDCS-induced neuroplasticity}

As revealed by the respective post hoc tests, under placebo medication anodal tDCS increased excitability compared to baseline for up to $30 \mathrm{~min}$ after stimulation, while 
cathodal tDCS significantly decreased excitability for 25 min (Figure 2A, 2B). Low dosage bromocriptine prevented any effect of tDCS, as compared to the respective baseline MEP values. For anodal tDCS, the low-dosage bromocriptine condition consequently differed from placebo until same evening, while for cathodal tDCS, the respective difference was significant for up to 25 minutes after stimulation (Figure 2A, 2B). Under medium dosage bromocriptine, the anodal tDCS-induced after effect was trendwise reversed until 30 minutes after stimulation and the evening of the second day. For cathodal tDCS, medium dosage bromocriptine prolonged the MEP-reducing after effect significantly for up to 60 minutes after stimulation compared to baseline. Compared to placebo medication, the anodal tDCS-elicited after effect was significantly different from medium dosage bromocriptine until 30 minutes after tDCS, while for cathodal tDCS no significant difference between placebo and medium dosage bromocriptine was observed (Figure 2A, 2B). High-dosage medication resulted in similar effects as low dosage medication on tDCS-generated excitability alterations. For anodal tDCS, MEP amplitudes did not differ from baseline values, but were significantly reduced relative to placebo medication for up to 30 minutes after stimulation. For cathodal tDCS, similarly, MEP amplitudes did not differ relative to baseline, but differed from cathodal tDCS-generated excitability reductions under placebo medication for 20 minutes (Figure 2A, 2B). For the pooled MEP amplitudes (first 60 minutes after anodal tDCS $)$, low $(p=<.001)$, medium $(p=<.001)$ and high dosage $(p=<.001)$ were significantly different compared to placebo medication (Figure 4A) (post hoc t-test, two-tailed, $p<$ 0.05). However, only low $(p=<.001)$ and high dosage $(\mathrm{p}=<.001)$ conditions were significant compared to placebo medication after cathodal tDCS (Figure 4A) (post hoc $t$ - 
test, two-tailed, $p<0.05)$. In summary, bromocriptine dosage-dependently prevented or modified tDCS-induced excitability changes towards an excitability-diminishing direction. As can be seen from figure 4B, relevant interindividual variability was present throughout the different medication conditions, especially with regard to low, and high dosage bromocriptine application.

\section{Dose-dependent effect of D2 receptor activation on PAS-induced neuroplasticity}

The results of the post hoc tests show that under placebo medication PAS25 increased excitability significantly compared to baseline for $30 \mathrm{~min}$, whereas PAS10 decreased excitability for 60 minutes after stimulation compared to baseline (Figure 3A, 3B). For low dosage bromocriptine, excitatory and inhibitory PAS had no impact on MEP amplitudes, as compared to baseline. Compared to placebo medication, MEP amplitudes differed significantly until 90 minutes after PAS25 and PAS10 after plasticity induction (Figure 3A, 3B). Under medium dosage bromocriptine, MEP amplitudes were significantly enhanced versus baseline only for $20 \mathrm{~min}$ after excitatory PAS. In relation to the placebo medication condition, the respective excitability enhancement was significantly diminished for 30 minutes after plasticity induction. The MEP amplitudes after PAS10 were significantly reduced compared to baseline values until 90 min after stimulation. Compared to placebo medication, MEP amplitudes were not significantly different for PAS10 (Figure 3A, 3B). High dosage bromocriptine prevented any aftereffects of PAS, as compared to baseline MEP values. Consequently MEP amplitudes differed significantly from those under placebo medication for 30 minutes after PAS25 and $25 \mathrm{~min}$ after PAS10 (Figure 3A, 3B). For the pooled MEP amplitudes (up to $60 \mathrm{~min}$ after stimulation), the after effects of excitatory PAS under bromocriptine were 
significantly different compared with the placebo medication condition [(low dose $(p=<.001)$; medium dose $(p=<.001)$ and high dose $(p=<.001)]$ (Figure 4A) (post hoc $t$ test, two-tailed, $p<0.05)$. For inhibitory PAS, low $(p=<.001)$ and high dosages $(p=<.001)$ of the drug were significantly different from the placebo medication condition while the medium dosage ( $p=.339)$ did not result in significant differences (Figure 4A) (post hoc t-test, two-tailed, $p<0.05$ ). In summary, D2 receptor activation by bromocriptine has a non-linear dosage-dependent effect on PAS-induced plasticity: whereas low and high dosages prevented any PAS-induced neuroplasticity, the medium dosage preserved PAS10-induced LTD-like plasticity, and did diminish, but not completely abolish the after-effects of PAS25. Similar as for the tDCS data, condiderable interindividual variability of the results can be seen in figure $4 \mathrm{~B}$, which is largest for medium and high bromocriptine for PAS25, and for the low, and high dosage of the drug for PAS10.

\section{Discussion}

D2 receptor activation had non-linear dosage-dependent effects on motor cortex plasticity in humans. Low and high D2 receptor activation prevented plasticity induction irrespective of the specific stimulation protocol. Medium activation preserved inhibitory plasticity however, diminished focal and prevented non-focal facilitatory plasticity. These effects differ from those of combined D2/D3 activation (Monte-Silva et al., 2009).

\section{D2 receptor modulation of LTP-like plasticity}

D2 receptor activation caused non-linear dosage-dependent effects on LTP-like plasticity induced by focal plasticity induction and prevented non-focal plasticity 
irrespective of drug concentration. Low, and high receptor activation prevented plasticity. Under medium-dosage bromocriptine, focal PAS-generated plasticity was diminished, while non-focal facilitatory plasticity was prevented. Thus D2 activation, as performed in the present study, has a deleterious effect on LTP-like plasticity. This does not mean that D2 receptor activity per se has a disruptive effect on LTP-like plasticity. D2 receptor block abolished LTP-like plasticity in previous experiments (Nitsche et al., 2006; Nitsche et al., 2009), and in the present experiment bromocriptine in any dosage enhanced D2 activity on top of physiological activity. Therefore physiological activity of D2 receptors, which is compromised by both, D2 receptor block, or hyperactivity induced by bromocriptine, might be necessary for optimal plasticity induction. Since bromocriptine had however heterogeneous effects on cognitive functions in humans (Luciana et al., 1992; Kimberg et al., 1997; Luciana and Collins, 1997; Müller et al., 1998; Mehta et al., 2001) including improvement, it might also be argued that state-dependent heterogeneous optimal physiological levels of D2 activity do exist, which to a certain degree are mimicked by pharmacological intervention. In accordance, global activation of the dopaminergic system, and predominant activation of D3 or D1 receptors did not in each case disrupt plasticity (Monte-Silva et al., 2009; Monte-Silva et al., 2010; Thirugnanasambandam et al., 2011; Fresnoza et al., 2014). The non-linear effect of D2 receptor activation on focal LTP-like plasticity is in accordance with results of D2/D3 receptor activation and of non-selective dopamine receptor activation (Monte-Silva et al., 2009; Thirugnanasambandam et al., 2011). However, the plasticity-preventing effect of bromocriptine on non-focal plasticity (anodal tDCS) under the medium dose differs from the conversion to LTD-like plasticity accomplished via global dopamine receptor 
activation (Kuo et al., 2008; Monte-Silva et al., 2010), suggesting a role of D1 receptor activation for this type of plasticity (Fresnoza et al., 2014). It also differs from the results obtained by predominant $\mathrm{D} 3$ receptor activation, which preserved the respective aftereffects. The differences between D2 and D3 receptor activation might be mechanistically explained by the fact that $\mathrm{D} 3$ receptors modulate cortical activity by coactivation with $\mathrm{D} 1$ receptors (Avalos-Fuentes et al., 2013). Thus enhanced activation of D3 receptors together with spontaneous D1 activity could cause the effects of ropinirole. Accordingly, medium-dosage D1 activation resulted in similar effects (Nitsche et al., 2009).

The effect of D2 receptor activation on LTP-like plasticity can be explained by pre-, and postsynaptic effects. Low concentrations of the drug act primarily on presynaptic auto-receptors, thus reducing freely available dopamine (Benoit-Marand et al., 2001), which would result in reduced glutamatergic activity and calcium release needed for plasticity induction (Lisman, 2001). Indeed, reduction of postsynaptic dopaminergic activity has been shown to prevent tDCS-, and PAS-induced plasticity (Nitsche et al., 2006; Nitsche et al., 2009). For the medium dosage, D2 receptor stimulation diminished the excitatory effect of PAS25, and prevented plasticity induction by anodal tDCS. This can be explained the activation of postsynaptic D2 receptors, which diminish GABAergic, and glutamatergic receptor activity (Seamans and Yang, 2004). For PAS, which induces phasic suprathreshold synaptic activation, the reduction of glutamate-driven calcium influx in the postsynaptic neuron might have been not sufficient to block LTP-like plasticity, while being sufficient to reduce the tonic, lowerlevel calcium influx induced by subthreshold tDCS to prevent plasticity. Alternatively, GABA reduction might have caused a lack of inhibition, and thus might have resulted in 
calcium overflow predominantly for tDCS-induced LTP-like plasticity, which could result in larger calcium levels as compared to PAS, because it is synaptically less restricted, and causes tonic calcium influx. In accordance, excessive duration of anodal tDCS induces LTD-like plasticity (Monte-Silva et al., 2013). These mechanisms would then be responsible also for the abolishment of LTP-like plasticity independent from the induction procedure in case of high level D2 receptor activation.

\section{D2 receptor modulation of LTD-like plasticity}

The impact of D2 receptor activation on LTD-like plasticity follows an inverted U-shaped curve, strengthening the assumption that LTD depends on D2 receptor activation (Wilson, 2006), and consistent with the effect of global dopaminergic activation on cathodal tDCS and PAS10 (Monte-Silva et al., 2010; Thirugnanasambandam et al., 2011), as well as with the impact of D3/D2 receptor activation on cathodal tDCS (Monte-Silva et al., 2009). In difference, ropinirole had no impact on PAS10-induced plasticity at any dosage.

Mechanisms of action might be similar to the effect of D2 agonism on LTP-like plasticity, since PAS10 and cathodal tDCS also induce glutamatergic and calciumdependent plasticity (Liebetanz et al., 2002; Wolters et al., 2003). Under low-dosage bromocriptine, D2 autoreceptor activation could prevent plasticity due to reduced dopamine release. For the medium dose, the preservation of both focal and nonfocal LTD-like plasticity would have been caused by a sufficient calcium influx via D2 activation for LTD-like plasticity induction. High dosage bromocriptine would abolish the after effects of both, cathodal tDCS and inhibitory PAS, by exceeding calcium increase caused by reduced GABAergic inibition. In accordance, cathodal tDCS with an 
intensity of $2 \mathrm{~mA}$, which should result in larger calcium increase compared to $1 \mathrm{~mA}$ stimulation, as applied in the present study, induces no LTD-like plasticity (Batsikadze et al., 2013). Alternatively, D2 receptor-dependent reduction of NMDA receptor activation (Seamans and Yang, 2004) could have abolished plasticity, since both, cathodal tDCS, and PAS10, require NMDA receptor activation.

\section{General Remarks}

The present study together with former experiments (Nitsche et al., 2006; Kuo et al., 2008; Monte-Silva et al., 2009; Nitsche et al., 2009; Monte-Silva et al., 2010) adds information about the contribution of dopamine receptor subtypes to neuroplasticity. Our results support to some extent the contribution of D2 receptors to the "focusing effect" (strengthening of focally induced, but weakening/conversion of non-focally induced LTP-like plasticity) observed under global dopaminergic activation (Kuo et al., 2008). Focal facilitatory plasticity was diminished, but not abolished, whereas non-focal plasticity was prevented. This effect might underlie the signal-to-noise modulation that dopamine exerts on task-relevant neural processes. Accordingly, optimal dopamine levels would modulate task-related neural processing allowing for flexible use of information, whereas low level of dopamine would reduce the likelihood that a memory trace will be

retained and excessive dopamine levels prevent the updating or replacement of information in current memory stores (Durstewitz et al., 2000). Whereas these mechanisms were proposed primarily for working memory functions, the results of our studies propose that they might also be relevant for long-term memory storage. The nonlinear effects of D2 receptor stimulation on plasticity do not only imply the need for an 
optimal degree of D2 receptor activation, but might also explain the contribution of D2 receptor over-activity for the development of psychotic symptoms (Seeman and Kapur, 2000). Specifically, the lack of plasticity present under high activation of D2 receptors might enhance noise in brain networks, and therefore lead to erroneous information processing. Furthermore, the involvement of D2-like receptors in the facilitatory control of memory consolidation (Sigala et al., 1997) might have a promising therapeutic potential for patients suffering from Parkinson's disease, where rehabilitation involves improving cognitive functions as well.

Some potential limitations of the present study should be taken into account. First, the mechanistical explanation of the results is speculative at present. However, our findings correlate well with known D2 receptor action. Second, high variability in the response to tDCS was reported recently (Wiethoff et al., 2014), and variability, although to a somewhat minor degree, was also present in this study. Differences of variability between studies might be caused by the fact that our plasticity-induction protocols differ from that performed in the aforementioned study. Stimulation with an intensity of $2 \mathrm{~mA}$, as compared with $1 \mathrm{~mA}$ stimulation, as performed in the present study, might result in non-linear effects of tDCS (Batsikadze et al. 2013). Third, dopaminergic medication seems to enhance interindividual variability. This is probably caused by the dosagedependent modulatory effect of dopamine, which could in combination with genetic polymorphisms (Hung Choy Wong et al., 2000; Witte and Flöel, 2012; Witte et al., 2012; Kristin et al., 2013), and differences of resorption of the substance, which we both did not explore, result in interindividually different activation of $\mathrm{D} 2$ receptors in spite of identical dosages. Finally, blinding might have been compromised in 1 subject for whom the 
respective session had to be cancelled due to vomiting after the high dosage of bromocriptine. In the majority of subjects however, side effects, if present, occurred across different dosages of the drug, thus blinding should have been maintained in these cases. Additionally, multiple sessions, blinded tDCS and PAS protocols, medication, and identical after-measurement durations in all conditions should have guaranteed blinding in general.

\section{Reference}

Avalos-Fuentes A, Loya-López S, Flores-Pérez A, Recillas-Morales S, Cortés H, PazBermúdez F, Aceves J, Erlij D, Florán B (2013) Presynaptic CaMKII $\alpha$ modulates dopamine $\mathrm{D} 3$ receptor activation in striatonigral terminals of the rat brain in a Ca2+ dependent manner. Neuropharmacology 71:273-281.

Batsikadze G, Moliadze V, Paulus W, Kuo M-F, Nitsche MA (2013) Partially non-linear stimulation intensity-dependent effects of direct current stimulation on motor cortex excitability in humans. The Journal of Physiology 591:1987-2000.

Benoit-Marand M, Borrelli E, Gonon F (2001) Inhibition of Dopamine Release Via Presynaptic D2 Receptors: Time Course and Functional Characteristics In Vivo. The Journal of Neuroscience 21:9134-9141.

Breitenstein C, Korsukewitz C, Floel A, Kretzschmar T, Diederich K, Knecht S (2006) Tonic Dopaminergic Stimulation Impairs Associative Learning in Healthy Subjects. Neuropsychopharmacology 31:2552-2564.

Chen Z, Ito K, Fujii S, Miura M, Furuse H, Sasaki H, Kaneko K, Kato H, Miyakawa H (1996) Roles of dopamine receptors in long-term depression: enhancement via D1 receptors and inhibition via D2 receptors. Receptors Channels 4:1-8.

Coldwell MC, Boyfield I, Brown T, Hagan JJ, Middlemiss DN (1999) Comparison of the functional potencies of ropinirole and other dopamine receptor agonists at human D2(long), D3 and D4.4 receptors expressed in Chinese hamster ovary cells. British Journal of Pharmacology 127:1696-1702.

Diaz J, Lévesque D, Griffon N, Lammers CH, Martres MP, Sokoloff P, Schwartz JC (1994) Opposing Roles for Dopamine D2 and D3 Receptors on Neurotensin mRNA Expression in Nucleus Accumbens. European Journal of Neuroscience 6:1384-1387.

Durstewitz D, Seamans JK, Sejnowski TJ (2000) Dopamine-Mediated Stabilization of Delay-Period Activity in a Network Model of Prefrontal Cortex. Journal of Neurophysiology 83:1733-1750.

Franken IA, Nijs I, Pepplinkhuizen L (2008) Effects of dopaminergic modulation on electrophysiological brain response to affective stimuli. Psychopharmacology 195:537-546. 
Fresnoza S, Paulus W, Nitsche MA, Kuo M-F (2014) Nonlinear Dose-Dependent Impact of D1 Receptor Activation on Motor Cortex Plasticity in Humans. The Journal of Neuroscience 34:2744-2753.

Grundey J, Freznosa S, Klinker F, Lang N, Paulus W, Nitsche MA (2013) Cortical excitability in smoking and not smoking individuals with and without nicotine. Psychopharmacology 229:653-664.

Hung Choy Wong A, Buckle CE, Van Tol HHM (2000) Polymorphisms in dopamine receptors: what do they tell us? European Journal of Pharmacology 410:183-203.

Jay TM (2003) Dopamine: a potential substrate for synaptic plasticity and memory mechanisms. Progress in Neurobiology 69:375-390.

Kimberg DY, D'Esposito M, Farah MJ (1997) Effects of bromocriptine on human subjects depend on working memory capacity. Neuroreport 8:3581-3585.

Kimberg DY, Aguirre GK, Lease J, D'Esposito M (2001) Cortical effects of bromocriptine, a D-2 dopamine receptor agonist, in human subjects, revealed by fMRI. Human Brain Mapping 12:246-257.

Kling-Petersen T, Ljung E, Svensson K (1995) Effects on locomotor activity after local application of D3 preferring compounds in discrete areas of the rat brain. J Neural Transmission 102:209-220.

Kristin MP-F, Brian M, Daniel A, Babak S, Steven CC (2013) Genetic Variation in the Human Brain Dopamine System Influences Motor Learning and Its Modulation by L-Dopa. PLoS One 8.

Kuo M-F, Paulus W, Nitsche MA (2008) Boosting Focally-Induced Brain Plasticity by Dopamine. Cerebral Cortex 18:648-651.

Liebetanz D, Nitsche MA, Tergau F, Paulus W (2002) Pharmacological approach to the mechanisms of transcranial DC-stimulation-induced after-effects of human motor cortex excitability. Brain 125:2238-2247.

Lisman JE (2001) Three Ca2+ levels affect plasticity differently: the LTP zone, the LTD zone and no man's land. The Journal of Physiology 532:285-285.

Luciana M, Collins PF (1997) Dopaminergic Modulation of Working Memory for Spatial but Not Object Cues in Normal Humans. Journal of Cognitive Neuroscience 9:330-347.

Luciana M, Depue RA, Arbisi P, Leon A (1992) Facilitation of Working Memory in Humans by a D2 Dopamine Receptor Agonist. Journal of Cognitive Neuroscience 4:58-68.

Manahan-Vaughan D, Kulla A (2003) Regulation of Depotentiation and Long-term Potentiation in the Dentate Gyrus of Freely Moving Rats by Dopamine D2-like Receptors. Cerebral Cortex 13:123-135.

Mehta M, Swainson R, Ogilvie A, Sahakian B, Robbins T (2001) Improved short-term spatial memory but impaired reversal learning following the dopamine D2 agonist bromocriptine in human volunteers. Psychopharmacology 159:10-20.

Meintzschel F, Ziemann U (2006) Modification of Practice-dependent Plasticity in Human Motor Cortex by Neuromodulators. Cerebral Cortex 16:1106-1115.

Monte-Silva K, Liebetanz D, Grundey J, Paulus W, Nitsche MA (2010) Dosagedependent non-linear effect of 1-dopa on human motor cortex plasticity. The Journal of Physiology 588:3415-3424. 
Monte-Silva K, Kuo M-F, Thirugnanasambandam N, Liebetanz D, Paulus W, Nitsche MA (2009) Dose-Dependent Inverted U-Shaped Effect of Dopamine (D2-Like) Receptor Activation on Focal and Nonfocal Plasticity in Humans. The Journal of Neuroscience 29:6124-6131.

Monte-Silva K, Kuo M-F, Hessenthaler S, Fresnoza S, Liebetanz D, Paulus W, Nitsche MA (2013) Induction of Late LTP-Like Plasticity in the Human Motor Cortex by Repeated Non-Invasive Brain Stimulation. Brain Stimulation 6:424-432.

Müller U, von Cramon DY, Pollmann S (1998) D1- Versus D2-Receptor Modulation of Visuospatial Working Memory in Humans. The Journal of Neuroscience 18:27202728.

Nitsche MA, Kuo M-F, Grosch J, Bergner C, Monte-Silva K, Paulus W (2009) D1Receptor Impact on Neuroplasticity in Humans. The Journal of Neuroscience 29:2648-2653.

Nitsche MA, Lampe C, Antal A, Liebetanz D, Lang N, Tergau F, Paulus W (2006) Dopaminergic modulation of long-lasting direct current-induced cortical excitability changes in the human motor cortex. European Journal of Neuroscience 23:1651-1657.

Nitsche MA, Cohen LG, Wassermann EM, Priori A, Lang N, Antal A, Paulus W, Hummel F, Boggio PS, Fregni F, Pascual-Leone A (2008) Transcranial direct current stimulation: State of the art 2008. Brain Stimulation 1:206-223.

Otani S, Blond O, Desce JM, Crépel F (1998) Dopamine facilitates long-term depression of glutamatergic transmission in rat prefrontal cortex. Neuroscience 85:669-676.

Seamans JK, Yang CR (2004) The principal features and mechanisms of dopamine modulation in the prefrontal cortex. Progress in Neurobiology 74:1-58.

Seeman P, Kapur S (2000) Schizophrenia: More dopamine, more D2 receptors. Proceedings of the National Academy of Sciences 97:7673-7675.

Sigala S, Missale C, Spano P (1997) Opposite effects of dopamine D2 and D3 receptors on learning and memory in the rat. European Journal of Pharmacology 336:107112.

Stefan K, Kunesch E, Cohen LG, Benecke R, Classen J (2000) Induction of plasticity in the human motor cortex by paired associative stimulation. Brain 123:572-584.

Stefan K, Kunesch E, Benecke R, Cohen LG, Classen J (2002) Mechanisms of enhancement of human motor cortex excitability induced by interventional paired associative stimulation. The Journal of Physiology 543:699-708.

Thirugnanasambandam N, Grundey J, Paulus W, Nitsche MA (2011) Dose-Dependent Nonlinear Effect of 1-DOPA on Paired Associative Stimulation-Induced Neuroplasticity in Humans. The Journal of Neuroscience 31:5294-5299.

Wiethoff S, Hamada M, Rothwell JC (2014) Variability in Response to Transcranial Direct Current Stimulation of the Motor Cortex. BRAIN STIMULATION: Basic, Translational, and Clinical Research in Neuromodulation 7:468-475.

Williams GV, Goldman-Rakic PS (1995) Modulation of memory fields by dopamine Dl receptors in prefrontal cortex. Nature 376:572-575.

Wilson CJ (2006) Striatal D2 Receptors and LTD: Yes, but Not Where You Thought They Were. Neuron 50:347-348.

Witte AV, Flöel A (2012) Effects of COMT polymorphisms on brain function and behavior in health and disease. Brain Research Bulletin 88:418-428. 
Witte AV, Kürten J, Jansen S, Schirmacher A, Brand E, Sommer J, Flöel A (2012) Interaction of BDNF and COMT Polymorphisms on Paired-Associative

Stimulation-Induced Cortical Plasticity. The Journal of Neuroscience 32:45534561.

Wolters A, Sandbrink F, Schlottmann A, Kunesch E, Stefan K, Cohen LG, Benecke R, Classen J (2003) A Temporally Asymmetric Hebbian Rule Governing Plasticity in the Human Motor Cortex. Journal of Neurophysiology 89:2339-2345.

Table 1. Peak-to-peak MEP amplitudes and TMS intensity before and after application of bromocriptine.

\begin{tabular}{|l|c|l|l|l|l|l|l|}
\hline & $\begin{array}{l}\text { Bromo } \\
\text { Criptine }\end{array}$ & \multicolumn{2}{|c}{ Baseline 1 } & \multicolumn{2}{c|}{ Baseline 2 } & \multicolumn{2}{c|}{ Baseline 3 } \\
\hline & & MEP (mV) & MSO (\%) & MEP (mV) & MSO (\%) & MEP (mV) & MSO (\%) \\
\hline Anodal & $2.5 \mathrm{mg}$ & $1.078 \pm 0.03$ & $41.5 \pm 1.7$ & $1.207 \pm 0.15$ & $41.5 \pm 1.7$ & $1.135 \pm 0.03$ & $40.4 \pm 1.8$ \\
\hline tDCS & $10 \mathrm{mg}$ & $1.122 \pm 0.02$ & $40.0 \pm 1.5$ & $1.067 \pm 0.10$ & $40.0 \pm 1.5$ & $1.064 \pm 0.03$ & $40.7 \pm 1.6$ \\
\hline & $20 \mathrm{mg}$ & $1.115 \pm 0.02$ & $41.5 \pm 2.0$ & $1.074 \pm 0.06$ & $41.5 \pm 2.0$ & $1.079 \pm 0.02$ & $39.0 \pm 1.5$ \\
\hline Cathodal & $2.5 \mathrm{mg}$ & $1.080 \pm 0.03$ & $42.2 \pm 1.7$ & $1.241 \pm 0.12$ & $42.2 \pm 1.7$ & $1.082 \pm 0.03$ & $39.7 \pm 2.0$ \\
\hline tDCS & $10 \mathrm{mg}$ & $1.051 \pm 0.02$ & $41.7 \pm 2.1$ & $1.021 \pm 0.04$ & $41.7 \pm 2.1$ & $1.040 \pm 0.02$ & $41.2 \pm 0.7$ \\
\hline & $20 \mathrm{mg}$ & $1.063 \pm 0.02$ & $42.2 \pm 1.6$ & $1.234 \pm 0.20$ & $42.2 \pm 1.6$ & $1.123 \pm 0.02$ & $43.0 \pm 1.7$ \\
\hline PAS25 & $2.5 \mathrm{mg}$ & $1.071 \pm 0.03$ & $47.6 \pm 2.8$ & $0.971 \pm 0.10$ & $47.6 \pm 2.8$ & $1.045 \pm 0.03$ & $48.0 \pm 3.2$ \\
\hline & $10 \mathrm{mg}$ & $1.070 \pm 0.02$ & $47.6 \pm 2.7$ & $0.879 \pm 0.13$ & $47.6 \pm 2.7$ & $1.045 \pm 0.02$ & $46.4 \pm 2.7$ \\
\hline & $20 \mathrm{mg}$ & $1.106 \pm 0.02$ & $50.2 \pm 3.5$ & $0.966 \pm 0.10$ & $50.2 \pm 3.5$ & $1.120 \pm 0.03$ & $49.0 \pm 2.1$ \\
\hline PAS10 & $2.5 \mathrm{mg}$ & $1.079 \pm 0.03$ & $50.2 \pm 3.1$ & $1.164 \pm 0.14$ & $50.2 \pm 3.1$ & $1.064 \pm 0.03$ & $49.8 \pm 3.2$ \\
\hline & $10 \mathrm{mg}$ & $1.119 \pm 0.03$ & $47.2 \pm 2.7$ & $0.966 \pm 0.06$ & $47.2 \pm 2.7$ & $1.041 \pm 0.03$ & $39.5 \pm 3.0$ \\
\hline & $20 \mathrm{mg}$ & $1.018 \pm 0.02$ & $47.7 \pm 2.7$ & $1.029 \pm 0.10$ & $42.3 \pm 2.4$ & $1.011 \pm 0.03$ & $50.4 \pm 4.0$ \\
\hline & & & & & & & \\
\hline
\end{tabular}


Shown are the mean MEP amplitudes and stimulation intensities (percentage of maximum stimulator output, MSO) mean \pm S.E.M. of baselines 1,2 and 3 . There was no significant difference between these parameters across the different conditions (Student's $\mathrm{t}$ test, paired, two-tailed, $p>0.05)$.

Table 2. Results of the ANOVA conducted for tDCS and PAS.

\begin{tabular}{|c|c|c|c|c|}
\hline & df & F value & $p$ value & $\eta^{2}$ \\
\hline Stimulation & 1 & 1.624 & .203 & .001 \\
\hline Dosage & 3 & 20.015 & $<.001 *$ & .020 \\
\hline Polarity & 1 & 139.812 & $<.001 *$ & .046 \\
\hline Time course & 14 & 1.947 & $.015 *$ & .010 \\
\hline Stimulation $\mathrm{x}$ dosage & 3 & 4.337 & $.005 *$ & .004 \\
\hline Stimulation x polarity & 1 & 3.373 & .066 & .001 \\
\hline Dosage x polarity & 3 & 75.237 & $<.001 *$ & .073 \\
\hline Stimulation $\mathrm{x}$ dosage $\mathrm{x}$ polarity & 3 & 5.111 & $.002 *$ & .005 \\
\hline Stimulation $\mathrm{x}$ time course & 14 & .756 & .718 & .004 \\
\hline Dosage $\mathrm{x}$ time course & 42 & .882 & .687 & .013 \\
\hline $\begin{array}{l}\text { Stimulation } \mathrm{x} \text { dosage } \mathrm{x} \text { time } \\
\text { course }\end{array}$ & 42 & .541 & .993 & .008 \\
\hline Polarity $\mathrm{x}$ time course & 14 & 6.701 & $<.001 *$ & .032 \\
\hline $\begin{array}{l}\text { Stimulation } \mathrm{x} \text { polarity } \mathrm{x} \text { time } \\
\text { course }\end{array}$ & 14 & .379 & .981 & .002 \\
\hline Dosage $\mathrm{x}$ polarity $\mathrm{x}$ time course & 42 & 3.361 & $<.001 *$ & .047 \\
\hline $\begin{array}{l}\text { Stimulation } \mathrm{x} \text { dosage } \mathrm{x} \text { polarity } \mathrm{x} \\
\text { time course }\end{array}$ & 42 & .571 & .988 & .008 \\
\hline
\end{tabular}


The ANOVA encompasses the time course of the MEP measures up to next evening after stimulation. Asterisks indicate significant results $(p<0.05)$. df, Degrees of freedom; $\eta^{2}$, partial eta squared (measure of effect size).

\section{Figures:}

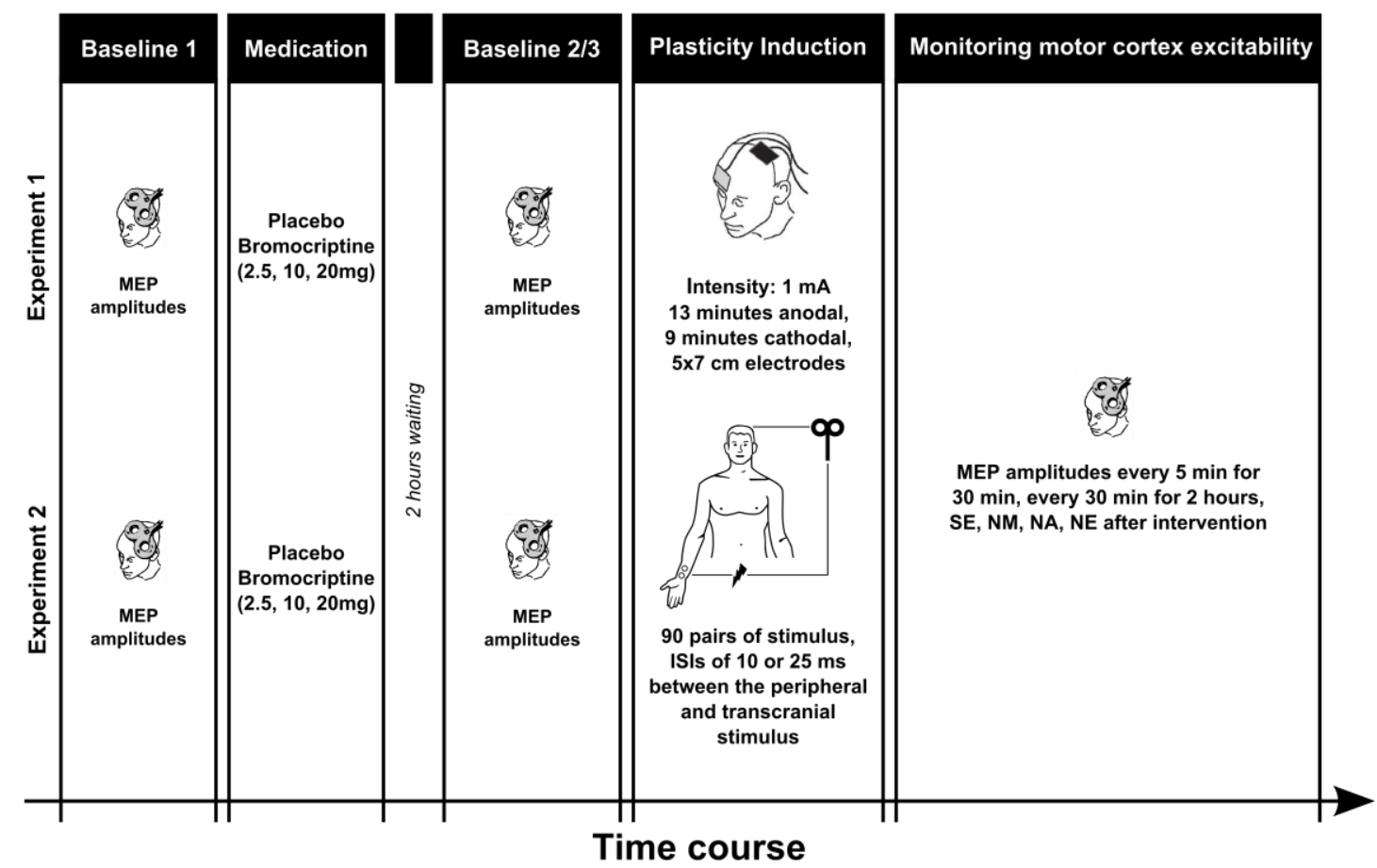

Figure 1. Course of the Experiments. MEPs elicited by single-pulse TMS over the motor hot spot of the right $\mathrm{ADM}$ were recorded at $1 \mathrm{mV}$ intensity before drug intake [baseline 1 (BL TMS 1)]. Two hours after drug intake, baseline 2 (BL TMS 2) was recorded to look for an effect of the drug on cortical excitability. In case of any MEP alterations from baseline 1, baseline 3 (BL TMS 3) was recorded by adjusting the stimulator output to obtain a mean MEP amplitude of $1 \mathrm{mV}$. Then tDCS (anodal or cathodal) or PAS (excitatory or inhibitory) were administered, immediately followed by 
MEP after-measurements that covered $120 \mathrm{~min}$. Additional after-measurements were performed at the same evening (SE), and the morning (NM), afternoon (NA) and evening (NE) of the second day following plasticity induction.
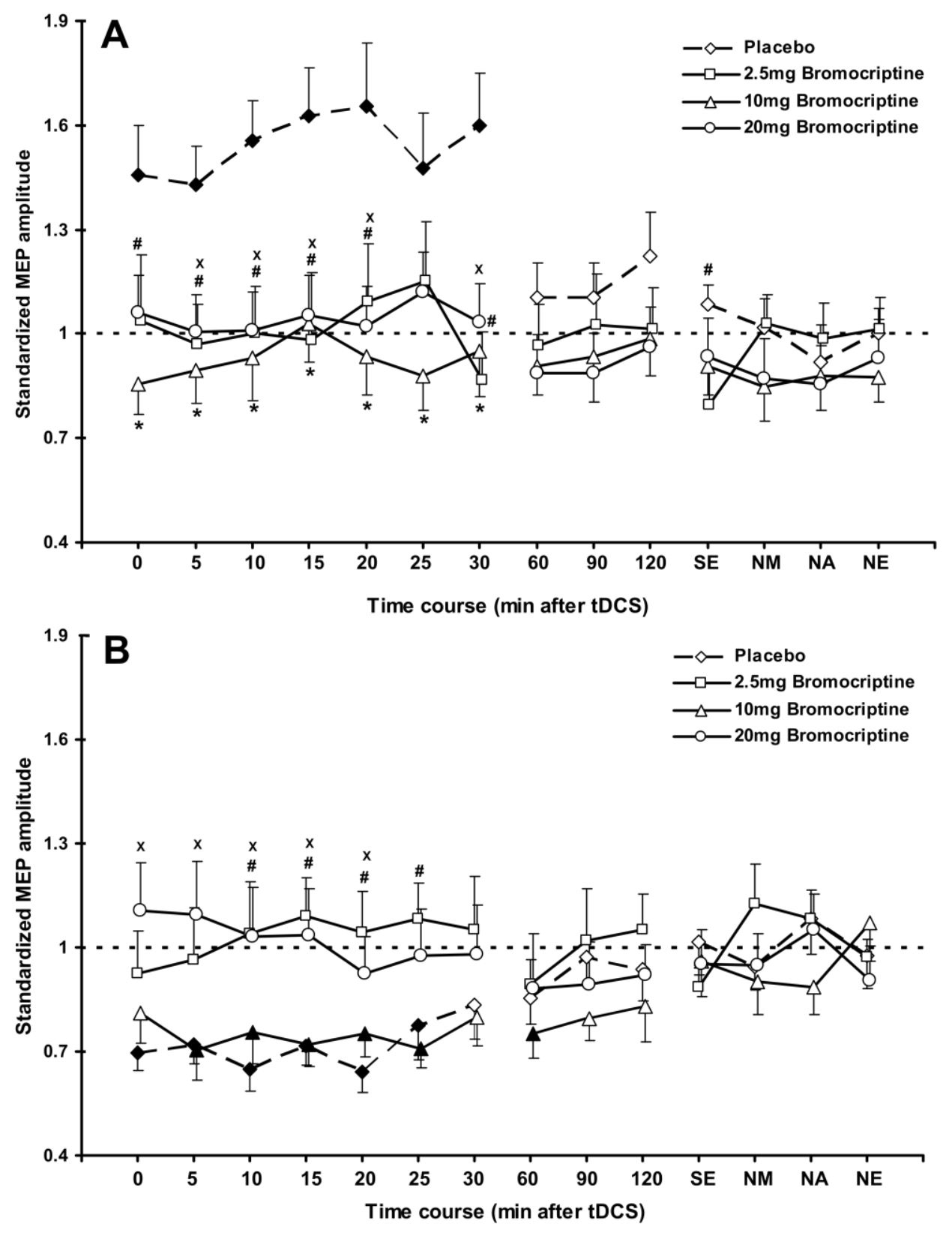
Figure 2. Dose-dependent effect of D2 receptor activation on nonfocal plasticity induced by anodal and cathodal tDCS (experiment 1). The $x$-axis displays the time points (in minutes) of after-measurements during the experiment. MEP amplitudes standardized to the corresponding baseline values (mean \pm SEM) are plotted on the $y$ axis. The graphs show that under placebo medication, anodal tDCS induces an excitability enhancement lasting for about $30 \mathrm{~min}$, whereas cathodal tDCS diminishes excitability for $25 \mathrm{~min}$ following stimulation. A, Low-dose (2.5mg), medium dose (10mg) and high-dose (20mg) bromocriptine prevented the anodal tDCS-generated aftereffects. B, Low dose and high dose bromocriptine prevented the cathodal tDCSgenerated aftereffects, while under medium dose the aftereffects were preserved. Filled symbols indicate statistically significant deviations of the post-tDCS MEP values compared to baseline. The "\#”“*” "X" symbols indicate significant differences of the real medication compared with the placebo medication conditions at the same time points after plasticity induction (Fisher LSD post hoc test , paired, two-tailed, $p \leq 0.05$ ). SE: same evening; NM: next morning; NA: next afternoon; NE: next evening. Error bars show standard error of mean (S.E.M.). \#: $2.5 \mathrm{mg}$ bromocriptine. *: $10 \mathrm{mg}$ bromocriptine. $\mathrm{X}$ : 20mg bromocriptine. 

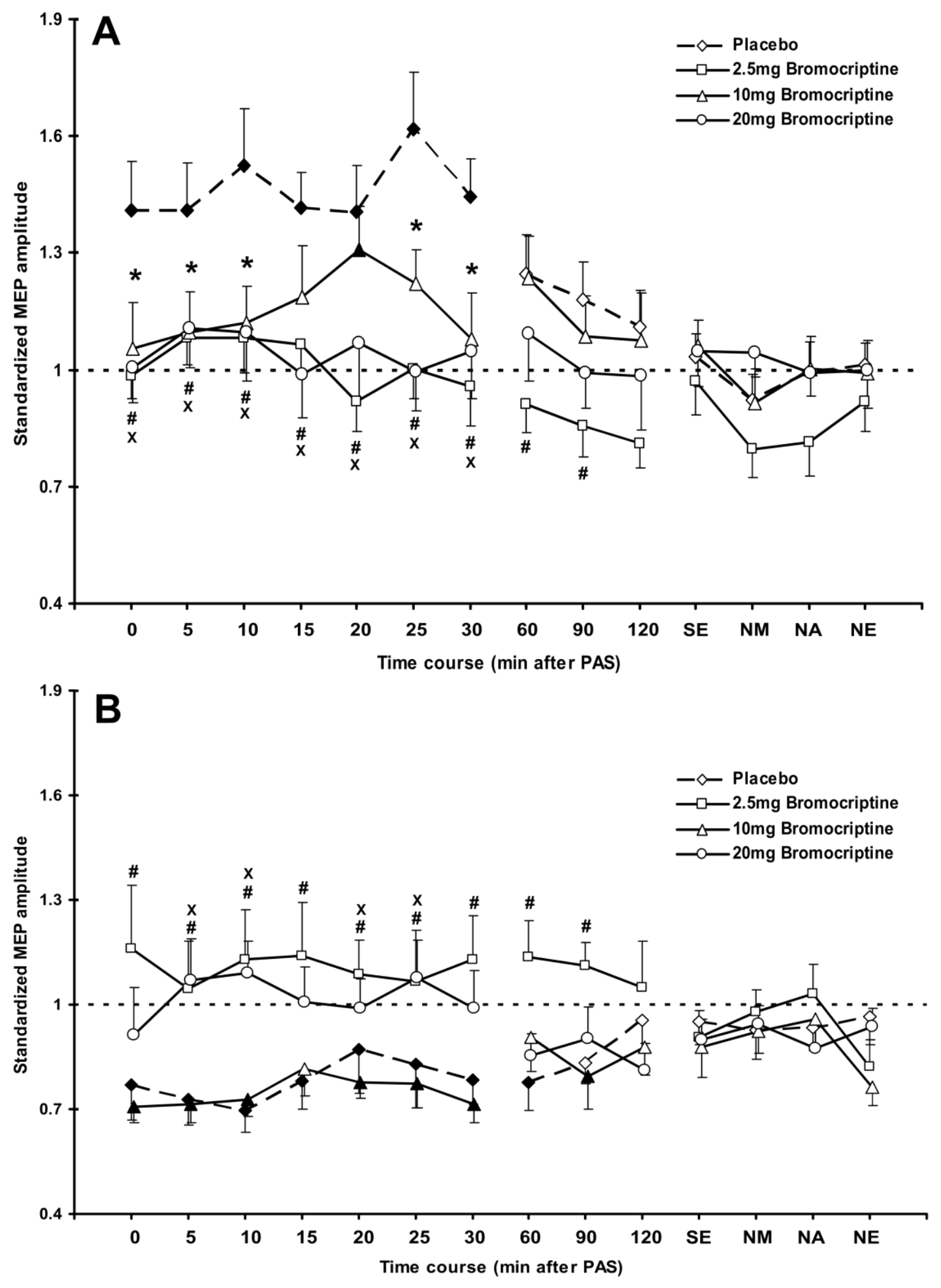

Figure 3. Dose-dependent effects of $D 2$ receptor activation on focal neuroplasticity induced by PAS25 and PAS10 (experiment 2). The $x$-axis displays the time points (in 
minutes) of after-measurements during the experiment. MEP amplitudes standardized to the corresponding baseline values (mean \pm SEM) are plotted on the $y$-axis. The graphs show that under placebo medication, excitatory PAS (PAS25) induces an excitability enhancement lasting for about 30 min, whereas inhibitory PAS (PAS10) diminishes excitability for $60 \mathrm{~min}$ following stimulation. A, Low dose $(2.5 \mathrm{mg})$ and high dose (20mg) bromocriptine suppress the aftereffects of PAS25 respectively, whereas medium dose (10mg) reduced, but did not abolish them. B, Low dose $(2.5 \mathrm{mg})$ and high dose (20mg) bromocriptine prevented the PAS10 aftereffects. Filled symbols indicate statistically significant deviations of the post-tDCS MEP values compared to baseline. The “\#”“**" "X" symbols indicate significant differences of the real medication compared with the placebo medication conditions at the same time points after plasticity induction (Fisher LSD post hoc test, paired, two-tailed, $p \leq 0.05$ ). SE: same evening; NM: next morning; NA: next afternoon; NE: next evening. Error bars show standard error of mean (S.E.M.). \#: $2.5 \mathrm{mg}$ bromocriptine. *: $10 \mathrm{mg}$ bromocriptine. X: $20 \mathrm{mg}$ bromocriptine. 


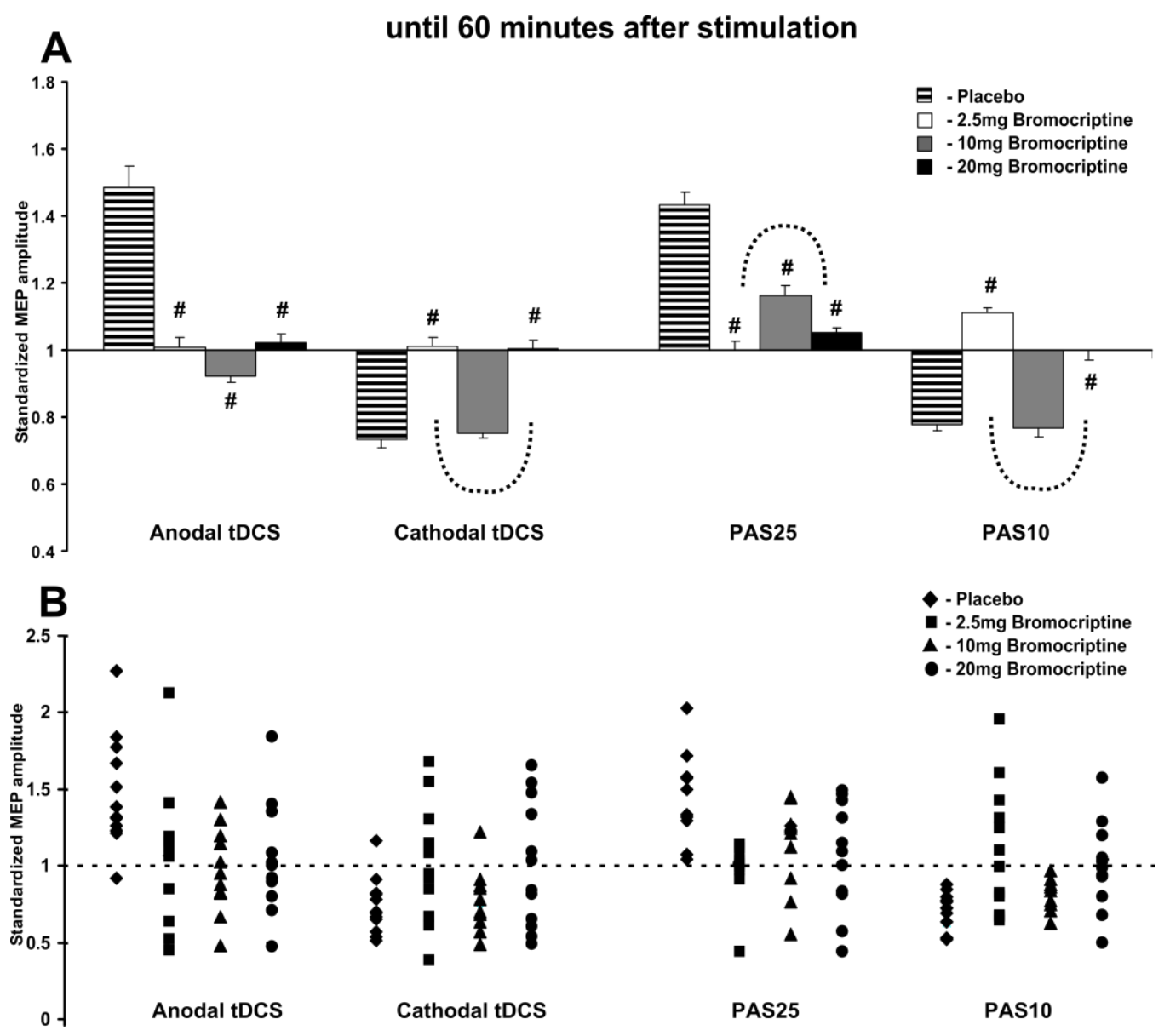

Figure 4. Dose-dependent effects of $\mathrm{D} 2$ receptor activation on nonfocal and focal plasticity induced by tDCS and PAS. The horizontal line represent the baseline value of $1 \mathrm{mv}$ before the start of the each stimulation condition, while the vertical line (y-axis) represent the MEP amplitudes standardized to the corresponding baseline values. A, D2 receptor activation by bromocriptine has a non-linear dosage-dependent effect on neuroplasticity induced by cathodal tDCS and inhibitory PAS. Low and high dosages impaired or prevented excitability alterations while the medium dosage preserved these. In contrast, the effects of anodal tDCS and excitatory PAS were either impaired or prevented in all dosages. Each column represents the baseline-standardized MEP amplitudes pooled for 60 minutes after anodal/cathodal tDCS and PAS25/PAS10 from 24 
participants. Error bars represent the standard error of mean (S.E.M.) of the measurement immediately after until 60 minutes post stimulation. The "\#” symbol indicates significant differences of the real medication compared with placebo medication (Post hoc $t$ test, paired, two-tailed, $p \leq 0.05$ ). B, Each point represents the mean of the MEP amplitude (calculated for the first $60 \mathrm{~min}$ after intervention) from each subject for each drug/stimulation condition combination. The results show considerable interindividual variability, especially under bromocriptine. 


\section{Chapter 3: Summary, Limitations and Conclusions}

The present thesis further explored the contribution of the dopaminergic system to functional plasticity mechanisms in the human brain. The results of the studies help to elucidate the specific contribution of dopamine receptor subtypes as well as the effect of dosage or level of receptor activation on plasticity induction in the human motor cortex. Under global/non-specific dopamine receptors stimulation, a non-linear dosagedependent effect on stimulation induced by tDCS and PAS was observed in previous studies (Monte-Silva et al., 2010; Thirugnanasambandam et al., 2011). Low and high dose L-dopa abolished or impaired plasticity induced by both protocols, whereas under medium dosage plasticity induced by excitatory and inhibitory PAS was preserved. For tDCS, medium dosage preserved the excitability-reducing effect of cathodal tDCS, but reversed the excitability-enhancing effect of anodal tDCS into inhibition.

In the present project, we have shown that specific activation of D1-like (first study) and D2 receptors (second study) also has a non-linear dosage-dependent effect on plasticity. For D1-like receptor activation, low and high dosages impaired or reversed, whereas medium dosage preserved the focal and non-focal excitability-enhancing effect of excitatory PAS and anodal tDCS respectively. However, the excitability-reducing effect of inhibitory PAS was reversed and the after effect of cathodal tDCS was abolished. In general, these results suggest that D1-like receptor activation is relevant for the induction of LTP-like plasticity. However, as compared to global dopaminergic activation, which had a focusing effect on facilitatory plasticity, the promoting effect of D1 activation on facilitatory plasticity was independent from the focality of the plasticity-induction procedure. This result is in accordance to the enhancing effect of optimal D1 receptor 
activation on LTP observed in animal plasticity and cognitive studies (Seamans and Yang, 2004) and provides the first evidence of related effects in the human brain, at least electrophysiologically. Taking into account the impact of D1 receptor activation on LTPlike plasticity, as well as positive cognitive effects, as explored in animal experiments, modulation of D1 receptors could have beneficial effects especially in the field of cognitive rehabilitation. In the PFC, the area with the largest density of D1 receptors (Camps et al., 1990; Lidow et al., 1991), activation of the D1 receptor is relevant for maintaining active memory representation (Cohen et al., 2002). In accordance, insufficient D1 receptor signaling results in working memory deficits, which can be ameliorated by D1 receptor stimulation (Goldman-Rakic et al., 2004). In schizophrenia, alteration of D1 receptor activity and its signaling pathway in the $\mathrm{PFC}$ has been associated to impairment of working memory and negative symptoms (Kashima, 1991; Okubo et al., 1997; Karlsson et al., 2002; Koh et al., 2003; Potkin et al., 2003). Impaired LTP and LTD recently observed in schizophrenic patients (Harvey and Lacey, 1997; Hasan et al., 2011) corroborates with our findings that dysregulation of dopamine modulation can alter plasticity. Furthermore, in Parkinson's disease a critical role of D1 receptors in attenuating Parkinsonian symptoms was suggested. D1 receptor activity enhancement improved symptoms in the monkey model of Parkinson's disease, and also in humans (Taylor et al., 1991; Blanchet et al., 1998; Rascol et al., 1999; Goulet and Madras, 2000; Rascol et al., 2001). Thus, agents targeting the D1 receptors might be an interesting direction in Schizophrenia and Parkinson's disease treatment in the future.

The second study elucidated the specific impact of the D2 receptor on motor cortex plasticity via bromocriptine. This substance exerted a non-linear dosage-dependent 
effect on LTP- and LTD-like plasticity induced by tDCS and PAS. Low and high D2 receptor activation prevented plasticity induction irrespective of the specific stimulation protocol. Medium activation preserved inhibitory plasticity, however it diminished focal and prevented non-focal facilitatory plasticity. These effects differ from global receptor activation with regard to facilitatory plasticity gradually, since plasticity induced by anodal tDCS under medium dosage was reversed while the excitatory PAS after effect was preserved under L-Dopa (Kuo et al., 2008; Monte-Silva et al., 2010; Thirugnanasambandam et al., 2011). The results differ moreover clearly from those obtained via application of the combined D2/D3 receptor agonist ropinirole. In that study, the effect of anodal tDCS under medium dosage was preserved and there was no nonlinear dosage dependent effect observed on inhibitory PAS regardless of dosage (MonteSilva et al., 2009). These differences might be caused at least partially by a co-activation of D1 receptors accomplished by D3 receptor activation. Indeed, the impact of a medium dosage of ropinirole on facilitatory plasticity resembled those of medium D1 receptor activation. Under physiological conditions, D2 receptor activation is proposed to phasically gate signals in order to update the contents of working memory (Cohen et al., 2002; Gibbs and D'Esposito, 2005). Thus, the predominant induction of LTD-like plasticity observed under D2 receptor activation might be beneficial for tasks requiring flexibility or the ability to update and manipulate neural information/representation, because D2 receptor activation would prevent in this case dys-functional stabilization of task-related connections (Nicholls et al., 2008). With regard to implications of D2 receptor effects on plasticity for cognitive performance, so far heterogeneous effects have been obtained. Beyond the above-mentioned task-dependent effects, this might be caused 
by the non-linear dosage-dependent effects of receptor activation on plasticity. For taskdependent effects, future studies dealing with specific cognitive demands involving the D2 receptor might shed light on the still poorly understood mechanisms. The impairment of plasticity induction seen under both, low and high dosages of bromocriptine could also account for symptoms observed in schizophrenia and Parkinson's disease. In schizophrenia, where the dopaminergic system is assumed to be hyper-active, although not associated with the severity of positive symptoms per se, increased activity of striatal D2 receptors is associated with the first episode of illness and subsequent episodes of illness exacerbation (Howes and Kapur, 2009). In Parkinson's disease on the other hand, low doses of D2 agonists occasionally worsen motor symptoms (Tolosa et al., 1987). Bradykinesia was also observed in a rat model following high dosage of L-dopa or D2 agonists, which could be due to overstimulation of postsynaptic D2 receptors (Picconi et al., 2003; Picconi et al., 2008). Although speculative, the lack of plasticity observed in our study under low and high dosages may underlie these symptoms. Thus, titrating the dosage to achieve an optimal stimulation of the D2 receptors could improve the therapeutic use of $\mathrm{D} 2$ receptor stimulation.

Taken together, as compared to global dopamine receptor activation, D1-like receptor activation favors LTP-like plasticity induction (first study) and D2 receptor activation favors LTD-like plasticity induction (second study). The signal-to-noise modulator function of dopamine as suggested by animal (Sawaguchi et al., 1990; Sawaguchi, 2001) and human electrophysiological studies (Kuo et al., 2008; Monte-Silva et al., 2010; Thirugnanasambandam et al., 2011) can then be accounted for at least partially by the results of each study. Specifically, the results of our studies suggest that 
global dopamine receptor activation inhibits non-focal facilitatory plasticity probably via D2 receptor activation, while D1 receptors might be relevant for the stabilization of focal facilitatory plasticity. The functional implications of these findings for learning and memory mechanisms have to be explored in future studies. These might be conceptually analogous to the effects of dopamine on working memory performance. Here, suboptimal dopamine levels are assumed to reduce the likelihood that a memory trace will be retained through a delay interval (no plasticity at low doses), whereas excessive dopamine levels may prevent the updating or replacement of information in current memory stores (no plasticity at higher doses) (Durstewitz et al., 2000; Cohen et al., 2002; Gibbs and D'Esposito, 2005). In contrast, an optimal dopamine level may modulate taskrelated neural processing to allow for the flexible use of information encoded in working memory (LTD-like effect under medium dosage of D2 receptor stimulation) (Gibbs and D'Esposito, 2005) while keeping this information stable for future use (LTP-like effect under medium dosage of D1 receptor stimulation) (Durstewitz et al., 2000; Seamans and Yang, 2004).

Some limitations of our studies have to be taken into account: First, in the majority of animal electrophysiological and cognitive studies, specific D1 receptor agonists and antagonists were used, whereas we used L-dopa under D2 receptor block to stimulate D1-like receptors in the first study. There are specific differences in the pharmacological profile of L-dopa and dopamine agonists that should be considered, because these might affect the physiological outcomes. Dopamine agonists do not increase the presynaptic availability of dopamine and are thus not capable of enhancing phasic dopamine signaling, but rather exert a tonic effect on postsynaptic dopamine 
receptors (Jaber et al., 1996; Breitenstein et al., 2006). L-dopa on the other hand, increases presynaptic dopamine availability and has the potential to mimic the endogenous dopamine-mediated phasic release observed e.g. during learning (Floel et al., 2005), where phasic neuronal impulses are required for stimulus salience coding (Schultz, 2002; Breitenstein et al., 2006). This limitation should apply too when comparing the result of the second study to other studies, in which L-dopa or dopamine were administered. Second, plasticity studies in animals are usually conducted in hippocampal, PFC, and striatal neurons or slices, whereas our study was conducted in the motor cortex of awake humans. This must be taken in consideration since anatomic differences in the distribution of dopamine receptors are present between different cortical regions across species. For instance, D1 receptors in rodent's PFC are restricted to layer V (Vincent et al., 1993; Goldman-Rakic et al., 2004),whereas in primates D1 receptors are abundant in layers II, III and V (Lidow et al., 1991). These limitations can be a challenge for future translational studies exploring specific dopamine receptors functions. Furthermore, our information on how dopaminergic modulation affects plasticity in humans is still limited. Studies using TMS or new imaging techniques such as magnetic resonance spectroscopy, which deliver information about receptor activation, and transmitter concentration non-invasively, might be suited to clarify this to a larger extent. To explore the dosage-dependent impact of D1 receptors on plasticity also for deactivated states, and thus to explore the full range of non-linear dosage-dependent effects, block of D1 receptors by respective antagonists might be a promising approach.

In conclusion, this project confirmed the findings from animal studies regarding the dosage-dependent effect of dopamine receptor subtype activation on plasticity. The 
results of these studies also further our understanding of the complex mechanisms underlying the dopaminergic modulation of plasticity especially in humans and help to set a foundation with regard to future research concerning dopamine receptor functions. Future studies should explore the specific physiological mechanisms how dopamine exerts these effects to a larger extent, and explore the relevance for cognitive and behavioral processes. 


\section{References}

Abbott A (2010) Levodopa: the story so far. Nature 466:S6-7.

Abe K, Niikura Y, Fujimoto T, Akaishi T, Misawa M (2008) Involvement of dopamine $\mathrm{D} 2$ receptors in the induction of long-term potentiation in the basolateral amygdala-dentate gyrus pathway of anesthetized rats. Neuropharmacology 55:1419-1424.

Antal A, Nitsche MA, Kincses TZ, Kruse W, Hoffmann K-P, Paulus W (2004) Facilitation of visuo-motor learning by transcranial direct current stimulation of the motor and extrastriate visual areas in humans. European Journal of Neuroscience 19:2888-2892.

Arnsten A, Goldman-Rakic P (1998) Noise stress impairs prefrontal cortical cognitive function in monkeys: Evidence for a hyperdopaminergic mechanism. Archives of General Psychiatry 55:362-368.

Arnsten AFT (1997) Catecholamine regulation of the prefrontal cortex. Journal of Psychopharmacology 11:151-162.

Artola A, Singer W (1993) Long-term depression of excitatory synaptic transmission and its relationship to long-term potentiation. Trends in Neurosciences 16:480-487.

Avalos-Fuentes A, Loya-López S, Flores-Pérez A, Recillas-Morales S, Cortés H, PazBermúdez F, Aceves J, Erlij D, Florán B (2013) Presynaptic CaMKII $\alpha$ modulates dopamine D3 receptor activation in striatonigral terminals of the rat brain in a Ca2+ dependent manner. Neuropharmacology 71:273-281.

Awenowicz PW, Porter LL (2002) Local Application of Dopamine Inhibits Pyramidal Tract Neuron Activity in the Rodent Motor Cortex. Journal of Neurophysiology 88:3439-3451.

Aydin K, Ucar A, Oguz KK, Okur OO, Agayev A, Unal Z, Yilmaz S, Ozturk C (2007) Increased Gray Matter Density in the Parietal Cortex of Mathematicians: A Voxel-Based Morphometry Study. American Journal of Neuroradiology 28:18591864.

Bailey CH, Giustetto M, Huang YY, Hawkins RD, Kandel ER (2000) Is heterosynaptic modulation essential for stabilizing Hebbian plasticity and memory? Nature reviews Neuroscience 1:11-20.

Barchas J, Akil H, Elliott G, Holman R, Watson S (1978) Behavioral neurochemistry: neuroregulators and behavioral states. Science 200:964-973.

Barker AT, Jalinous R, Freeston IL (1985) NON-INVASIVE MAGNETIC STIMULATION OF HUMAN MOTOR CORTEX. The Lancet 325:1106-1107.

Barnes SJ, Finnerty GT (2010) Sensory Experience and Cortical Rewiring. The Neuroscientist 16:186-198.

Barnett JH, Jones PB, Robbins TW, Muller U (2007) Effects of the catechol-Omethyltransferase Val158Met polymorphism on executive function: a metaanalysis of the Wisconsin Card Sort Test in schizophrenia and healthy controls. Mol Psychiatry 12:502-509.

Batsikadze G, Moliadze V, Paulus W, Kuo M-F, Nitsche MA (2013) Partially non-linear stimulation intensity-dependent effects of direct current stimulation on motor cortex excitability in humans. The Journal of Physiology 591:1987-2000. 
Battaglia F, Wang H-Y, Ghilardi MF, Gashi E, Quartarone A, Friedman E, Nixon RA (2007) Cortical Plasticity in Alzheimer's Disease in Humans and Rodents. Biological psychiatry 62:1405-1412.

Beaulieu J-M, Gainetdinov RR (2011) The Physiology, Signaling, and Pharmacology of Dopamine Receptors. Pharmacological Reviews 63:182-217.

Beck H, Goussakov IV, Lie A, Helmstaedter C, Elger CE (2000) Synaptic Plasticity in the Human Dentate Gyrus. The Journal of Neuroscience 20:7080-7086.

Benoit-Marand M, Borrelli E, Gonon F (2001) Inhibition of Dopamine Release Via Presynaptic D2 Receptors: Time Course and Functional Characteristics In Vivo. The Journal of Neuroscience 21:9134-9141.

Bernardi G, Cherubini E, Marciani MG, Mercuri N, Stanzione P (1982) Responses of intracellularly recorded cortical neurons to the iontophoretic application of dopamine. Brain Research 245:267-274.

Bi G-q, Poo M-m (1998) Synaptic Modifications in Cultured Hippocampal Neurons: Dependence on Spike Timing, Synaptic Strength, and Postsynaptic Cell Type. The Journal of Neuroscience 18:10464-10472.

Bindman LJ LO, Redfearn JWT (1964) The action of brief polarizing current on the cerebral cortex of the rat (during current flow and (2) in the production of longlasting after-effects. JPhysiol 172.

Blanchet PJ, Fang J, Gillespie M, Sabounjian L, Locke KW, Gammans R, Mouradian MM, Chase TN (1998) Effects of the Full Dopamine D1 Receptor Agonist Dihydrexidine in Parkinson's Disease. Clinical Neuropharmacology 21:339-343.

Bliss T, Collingridge G (2013) Expression of NMDA receptor-dependent LTP in the hippocampus: bridging the divide. Molecular Brain 6:1-14.

Bliss TVP, Gardner-Medwin AR (1973) Long-lasting potentiation of synaptic transmission in the dentate area of the unanaesthetized rabbit following stimulation of the perforant path. The Journal of Physiology 232:357-374.

Bliss TVP, Lømo T (1973) Long-lasting potentiation of synaptic transmission in the dentate area of the anaesthetized rabbit following stimulation of the perforant path. The Journal of Physiology 232:331-356.

Bliss TVP, Collingridge GL (1993) A synaptic model of memory: long-term potentiation in the hippocampus. Nature 361:31-39.

Bliss TVP, Cooke SF (2011) Long-term potentiation and long-term depression: a clinical perspective. Clinics 66:3-17.

Bliss TVP, Collingridge GL, Laroche S (2006) ZAP and ZIP, a Story to Forget. Science 313:1058-1059.

Boggio PS, Khoury LP, Martins DCS, Martins OEMS, de Macedo EC, Fregni F (2009a) Temporal cortex direct current stimulation enhances performance on a visual recognition memory task in Alzheimer disease. Journal of Neurology, Neurosurgery \& Psychiatry 80:444-447.

Boggio PS, Ferrucci R, Rigonatti SP, Covre P, Nitsche M, Pascual-Leone A, Fregni F (2006) Effects of transcranial direct current stimulation on working memory in patients with Parkinson's disease. Journal of the Neurological Sciences 249:31-38.

Boggio PS, Fregni F, Valasek C, Ellwood S, Chi R, Gallate J, Pascual-Leone A, Snyder A (2009b) Temporal Lobe Cortical Electrical Stimulation during the Encoding and Retrieval Phase Reduces False Memories. PLoS One 4:e4959. 
Borsook D, Becerra L, Fishman S, Edwards A, Jennings CL, Stojanovic M, Papinicolas L, Ramachandran VS, Gonzalez RG, Breiter H (1998) Acute plasticity in the human somatosensory cortex following amputation. Neuroreport 9:1013-1017.

Boven RWV, Hamilton RH, Kauffman T, Keenan JP, Pascual-Leone A (2000) Tactile spatial resolution in blind Braille readers. Neurology 54:2230-2236.

Bradshaw CM, Sheridan RD, Szabadi E (1985) Excitatory neuronal responses to dopamine in the cerebral cortex: involvement of D2 but not D1 dopamine receptors. British Journal of Pharmacology 86:483-490.

Breitenstein C, Korsukewitz C, Floel A, Kretzschmar T, Diederich K, Knecht S (2006) Tonic Dopaminergic Stimulation Impairs Associative Learning in Healthy Subjects. Neuropsychopharmacology 31:2552-2564.

Brozoski T, Brown R, Rosvold H, Goldman P (1979) Cognitive deficit caused by regional depletion of dopamine in prefrontal cortex of rhesus monkey. Science 205:929-932.

Cai JX, Arnsten AFT (1997) Dose-Dependent Effects of the Dopamine D1 Receptor Agonists A77636 or SKF81297 On Spatial Working Memory in Aged Monkeys. Journal of Pharmacology and Experimental Therapeutics 283:183-189.

Calabresi P, Maj R, Pisani A, Mercuri N, Bernardi G (1992) Long-term synaptic depression in the striatum: physiological and pharmacological characterization. The Journal of Neuroscience 12:4224-4233.

Calabresi P, Gubellini P, Centonze D, Picconi B, Bernardi G, Chergui K, Svenningsson P, Fienberg AA, Greengard P (2000) Dopamine and cAMP-Regulated Phosphoprotein $32 \mathrm{kDa}$ Controls Both Striatal Long-Term Depression and LongTerm Potentiation, Opposing Forms of Synaptic Plasticity. The Journal of Neuroscience 20:8443-8451.

Camps M, Kelly PH, Palacios JM (1990) Autoradiographic localization of dopamine D1 and D2 receptors in the brain of several mammalian species. J Neural Transmission 80:105-127.

Carmichael ST (2003) Plasticity of Cortical Projections after Stroke. The Neuroscientist 9:64-75.

Castro-Alamancos M, Donoghue J, Connors B (1995) Different forms of synaptic plasticity in somatosensory and motor areas of the neocortex. The Journal of Neuroscience 15:5324-5333.

Centonze D, Picconi B, Gubellini P, Bernardi G, Calabresi P (2001) Dopaminergic control of synaptic plasticity in the dorsal striatum. European Journal of Neuroscience 13:1071-1077.

Centonze D, Grande C, Saulle E, Martín AB, Gubellini P, Pavón N, Pisani A, Bernardi G, Moratalla R, Calabresi P (2003) Distinct Roles of D1 and D5 Dopamine Receptors in Motor Activity and Striatal Synaptic Plasticity. The Journal of Neuroscience 23:8506-8512.

Chen WR, Lee S, Kato K, Spencer DD, Shepherd GM, Williamson A (1996a) Long-term modifications of synaptic efficacy in the human inferior and middle temporal cortex. Proceedings of the National Academy of Sciences 93:8011-8015.

Chen Z, Ito K, Fujii S, Miura M, Furuse H, Sasaki H, Kaneko K, Kato H, Miyakawa H (1996b) Roles of dopamine receptors in long-term depression: enhancement via D1 receptors and inhibition via D2 receptors. Receptors Channels 4:1-8. 
Cho K, Aggleton JP, Brown MW, Bashir ZI (2001) An experimental test of the role of postsynaptic calcium levels in determining synaptic strength using perirhinal cortex of rat. The Journal of Physiology 532:459-466.

Citri A, Malenka RC (2007) Synaptic Plasticity: Multiple Forms, Functions, and Mechanisms. Neuropsychopharmacology 33:18-41.

Cohen JD, Braver TS, Brown JW (2002) Computational perspectives on dopamine function in prefrontal cortex. Current Opinion in Neurobiology 12:223-229.

Coldwell MC, Boyfield I, Brown T, Hagan JJ, Middlemiss DN (1999) Comparison of the functional potencies of ropinirole and other dopamine receptor agonists at human D2(long), D3 and D4.4 receptors expressed in Chinese hamster ovary cells. British Journal of Pharmacology 127:1696-1702.

Collingridge GL, Peineau S, Howland JG, Wang YT (2010) Long-term depression in the CNS. Nat Rev Neurosci 11:459-473.

Collins G, Newman A, Grundt P, Rice K, Husbands S, Chauvignac C, Chen J, Wang S, Woods J (2007) Yawning and hypothermia in rats: effects of dopamine D3 and D2 agonists and antagonists. Psychopharmacology 193:159-170.

Collins GT, Witkin JM, Newman AH, Svensson KA, Grundt P, Cao J, Woods JH (2005) Dopamine Agonist-Induced Yawning in Rats: A Dopamine D3 ReceptorMediated Behavior. Journal of Pharmacology and Experimental Therapeutics 314:310-319.

Collins GT, Truccone A, Haji-Abdi F, Newman AH, Grundt P, Rice KC, Husbands SM, Greedy BM, Enguehard-Gueiffier C, Gueiffier A, Chen J, Wang S, Katz JL, Grandy DK, Sunahara RK, Woods JH (2009) Proerectile Effects of Dopamine D2-Like Agonists Are Mediated by the D3 Receptor in Rats and Mice. Journal of Pharmacology and Experimental Therapeutics 329:210-217.

Cooke SF, Bliss TVP (2006) Plasticity in the human central nervous system. Brain 129:1659-1673.

Cools R, D'Esposito M (2011) Inverted-U-Shaped Dopamine Actions on Human Working Memory and Cognitive Control. Biological psychiatry 69:e113-e125.

Cools R, Barker RA, Sahakian BJ, Robbins TW (2001) Enhanced or Impaired Cognitive Function in Parkinson's Disease as a Function of Dopaminergic Medication and Task Demands. Cerebral Cortex 11:1136-1143.

Cools R, Sheridan M, Jacobs E, D'Esposito M (2007) Impulsive Personality Predicts Dopamine-Dependent Changes in Frontostriatal Activity during Component Processes of Working Memory. The Journal of Neuroscience 27:5506-5514.

Cormier RJ, Greenwood AC, Connor JA (2001) Bidirectional Synaptic Plasticity Correlated With the Magnitude of Dendritic Calcium Transients Above a Threshold. Journal of Neurophysiology 85:399-406.

Costa A, Peppe A, Mazz, \#xf9, I, Longarzo M, Caltagirone C, Carlesimo GA (2014) Dopamine Treatment and Cognitive Functioning in Individuals with Parkinson\&\#x2019; s Disease: The \&\#x201c;Cognitive Flexibility\&\#x201d; Hypothesis Seems to Work. Behavioural Neurology 2014:11.

Creutzfeldt OD, Fromm GH, Kapp H (1962) Influence of transcortical d-c currents on cortical neuronal activity. Experimental Neurology 5:436-452. 
D’Ardenne K, Eshel N, Luka J, Lenartowicz A, Nystrom LE, Cohen JD (2012) Role of prefrontal cortex and the midbrain dopamine system in working memory updating. Proceedings of the National Academy of Sciences 109:19900-19909.

Dancause N, Barbay S, Frost SB, Plautz EJ, Chen D, Zoubina EV, Stowe AM, Nudo RJ (2005) Extensive Cortical Rewiring after Brain Injury. The Journal of Neuroscience 25:10167-10179.

Debanne D, Gähwiler BH, Thompson SM (1998) Long-term synaptic plasticity between pairs of individual CA3 pyramidal cells in rat hippocampal slice cultures. The Journal of Physiology 507:237-247.

Di Lazzaro V, Oliviero A, Profice P, Saturno E, Pilato F, Insola A, Mazzone P, Tonali P, Rothwell JC (1998) Comparison of descending volleys evoked by transcranial magnetic and electric stimulation in conscious humans. Electroencephalography and Clinical Neurophysiology/Electromyography and Motor Control 109:397401.

Diaz J, Lévesque D, Griffon N, Lammers CH, Martres MP, Sokoloff P, Schwartz JC (1994) Opposing Roles for Dopamine D2 and D3 Receptors on Neurotensin mRNA Expression in Nucleus Accumbens. European Journal of Neuroscience 6:1384-1387.

Donoghue JP (1995) Plasticity of adult sensorimotor representations. Current Opinion in Neurobiology 5:749-754.

Draganski B, Gaser C, Busch V, Schuierer G, Bogdahn U, May A (2004)

Neuroplasticity: Changes in grey matter induced by training. Nature 427:311-312.

Durstewitz D, Seamans JK, Sejnowski TJ (2000) Dopamine-Mediated Stabilization of Delay-Period Activity in a Network Model of Prefrontal Cortex. Journal of Neurophysiology 83:1733-1750.

Egan MF, Goldberg TE, Kolachana BS, Callicott JH, Mazzanti CM, Straub RE, Goldman D, Weinberger DR (2001) Effect of COMT Val108/158 Met genotype on frontal lobe function and risk for schizophrenia. Proceedings of the National Academy of Sciences 98:6917-6922.

Elbert T, Pantev C, Wienbruch C, Rockstroh B, Taub E (1995) Increased Cortical Representation of the Fingers of the Left Hand in String Players. Science 270:305-307.

Fitzgerald PB, Brown TL, Marston NAU, Oxley T, de Castella A, Daskalakis ZJ, Kulkarni J (2004) Reduced plastic brain responses in schizophrenia: a transcranial magnetic stimulation study. Schizophrenia Research 71:17-26.

Floel A, Garraux G, Herscovitch P, Knecht S, Cohen LG (2005) Modulation of motor memory formation by levodopa in healthy subjects and in chronic stroke patients: A study with 11C-raclopride PET. J Cereb Blood Flow Metab 25:S329-S329.

Flöel A, Breitenstein C, Hummel F, Celnik P, Gingert C, Sawaki L, Knecht S, Cohen LG (2005) Dopaminergic influences on formation of a motor memory. Annals of Neurology 58:121-130.

Floresco SB, Phillips AG (2001) Delay-dependent modulation of memory retrieval by infusion of a dopamine $\mathrm{D}_{1}$ agonist into the rat medial prefrontal cortex.

Behavioral Neuroscience 115:934-939.

Foscarin S, Rossi F, Carulli D (2012) Influence of the environment on adult CNS plasticity and repair. Cell and Tissue Research 349:161-167. 
Fox K (2002) Anatomical pathways and molecular mechanisms for plasticity in the barrel cortex. Neuroscience 111:799-814.

Franken IA, Nijs I, Pepplinkhuizen L (2008) Effects of dopaminergic modulation on electrophysiological brain response to affective stimuli. Psychopharmacology 195:537-546.

Frantseva MV, Fitzgerald PB, Chen R, Möller B, Daigle M, Daskalakis ZJ (2008) Evidence for Impaired Long-Term Potentiation in Schizophrenia and Its Relationship to Motor Skill Leaning. Cerebral Cortex 18:990-996.

Fregni F, Boggio PS, Nitsche MA, Rigonatti SP, Pascual-Leone A (2006) Cognitive effects of repeated sessions of transcranial direct current stimulation in patients with depression. Depression and Anxiety 23:482-484.

Freitas C, Mondragón-Llorca H, Pascual-Leone A (2011) Noninvasive brain stimulation in Alzheimer's disease: Systematic review and perspectives for the future. Experimental Gerontology 46:611-627.

Fresnoza S, Paulus W, Nitsche MA, Kuo M-F (2014) Nonlinear Dose-Dependent Impact of D1 Receptor Activation on Motor Cortex Plasticity in Humans. The Journal of Neuroscience 34:2744-2753.

Frey U, Hartmann S, Matthies H (1989) Domperidone, an inhibitor of the D2-receptor, blocks a late phase of an electrically induced long-term potentiation in the CA1region in rats. BiomedBiocim Acta 48:473-476.

Gartside IB (1968) Mechanisms of Sustained Increases of Firing Rate of Neurones in the Rat Cerebral Cortex after Polarization: Reverberating Circuits or Modification of Synaptic Conductance? Nature 220:382-383.

Gaser C, Schlaug G (2003) Brain Structures Differ between Musicians and NonMusicians. The Journal of Neuroscience 23:9240-9245.

Gibbs S, D'Esposito M (2005) Individual capacity differences predict working memory performance and prefrontal activity following dopamine receptor stimulation. Cognitive, Affective, \& Behavioral Neuroscience 5:212-221.

Gibbs S, D'Esposito M (2005) A functional MRI study of the effects of bromocriptine, a dopamine receptor agonist, on component processes of working memory. Psychopharmacology 180:1-10.

Goldman-Rakic P, Castner S, Svensson T, Siever L, Williams G (2004) Targeting the dopamine D1 receptor in schizophrenia: insights for cognitive dysfunction. Psychopharmacology 174:3-16.

Goldman-Rakic PS, Muly IEC, Williams GV (2000) D1 receptors in prefrontal cells and circuits. Brain Research Reviews 31:295-301.

Goulet M, Madras BK (2000) D1 Dopamine Receptor Agonists Are More Effective in Alleviating Advanced than Mild Parkinsonism in 1-Methyl-4-phenyl-1,2,3,6tetrahydropyridine-Treated Monkeys. Journal of Pharmacology and Experimental Therapeutics 292:714-724.

Gruart A, Muñoz MD, Delgado-García JM (2006) Involvement of the CA3-CA1 Synapse in the Acquisition of Associative Learning in Behaving Mice. The Journal of Neuroscience 26:1077-1087.

Grundey J, Freznosa S, Klinker F, Lang N, Paulus W, Nitsche MA (2013) Cortical excitability in smoking and not smoking individuals with and without nicotine. Psychopharmacology 229:653-664. 
Gurden H, Takita M, Jay TM (2000) Essential role of D1 but not D2 receptors in the NMDA receptor-dependent long-term potentiation at hippocampal-prefrontal cortex synapses in vivo. The Journal of neuroscience : the official journal of the Society for Neuroscience 20:RC106.

Gustafsson B, Wigstrom H, Abraham W, Huang Y (1987) Long-term potentiation in the hippocampus using depolarizing current pulses as the conditioning stimulus to single volley synaptic potentials. The Journal of Neuroscience 7:774-780.

Haney M, Ward A, Foltin R, Fischman M (2001) Effects of ecopipam, a selective dopamine D1 antagonist, on smoked cocaine self-administration by humans. Psychopharmacology 155:330-337.

Haney M, Collins ED, Ward AS, Foltin RW, Fischman MW (1999) Effect of a selective dopamine D1 agonist (ABT-431) on smoked cocaine self-administration in humans. Psychopharmacology 143:102-110.

Hänggi J, Koeneke S, Bezzola L, Jäncke L (2010) Structural neuroplasticity in the sensorimotor network of professional female ballet dancers. Human Brain Mapping 31:1196-1206.

Hansel C, Artola A, Singer W (1996) Different threshold levels of postsynaptic [Ca2+]i have to be reached to induce LTP and LTD in neocortical pyramidal cells. Journal of Physiology-Paris 90:317-319.

Hansel C, Artola A, Singer W (1997) Relation Between Dendritic Ca2+ Levels and the Polarity of Synaptic Long-term Modifications in Rat Visual Cortex Neurons. European Journal of Neuroscience 9:2309-2322.

Harvey J, Lacey MG (1997) A Postsynaptic Interaction between Dopamine D1 and NMDA Receptors Promotes Presynaptic Inhibition in the Rat Nucleus Accumbens via Adenosine Release. The Journal of Neuroscience 17:5271-5280.

Hasan A, Nitsche MA, Herrmann M, Schneider-Axmann T, Marshall L, Gruber O, Falkai P, Wobrock T (2011) Impaired long-term depression in schizophrenia: a cathodal tDCS pilot study. Brain Stimulation.

Hattori Y, Moriwaki A, Hori Y (1990) Biphasic effects of polarizing current on adenosine-sensitive generation of cyclic AMP in rat cerebral cortex. Neuroscience Letters 116:320-324.

Hebb DO (1988) The organization of behavior. In: Neurocomputing: foundations of research (James AA, Edward R, eds), pp 43-54: MIT Press.

Heynen AJ, Bear MF (2001) Long-Term Potentiation of Thalamocortical Transmission in the Adult Visual Cortex In Vivo. The Journal of Neuroscience 21:9801-9813.

Holtmaat A, Wilbrecht L, Knott GW, Welker E, Svoboda K (2006) Experiencedependent and cell-type-specific spine growth in the neocortex. Nature 441:979983.

Howes OD, Kapur S (2009) The Dopamine Hypothesis of Schizophrenia: Version IIIThe Final Common Pathway. Schizophrenia Bulletin 35:549-562.

Huang Y-Y, Simpson E, Kellendonk C, Kandel ER (2004) Genetic evidence for the bidirectional modulation of synaptic plasticity in the prefrontal cortex by D1 receptors. Proceedings of the National Academy of Sciences of the United States of America 101:3236-3241.

Huang Y-Z, Edwards MJ, Rounis E, Bhatia KP, Rothwell JC (2005) Theta Burst Stimulation of the Human Motor Cortex. Neuron 45:201-206. 
Hung Choy Wong A, Buckle CE, Van Tol HHM (2000) Polymorphisms in dopamine receptors: what do they tell us? European Journal of Pharmacology 410:183-203.

Ichihara K, Nabeshima T, Kameyama T (1988) Effects of haloperidol, sulpiride and SCH 23390 on passive avoidance learning in mice. European Journal of Pharmacology 151:435-442.

Islam N, Aftabuddin M, Moriwaki A, Hattori Y, Hori Y (1995a) Increase in the calcium level following anodal polarization in the rat brain. Brain Research 684:206-208.

Islam N, Moriwaki A, Hattori Y, Hayashi Y, Lu Y-F, Hori Y (1995b) c-Fos Expression Mediated by N-Methyl-d-aspartate Receptors Following Anodal Polarization in the Rat Brain. Experimental Neurology 133:25-31.

Jaber M, Robinson SW, Missale C, Caron MG (1996) Dopamine receptors and brain function. Neuropharmacology 35:1503-1519.

Jay TM (2003) Dopamine: a potential substrate for synaptic plasticity and memory mechanisms. Progress in Neurobiology 69:375-390.

Jung NH, Janzarik WG, Delvendahl I, MÜNchau A, Biscaldi M, Mainberger F, BÄUmer T, Rauh R, Mall V (2013) Impaired induction of long-term potentiation-like plasticity in patients with high-functioning autism and Asperger syndrome. Developmental Medicine \& Child Neurology 55:83-89.

Kami A, Meyer G, Jezzard P, Adams MM, Turner R, Ungerleider LG (1995) Functional MRI evidence for adult motor cortex plasticity during motor skill learning. Nature 377:155-158.

Kano M (1995) Plasticity of inhibitory synapses in the brain: a possible memory mechanism that has been overlooked. Neuroscience Research 21:177-182.

Karlsson, \#160, Per, Farde, Lars, Halldin, Christer, Sedvall, \#246, ran (2002) PET study of $\mathrm{D}[1]$ dopamine receptor binding in neuroleptic-naive patients with schizophrenia. Arlington, VA, ETATS-UNIS: American Psychiatric Association.

Kashima H (1991) Frontal dysfunction of chronic schizophrenia--the pros and cons in neuropsychological assessment.

Kebabian JW, Calne DB (1979) Multiple receptors for dopamine. Nature 277:93-96.

Kerr JND, Wickens JR (2001) Dopamine D-1/D-5 Receptor Activation Is Required for Long-Term Potentiation in the Rat Neostriatum In Vitro. Journal of Neurophysiology 85:117-124.

Kimberg DY, D'Esposito M (2003) Cognitive effects of the dopamine receptor agonist pergolide. Neuropsychologia 41:1020-1027.

Kimberg DY, D'Esposito M, Farah MJ (1997) Effects of bromocriptine on human subjects depend on working memory capacity. Neuroreport 8:3581-3585.

Kimberg DY, Aguirre GK, Lease J, D'Esposito M (2001) Cortical effects of bromocriptine, a D-2 dopamine receptor agonist, in human subjects, revealed by fMRI. Human Brain Mapping 12:246-257.

Kirkwood A, Bear M (1994) Homosynaptic long-term depression in the visual cortex. The Journal of Neuroscience 14:3404-3412.

Klanker M, Feenstra M, Denys D (2013) Dopaminergic control of cognitive flexibility in humans and animals. Frontiers in Neuroscience 7.

Kleim JA, Barbay S, Nudo RJ (1998) Functional reorganization of the rat motor cortex following motor skill learning. Journal of Neurophysiology 80:3321-3325. 
Kleim JA, Lussnig E, Schwarz ER, Comery TA, Greenough WT (1996) Synaptogenesis and FOS Expression in the Motor Cortex of the Adult Rat after Motor Skill Learning. The Journal of Neuroscience 16:4529-4535.

Kling-Petersen T, Ljung E, Svensson K (1995) Effects on locomotor activity after local application of $\mathrm{D} 3$ preferring compounds in discrete areas of the rat brain. J Neural Transmission 102:209-220.

Knecht S, Breitenstein C, Bushuven S, Wailke S, Kamping S, Flöel A, Zwitserlood P, Ringelstein EB (2004) Levodopa: Faster and better word learning in normal humans. Annals of Neurology 56:20-26.

Knott GW, Holtmaat A, Wilbrecht L, Welker E, Svoboda K (2006) Spine growth precedes synapse formation in the adult neocortex in vivo. Nat Neurosci 9:11171124.

Ko JH, Tang CC, Eidelberg D (2013) Brain stimulation and functional imaging with fMRI and PET. Handbook of clinical neurology 116:77-95.

Koch G, Di Lorenzo F, Bonnì S, Ponzo V, Caltagirone C, Martorana A (2012) Impaired LTP- but not LTD-Like Cortical Plasticity in Alzheimer's Disease Patients. Journal of Alzheimer's Disease 31:593-599.

Koch G, Esposito Z, Codecà C, Mori F, Kusayanagi H, Monteleone F, Di Lorenzo F, Bernardi G, Martorana A (2011) Altered dopamine modulation of LTD-like plasticity in Alzheimer's disease patients. Clinical Neurophysiology 122:703-707.

Koh P, Bergson C, Undie AS, Goldman-Rakic PS, Lidow MS (2003) UP-regulation of the $\mathrm{d} 1$ dopamine receptor-interacting protein, calcyon, in patients with schizophrenia. Archives of General Psychiatry 60:311-319.

Kristin MP-F, Brian M, Daniel A, Babak S, Steven CC (2013) Genetic Variation in the Human Brain Dopamine System Influences Motor Learning and Its Modulation by L-Dopa. PLoS One 8.

Kroener S, Chandler LJ, Phillips PEM, Seamans JK (2009) Dopamine Modulates Persistent Synaptic Activity and Enhances the Signal-to-Noise Ratio in the Prefrontal Cortex. PLoS One 4:e6507.

Kujirai T, Caramia MD, Rothwell JC, Day BL, Thompson PD, Ferbert A, Wroe S, Asselman P, Marsden CD (1993) Corticocortical inhibition in human motor cortex. The Journal of Physiology 471:501-519.

Kuo M-F, Nitsche MA (2012) Effects of Transcranial Electrical Stimulation on Cognition. Clinical EEG and Neuroscience 43:192-199.

Kuo M-F, Paulus W, Nitsche MA (2008) Boosting Focally-Induced Brain Plasticity by Dopamine. Cerebral Cortex 18:648-651.

Lamprecht R, LeDoux J (2004) Structural plasticity and memory. Nat Rev Neurosci 5:4554.

Levy WB, Steward O (1979) Synapses as associative memory elements in the hippocampal formation. Brain Research 175:233-245.

Lidow MS, Koh P-O, Arnsten AFT (2003) D1 dopamine receptors in the mouse prefrontal cortex: Immunocytochemical and cognitive neuropharmacological analyses. Synapse 47:101-108.

Lidow MS, Goldman-Rakic PS, Gallager DW, Rakic P (1991) Distribution of dopaminergic receptors in the primate cerebral cortex: Quantitative 
autoradiographic analysis using $[3 \mathrm{H}]$ raclopride, $[3 \mathrm{H}]$ spiperone and [3H]SCH23390. Neuroscience 40:657-671.

Liebetanz D, Nitsche MA, Tergau F, Paulus W (2002) Pharmacological approach to the mechanisms of transcranial DC-stimulation-induced after-effects of human motor cortex excitability. Brain 125:2238-2247.

Lisman J (1989) A mechanism for the Hebb and the anti-Hebb processes underlying learning and memory. Proceedings of the National Academy of Sciences 86:95749578.

Lisman J, Schulman H, Cline H (2002) The molecular basis of CaMKII function in synaptic and behavioural memory. Nat Rev Neurosci 3:175-190.

Lisman JE (2001) Three Ca2+ levels affect plasticity differently: the LTP zone, the LTD zone and no man's land. The Journal of Physiology 532:285-285.

Luciana M, Collins PF (1997) Dopaminergic Modulation of Working Memory for Spatial but Not Object Cues in Normal Humans. Journal of Cognitive Neuroscience 9:330-347.

Luciana M, Collins PF, Depue RA (1998) Opposing roles for dopamine and serotonin in the modulation of human spatial working memory functions. Cerebral Cortex 8:218-226.

Luciana M, Depue RA, Arbisi P, Leon A (1992) Facilitation of Working Memory in Humans by a D2 Dopamine Receptor Agonist. Journal of Cognitive Neuroscience 4:58-68.

Lynch GS, Dunwiddie T, Gribkoff V (1977) Heterosynaptic depression: a postsynaptic correlate of long-term potentiation. Nature 266:737-739.

Lynch GS, J. L, S. K, G. B, F. S (1983) Intracellular injection of EGTA block induction of hippocampal long-term potentian. Nature 305:719-721.

Malenka R, Kauer J, Zucker R, Nicoll R (1988) Postsynaptic calcium is sufficient for potentiation of hippocampal synaptic transmission. Science 242:81-84.

Malenka RC, Bear MF (2004) LTP and LTD: An Embarrassment of Riches. Neuron 44:5-21.

Malenka RC, Nicoll, A. R (1999) Long-Term Potentiation--A Decade of Progress? Science 285:1870-1874.

Malenka RCN, and Roger A. (1999 ) Long-Term Potentiation--A Decade of Progress? . Science 285:1870-1874.

Manahan-Vaughan D, Kulla A (2003) Regulation of Depotentiation and Long-term Potentiation in the Dentate Gyrus of Freely Moving Rats by Dopamine D2-like Receptors. Cerebral Cortex 13:123-135.

Markram H, Lübke J, Frotscher M, Sakmann B (1997) Regulation of Synaptic Efficacy by Coincidence of Postsynaptic APs and EPSPs. Science 275:213-215.

May A (2011) Experience-dependent structural plasticity in the adult human brain. Trends in Cognitive Sciences 15:475-482.

McClintock SM, Freitas C, Oberman L, Lisanby SH, Pascual-Leone A (2011) Transcranial Magnetic Stimulation: A Neuroscientific Probe of Cortical Function in Schizophrenia. Biological psychiatry 70:19-27.

Mehta M, Swainson R, Ogilvie A, Sahakian B, Robbins T (2001) Improved short-term spatial memory but impaired reversal learning following the dopamine D2 agonist bromocriptine in human volunteers. Psychopharmacology 159:10-20. 
Mehta M, Manes F, Magnolfi G, Sahakian B, Robbins T (2004) Impaired set-shifting and dissociable effects on tests of spatial working memory following the dopamine D2 receptor antagonist sulpiride in human volunteers. Psychopharmacology 176:331-342.

Mehta MA, Sahakian BJ, McKenna PJ, Robbins TW (1999) Systemic sulpiride in young adult volunteers simulates the profile of cognitive deficits in Parkinson's disease. Psychopharmacology 146:162-174.

Mehta MA, Hinton EC, Montgomery AJ, Bantick RA, Grasby PM (2005) Sulpiride and mnemonic function: effects of a dopamine D2 receptor antagonist on working memory, emotional memory and long-term memory in healthy volunteers. Journal of Psychopharmacology 19:29-38.

Meintzschel F, Ziemann U (2006) Modification of Practice-dependent Plasticity in Human Motor Cortex by Neuromodulators. Cerebral Cortex 16:1106-1115.

Merton PA, Morton HB (1980) Stimulation of the cerebral cortex in the intact human subject. Nature 285:227-227.

Miranda PC, Lomarev M, Hallett M (2006) Modeling the current distribution during transcranial direct current stimulation. Clinical Neurophysiology 117:1623-1629.

Misonou H, Mohapatra DP, Park EW, Leung V, Zhen D, Misonou K, Anderson AE, Trimmer JS (2004) Regulation of ion channel localization and phosphorylation by neuronal activity. Nat Neurosci 7:711-718.

Mizoguchi K, Yuzurihara M, Ishige A, Sasaki H, Chui D-H, Tabira T (2000) Chronic Stress Induces Impairment of Spatial Working Memory Because of Prefrontal Dopaminergic Dysfunction. The Journal of Neuroscience 20:1568-1574.

Mockett BG, Guévremont D, Williams JM, Abraham WC (2007) Dopamine D1/D5 Receptor Activation Reverses NMDA Receptor-Dependent Long-Term Depression in Rat Hippocampus. The Journal of Neuroscience 27:2918-2926.

Monte-Silva K, Liebetanz D, Grundey J, Paulus W, Nitsche MA (2010) Dosagedependent non-linear effect of 1-dopa on human motor cortex plasticity. The Journal of Physiology 588:3415-3424.

Monte-Silva K, Kuo M-F, Thirugnanasambandam N, Liebetanz D, Paulus W, Nitsche MA (2009) Dose-Dependent Inverted U-Shaped Effect of Dopamine (D2-Like) Receptor Activation on Focal and Nonfocal Plasticity in Humans. The Journal of Neuroscience 29:6124-6131.

Monte-Silva K, Ruge D, Teo JT, Paulus W, Rothwell JC, Nitsche MA (2011) D2 Receptor Block Abolishes Theta Burst Stimulation-Induced Neuroplasticity in the Human Motor Cortex. Neuropsychopharmacology 36:2097-2102.

Monte-Silva K, Kuo M-F, Hessenthaler S, Fresnoza S, Liebetanz D, Paulus W, Nitsche MA (2013) Induction of Late LTP-Like Plasticity in the Human Motor Cortex by Repeated Non-Invasive Brain Stimulation. Brain Stimulation 6:424-432.

Muellbacher W, Ziemann U, Wissel J, Dang N, Kofler M, Facchini S, Boroojerdi B, Poewe W, Hallett M (2002) Early consolidation in human primary motor cortex. Nature 415:640-644.

Müller-Dahlhaus F, Ziemann U, Classen J (2010) Plasticity resembling spike-timing dependent synaptic plasticity: the evidence in human cortex. Frontiers in Synaptic Neuroscience 2. 
Müller U, von Cramon DY, Pollmann S (1998) D1- Versus D2-Receptor Modulation of Visuospatial Working Memory in Humans. The Journal of Neuroscience 18:27202728.

Murphy BL, Arnsten AF, Goldman-Rakic PS, Roth RH (1996) Increased dopamine turnover in the prefrontal cortex impairs spatial working memory performance in rats and monkeys. Proceedings of the National Academy of Sciences 93:13251329.

Newton J, Sur M (2005) Rewiring Cortex: Functional Plasticity of the Auditory Cortex during Development. In: Plasticity and Signal Representation in the Auditory System (Syka J, Merzenich M, eds), pp 127-137: Springer US.

Nicholls RE, Alarcon JM, Malleret G, Carroll RC, Grody M, Vronskaya S, Kandel ER (2008) Transgenic Mice Lacking NMDAR-Dependent LTD Exhibit Deficits in Behavioral Flexibility. Neuron 58:104-117.

Nieoullon A (2002) Dopamine and the regulation of cognition and attention. Progress in Neurobiology 67:53-83.

Nishiyama M, Hong K, Mikoshiba K, Poo M-m, Kato K (2000) Calcium stores regulate the polarity and input specificity of synaptic modification. Nature 408:584-588.

Nitsche MA, Paulus W (2000) Excitability changes induced in the human motor cortex by weak transcranial direct current stimulation. The Journal of Physiology 527:633-639.

Nitsche MA, Paulus W (2001) Sustained excitability elevations induced by transcranial DC motor cortex stimulation in humans. Neurology 57:1899-1901.

Nitsche MA, Nitsche MS, Klein CC, Tergau F, Rothwell JC, Paulus W (2003a) Level of action of cathodal DC polarisation induced inhibition of the human motor cortex. Clinical Neurophysiology 114:600-604.

Nitsche MA, Jaussi W, Liebetanz D, Lang N, Tergau F, Paulus W (2004a) Consolidation of Human Motor Cortical Neuroplasticity by D-Cycloserine. Neuropsychopharmacology 29:1573-1578.

Nitsche MA, Kuo M-F, Grosch J, Bergner C, Monte-Silva K, Paulus W (2009) D1Receptor Impact on Neuroplasticity in Humans. The Journal of Neuroscience 29:2648-2653.

Nitsche MA, Schauenburg A, Lang N, Liebetanz D, Exner C, Paulus W, Tergau F (2003b) Facilitation of Implicit Motor Learning by Weak Transcranial Direct Current Stimulation of the Primary Motor Cortex in the Human. Journal of Cognitive Neuroscience 15:619-626.

Nitsche MA, Lampe C, Antal A, Liebetanz D, Lang N, Tergau F, Paulus W (2006) Dopaminergic modulation of long-lasting direct current-induced cortical excitability changes in the human motor cortex. European Journal of Neuroscience 23:1651-1657.

Nitsche MA, Fricke K, Henschke U, Schlitterlau A, Liebetanz D, Lang N, Henning S, Tergau F, Paulus W (2003c) Pharmacological modulation of cortical excitability shifts induced by transcranial direct current stimulation in humans. The Journal of Physiology 553:293-301.

Nitsche MA, Liebetanz D, Schlitterlau A, Henschke U, Fricke K, Frommann K, Lang N, Henning S, Paulus W, Tergau F (2004b) GABAergic modulation of DC 
stimulation-induced motor cortex excitability shifts in humans. European Journal of Neuroscience 19:2720-2726.

Nitsche MA, Cohen LG, Wassermann EM, Priori A, Lang N, Antal A, Paulus W, Hummel F, Boggio PS, Fregni F, Pascual-Leone A (2008) Transcranial direct current stimulation: State of the art 2008. Brain Stimulation 1:206-223.

Nitsche MA, Seeber A, Frommann K, Klein CC, Rochford C, Nitsche MS, Fricke K, Liebetanz D, Lang N, Antal A, Paulus W, Tergau F (2005) Modulating parameters of excitability during and after transcranial direct current stimulation of the human motor cortex. The Journal of Physiology 568:291-303.

Nudo, \#160, J. R (2003) Adaptive plasticity in motor cortex: Implications for rehabilitation after brain injury. Stockholm, SUEDE: Taylor \&amp; Francis.

Nudo, \#160, J. R, Milliken, W. G, Jenkins, M. W, Merzenich, M. M (1996) USEDEPENDENT ALTERATIONS OF MOVEMENT REPRESENTATIONS IN PRIMARY MOTOR CORTEX OF ADULT SQUIRREL MONKEYS.

Washington, DC, ETATS-UNIS: Society for Neuroscience.

O'Donnell P, Grace AA (1994) Tonic D2-mediated attenuation of cortical excitation in nucleus accumbens neurons recorded in vitro. Brain Research 634:105-112.

Oberman L, Eldaief M, Fecteau S, Ifert-Miller F, Tormos JM, Pascual-Leone A (2012) Abnormal modulation of corticospinal excitability in adults with Asperger's syndrome. European Journal of Neuroscience 36:2782-2788.

Okubo Y, Suhara T, Suzuki K, Kobayashi K, Inoue O, Terasaki O, Someya Y, Sassa T, Sudo Y, Matsushima E, Iyo M, Tateno Y, Toru M (1997) Decreased prefrontal dopamine D1 receptors in schizophrenia revealed by PET. Nature 385:634-636.

Otani S, Blond O, Desce JM, Crépel F (1998) Dopamine facilitates long-term depression of glutamatergic transmission in rat prefrontal cortex. Neuroscience 85:669-676.

Otmakhova NA, Lisman JE (1996) D1/D5 Dopamine Receptor Activation Increases the Magnitude of Early Long-Term Potentiation at CA1 Hippocampal Synapses. The Journal of Neuroscience 16:7478-7486.

Park I, Lee K, Han J, Lee N, Lee W, Park K, Rhyu I (2009) Experience-Dependent Plasticity of Cerebellar Vermis in Basketball Players. Cerebellum 8:334-339.

Park S-H, Seo J-H, Kim Y-H, Ko M-H (2014) Long-term effects of transcranial direct current stimulation combined with computer-assisted cognitive training in healthy older adults. Neuroreport 25:122-126 110.1097/WNR.0000000000000080.

Pascual-Leone A (1995) Modulation of muscle responses evoked by transcranial magnetic stimulation during the acquisition of new fine motor skills. $\mathbf{J}$ Neurophysiol 74:1037-1045.

Pascual-Leone A, Torres F (1993) Plasticity of the sensorimotor cortex representation of the reading finger in Braille readers. Brain 116:39-52.

Pascual-Leone A, Amedi A, Fregni F, Merabet LB (2005) THE PLASTIC HUMAN BRAIN CORTEX. Annu Rev Neurosci 28:377-401.

Pereda AE, Bell TD, Chang BH, Czernik AJ, Nairn AC, Soderling TR, Faber DS (1998) $\mathrm{Ca} 2+/$ calmodulin-dependent kinase II mediates simultaneous enhancement of gap-junctional conductance and glutamatergic transmission. Proceedings of the National Academy of Sciences 95:13272-13277.

Peterson JC (2012) The Adaptive Neuroplasticity Hypothesis of Behavioral Maintenance. Neural Plasticity 2012:12. 
Picconi B, Centonze D, Hakansson K, Bernardi G, Greengard P, Fisone G, Cenci MA, Calabresi P (2003) Loss of bidirectional striatal synaptic plasticity in L-DOPAinduced dyskinesia. Nat Neurosci 6:501-506.

Picconi B, Paillé V, Ghiglieri V, Bagetta V, Barone I, Lindgren HS, Bernardi G, Angela Cenci M, Calabresi P (2008) 1-DOPA dosage is critically involved in dyskinesia via loss of synaptic depotentiation. Neurobiology of Disease 29:327-335.

Potkin SG, Basile VS, Jin Y, Masellis M, Badri F, Keator D, Wu JC, Alva G, Carreon DT, Bunney WE, Fallon JH, Kennedy JL (2003) D1 receptor alleles predict PET metabolic correlates of clinical response to clozapine. Mol Psychiatry 8:109-113.

Pruszynski JA, Coderre AM, Lillicrap TP, Kurtzer I (2007) Temporal Encoding of Movement in Motor Cortical Neurons. The Journal of Neuroscience 27:1007610077.

Puig MV, Miller Earl K (2012) The Role of Prefrontal Dopamine D1 Receptors in the Neural Mechanisms of Associative Learning. Neuron 74:874-886.

Purpura DP, McMurtry JG (1965) INTRACELLULAR ACTIVITIES AND EVOKED POTENTIAL CHANGES DURING POLARIZATION OF MOTOR CORTEX. Journal of Neurophysiology 28:166-185.

Rascol O, Blin O, Thalamas C, Descombes S, Soubrouillard C, Azulay P, Fabre N, Viallet F, Lafnitzegger K, Wright S, Carter JH, Nutt JG (1999) ABT-431, a D1 receptor agonist prodrug, has efficacy in Parkinson's disease. Annals of Neurology 45:736-741.

Rascol OO, Nutt JG, Blin OO, et al. (2001) INduction by dopamine d1 receptor agonist abt-431 of dyskinesia similar to levodopa in patients with parkinson disease. Archives of Neurology 58:249-254.

Reis J, Schambra HM, Cohen LG, Buch ER, Fritsch B, Zarahn E, Celnik PA, Krakauer JW (2009) Noninvasive cortical stimulation enhances motor skill acquisition over multiple days through an effect on consolidation. Proceedings of the National Academy of Sciences 106:1590-1595.

Rioult-Pedotti M-S, Friedman D, Donoghue JP (2000) Learning-Induced LTP in Neocortex. Science 290:533-536.

Rioult-Pedotti MS, Friedman D, Hess G, Donoghue JP (1998a) Strengthening of horizontal cortical connections following skill learning. Nature neuroscience $1: 230-234$.

Rioult-Pedotti MS, Friedman D, Hess G, Donoghue JP (1998b) Strengthening of horizontal cortical connections following skill learning. Nature neuroscience $1: 230-234$.

Rosa E, Dickinson D, Apud J, Weinberger D, Elvevåg B (2010) COMT Val158Met polymorphism, cognitive stability and cognitive flexibility: an experimental examination. Behavioral and Brain Functions 6:1-6.

Rösser N, Heuschmann P, Wersching H, Breitenstein C, Knecht S, Flöel A (2008) Levodopa Improves Procedural Motor Learning in Chronic Stroke Patients. Archives of physical medicine and rehabilitation 89:1633-1641.

Rothwell JC (1993) Evoked potentials, magnetic stimulation studies, and event-related potentials. Current opinion in neurology 6:715-723. 
Rueda-Orozco PE, Mendoza E, Hernandez R, Aceves JJ, Ibanez-Sandoval O, Galarraga E, Bargas J (2009) Diversity in long-term synaptic plasticity at inhibitory synapses of striatal spiny neurons. Learning \& Memory 16:474-478.

Saiote C, Turi Z, Paulus W, Antal A (2013) Combining functional magnetic resonance imaging with transcranial electrical stimulation. Frontiers in Human Neuroscience 7.

Salatino A, Berra E, Troni W, Sacco K, Cauda F, D’Agata F, Geminiani G, Duca S, Dimanico U, Ricci R (2013) Behavioral and neuroplastic effects of low-frequency rTMS of the unaffected hemisphere in a chronic stroke patient: A concomitant TMS and fMRI study. Neurocase:1-12.

Sanes JN, Donoghue JP (2000) Plasticity and Primary Motor Cortex. Annu Rev Neurosci 23:393-415.

Sawaguchi T (2001) The effects of dopamine and its antagonists on directional delayperiod activity of prefrontal neurons in monkeys during an oculomotor delayedresponse task. Neuroscience Research 41:115-128.

Sawaguchi T, Matsumura M, Kubota K (1986) Dopamine modulates neuronal activities related to motor performance in the monkey prefrontal cortex. Brain Research 371:404-408.

Sawaguchi T, Matsumura M, Kubota K (1990) Effects of dopamine antagonists on neuronal activity related to a delayed response task in monkey prefrontal cortex. Journal of Neurophysiology 63:1401-1412.

Schaechter JD, Moore CI, Connell BD, Rosen BR, Dijkhuizen RM (2006) Structural and functional plasticity in the somatosensory cortex of chronic stroke patients. Brain 129:2722-2733.

Scheidtmann K, Fries W, Müller F, Koenig E (2001) Effect of levodopa in combination with physiotherapy on functional motor recovery after stroke: a prospective, randomised, double-blind study. The Lancet 358:787-790.

Schultz W (2002) Getting Formal with Dopamine and Reward. Neuron 36:241-263.

Seamans JK, Yang CR (2004) The principal features and mechanisms of dopamine modulation in the prefrontal cortex. Progress in Neurobiology 74:1-58.

Seamans JK, Floresco SB, Phillips AG (1998) D1 Receptor Modulation of HippocampalPrefrontal Cortical Circuits Integrating Spatial Memory with Executive Functions in the Rat. The Journal of Neuroscience 18:1613-1621.

Seeman P (1987) Dopamine receptors and the dopamine hypothesis of schizophrenia. Synapse 1:133-152.

Seeman P, Kapur S (2000) Schizophrenia: More dopamine, more D2 receptors. Proceedings of the National Academy of Sciences 97:7673-7675.

Sigala S, Missale C, Spano P (1997) Opposite effects of dopamine D2 and D3 receptors on learning and memory in the rat. European Journal of Pharmacology 336:107112.

Sluming V, Barrick T, Howard M, Cezayirli E, Mayes A, Roberts N (2002) Voxel-Based Morphometry Reveals Increased Gray Matter Density in Broca's Area in Male Symphony Orchestra Musicians. Neuroimage 17:1613-1622.

Sokoloff P, Schwartz J-C (1995) Novel dopamine receptors half a decade later. Trends in Pharmacological Sciences 16:270-275. 
Spencer JP, Murphy KPSJ (2000) Bi-directional changes in synaptic plasticity induced at corticostriatal synapses in vitro. Experimental Brain Research 135:497-503.

Stagg CJ, Nitsche MA (2011) Physiological Basis of Transcranial Direct Current Stimulation. The Neuroscientist 17:37-53.

Stefan K, Kunesch E, Cohen LG, Benecke R, Classen J (2000) Induction of plasticity in the human motor cortex by paired associative stimulation. Brain 123:572-584.

Stefan K, Kunesch E, Benecke R, Cohen LG, Classen J (2002) Mechanisms of enhancement of human motor cortex excitability induced by interventional paired associative stimulation. The Journal of Physiology 543:699-708.

Tang K-C, Low MJ, Grandy DK, Lovinger DM (2001) Dopamine-dependent synaptic plasticity in striatum during in vivo development. Proceedings of the National Academy of Sciences 98:1255-1260.

Taylor JR, Lawrence MS, Redmond Jr DE, Elsworth JD, Roth RH, Nichols DE, Mailman RB (1991) Dihydrexidine, a full dopamine D1 agonist, reduces MPTP-ioduced parkinsonism in monkeys. European Journal of Pharmacology 199:389-391.

Thirugnanasambandam N, Grundey J, Paulus W, Nitsche MA (2011) Dose-Dependent Nonlinear Effect of 1-DOPA on Paired Associative Stimulation-Induced Neuroplasticity in Humans. The Journal of Neuroscience 31:5294-5299.

Tokimura H, Ridding MC, Tokimura Y, Amassian VE, Rothwell JC (1996) Short latency facilitation between pairs of threshold magnetic stimuli applied to human motor cortex. Electroencephalography and Clinical Neurophysiology/Electromyography and Motor Control 101:263-272.

Tolosa,\#160, E., BLESA, R., BAYES, A., FORCADELL, F. (1987) Low-dose bromocriptine in the early phases of Parkinson's disease. Hagerstown, MD, ETATS-UNIS: Lippincott Williams \&amp; Wilkins.

Trachtenberg JT, Chen BE, Knott GW, Feng G, Sanes JR, Welker E, Svoboda K (2002) Long-term in vivo imaging of experience-dependent synaptic plasticity in adult cortex. Nature 420:788-794.

Tseng KY, O'Donnell P (2004) Dopamine-Glutamate Interactions Controlling Prefrontal Cortical Pyramidal Cell Excitability Involve Multiple Signaling Mechanisms. The Journal of Neuroscience 24:5131-5139.

Tyč F, Boyadjian A, Devanne H (2005) Motor cortex plasticity induced by extensive training revealed by transcranial magnetic stimulation in human. European Journal of Neuroscience 21:259-266.

Vallone D, Picetti R, Borrelli E (2000) Structure and function of dopamine receptors. Neuroscience \&amp; Biobehavioral Reviews 24:125-132.

Vijayraghavan S, Wang M, Birnbaum SG, Williams GV, Arnsten AFT (2007) Inverted-U dopamine D1 receptor actions on prefrontal neurons engaged in working memory. Nat Neurosci 10:376-384.

Vincent S, Khan Y, Benes F (1993) Cellular distribution of dopamine D1 and D2 receptors in rat medial prefrontal cortex. The Journal of Neuroscience 13:25512564.

Wagner T, Fregni F, Fecteau S, Grodzinsky A, Zahn M, Pascual-Leone A (2007) Transcranial direct current stimulation: A computer-based human model study. Neuroimage 35:1113-1124. 
Whitlock JR, Heynen AJ, Shuler MG, Bear MF (2006) Learning Induces Long-Term Potentiation in the Hippocampus. Science 313:1093-1097.

Wiethoff S, Hamada M, Rothwell JC (2014) Variability in Response to Transcranial Direct Current Stimulation of the Motor Cortex. BRAIN STIMULATION: Basic, Translational, and Clinical Research in Neuromodulation 7:468-475.

Williams GV, Goldman-Rakic PS (1995) Modulation of memory fields by dopamine Dl receptors in prefrontal cortex. Nature 376:572-575.

Wilson CJ (2006) Striatal D2 Receptors and LTD: Yes, but Not Where You Thought They Were. Neuron 50:347-348.

Witte AV, Flöel A (2012) Effects of COMT polymorphisms on brain function and behavior in health and disease. Brain Research Bulletin 88:418-428.

Witte AV, Kürten J, Jansen S, Schirmacher A, Brand E, Sommer J, Flöel A (2012) Interaction of BDNF and COMT Polymorphisms on Paired-Associative Stimulation-Induced Cortical Plasticity. The Journal of Neuroscience 32:45534561.

Wolters A, Sandbrink F, Schlottmann A, Kunesch E, Stefan K, Cohen LG, Benecke R, Classen J (2003) A Temporally Asymmetric Hebbian Rule Governing Plasticity in the Human Motor Cortex. Journal of Neurophysiology 89:2339-2345.

Yang S-N, Tang Y-G, Zucker RS (1999) Selective Induction of LTP and LTD by Postsynaptic [Ca2+]i Elevation. Journal of Neurophysiology 81:781-787.

Zahrt J, Taylor JR, Mathew RG, Arnsten AFT (1997) Supranormal Stimulation of D1 Dopamine Receptors in the Rodent Prefrontal Cortex Impairs Spatial Working Memory Performance. The Journal of Neuroscience 17:8528-8535.

Ziemann U (2004) TMS and drugs. Clinical Neurophysiology 115:1717-1729.

Ziemann U, Rothwell JC, Ridding MC (1996) Interaction between intracortical inhibition and facilitation in human motor cortex. The Journal of Physiology 496:873-881.

Zucker RS (1999) Calcium- and activity-dependent synaptic plasticity. Current Opinion in Neurobiology 9:305-313. 


\section{Acknowledgements}

First of all, I would like to thank my supervisor Prof. Michael Nitsche for the support, patience and trust he gave me. I learned so much from him during the years of my studies and this work could not have been accomplished without his encouragement and brilliant ideas. I will be forever grateful to him for believing in my potentials from the very start. His healthy attitude toward research and his humbleness as a person are the characters I look up to the most. Many thanks also to the other members of my thesis committee, Prof. Fuchs and Prof. Waldmann, for the support and advice they gave me during my PhD.

I felt particularly indebted to the chairman of our department, Prof. Walter Paulus, for his support and guidance through these years. My gratitude goes also to the other professors in the department Prof. Martin Sommer and Prof. David Liebetanz for their support and Prof. Andrea Antal for her trust and friendship. I am grateful to our secretary Marion Kurze for all her help. To Manuel Hewitt, thank you for the personal and professional help you gave me; I will keep our friendship forever.

Special thanks to Peter Dechent, Carsten Schmidt-Samoa, Ilona Pfahlert, Britta Perl and Nina Kaeding from the department of Cognitive Neurology for helping me in my other study.

To all the former colleagues and friends from whom I learned a lot, a big "Thank You": Min-Fang Kuo, Katalin Janossy, Leila Chaieb, Nicole Neef, Rafael Polania, Nivethida Tirugnanasambandam, Catarina Saiote, Olga Gamboa Vera Moliadze and Geza Ambrus. Thanks also to the members of my working group - Giorgi Batsikadze, Linda Kuo, Yuichiro Shirota, Aguida Foerster, Asif Jamil, Elisabeth Stiksrud and Jessica 
Grundey - for their cooperation and help. I would like to thank specially Zsolt Turi for his effort answering all my statistical questions. To Nathzidy Rivera Urbina and Marcelo Lugon, thank you for the friendship and the happy times we shared together.

Warmest thanks to Dr. Jean-François Flot and my sister Dr. Asuncion FresnozaFlot, for without them I would never have gone into research: to their children Sarah, Athos and Philéas for inspiring me all the time; and to my sister Rafonsil and my mother for their love, inspiration and support. Heartfelt thanks also to my second family Erika, Manfred and Sam for their love and care.

Finally, I would like to express my gratitude to the GGNB and CSN for providing a program that nurtures student and new researchers, and to Kirsten Pöhlker, Rike Göbel and Dr. Gerrit Hennecke for all their friendly assistance. 


\section{Curriculum Vitae}

Name: Shane Matsune Fresnoza

Date of Birth: May 29, 1979

Place of Birth: San Pablo City, Laguna, Philippines

Nationality: Filipino

Contact Details: Klinik für Klinische Neurophysiologie, Robert-Koch-Str.40

Göttingen, 37075 Germany

(+49)176-31650354

sfresnoza@yahoo.com, shanefresnoza@gmail.com

\section{EDUCATION}

August 2010- present: Student, Doctor of Philosophy

University of Goettingen

Goettingen, Germany

Thesis: Dopaminergic Modulation of Neuroplasticity and

Cognition

June 2000-March 2004: Doctor of Medicine

De La Salle University-College of Medicine

Dasmarinas City, Cavite, Philippines

Thesis: Community Diagnosis (Barangay Paliparan, Phase III, Blocks 5, 6, and 7)

June 1996- March 2000: Bachelor of Science in Biology

Far Eastern University

Manila, Philippines.

Thesis: Chemotaxis: Response of Euglena gracilis to chemical stimuli

\section{EMPLOYMENT HISTORY}

2010: Research assistant

Clinical Neurophysiology Department, Georg August University, Goettingen Germany

2007-2010: Medical Officer I

Philippine National Red Cross, General Trias Medicare Hospital, 
Firstcare Medical Clinic

Cavite, Philippines

2006-2009: Resident Physician

Del Rosario Hospital, Bautista Hospital, Escuadro Clinic, Primacare

Clinic and Laboratory

Cavite, Philippines

2004-2005: Medical Internship

De La Salle University Medical Center,

Dasmarinas, Cavite Philippines

\section{Conferences, Activities and Presentations}

June 4-6, 2014- $3^{\text {rd }}$ International Workshop on Synaptic Plasticity: From Bench to Bedside, Milazzo, Sicily Italy

Poster Presentation: Dosage-dependent effect of D2 receptor activation on motor cortex plasticity in humans

March 19-2, 2014- 30 ${ }^{\text {th }}$ International Congress of Clinical Neurophysiology (ICCN) of the IFCN, Berlin Germany

Poster Presentation: Dosage-dependent effect of D2 receptor activation on motor cortex plasticity in humans

March 17-19, 2014- NWG Workshop on Basic and Advanced Transcranial Stimulation

Göttingen, Germany

December 9, 2013- Science Day Goettingen

Goettingen Germany

Poster Presentation: Dosage-dependent effect of D2 receptor activation on motor cortex plasticity in humans

May 22-25 ${ }^{\text {th }}$, 2013- NEURIZONS 2013

Goettingen Germany

Poster Presentation: Non-linear dose dependency of D1 receptor activation on motor cortex plasticity in humans

April 4, 2013- Neuroscience Conference

University of Pavia, Milano Italy

Oral Presentation: Basic and Advance Practical Course on Transcranial

Magnetic Stimulation; Dopaminergic Modulation of Neuroplasticity and

Cognition

February 2013- NWG Workshop on Basic and Advanced Transcranial Stimulation

Göttingen, Germany 
July 14-18, 2012- $8^{\text {th }}$ Federation of European Neuroscience Societies (FENS) Forum, Barcelona, Spain

Poster Presentation: Dosage-dependent effect of D1 receptor activation on motor cortex plasticity in humans

November 29, 2011-2 ${ }^{\text {nd }}$ GGNB Science Day

Göttingen Germany

Poster Presentation: Double dissociation of cortical excitability in smoking and none smoking individuals with and without nicotine

June $21-25,2011-14^{\text {th }}$ European Congress on Clinical Neurophysiology and $4^{\text {th }}$

International Conference on Transcranial Magnetic and Direct Current

Stimulation

Rome Italy

Poster Presentation: Double dissociation of cortical excitability in smoking and none smoking individuals with and without nicotine

May 28-29, 2011- Magstim 2011 TMS Summer School

University of Oxford, Oxford UK

Poster Presentation: Double dissociation of cortical excitability in smoking and none smoking individuals with and without nicotine

February 2011- NWG Workshop on Basic and Advanced Transcranial Stimulation Göttingen, Germany

February 2010- NWG Workshop on Basic and Advanced Transcranial Stimulation Göttingen, Germany.

\section{Publications}

Fresnoza S, Stiksrud E, Klinker F, Liebetanz D, Paulus W, Kuo M-F, Nitsche MA (2014) Dosage-dependent effect of D2 receptor activation on motor cortex plasticity in humans. The Journal of Neuroscience (Accepted)

Fresnoza S, Paulus W, Nitsche MA, Kuo M-F (2014) Nonlinear Dose-Dependent Impact of D1 Receptor Activation on Motor Cortex Plasticity in Humans. The Journal of Neuroscience 34(7):2744-2753.

Grundey J, Freznosa S, Klinker F, Lang N, Paulus W, Nitsche MA (2013). Cortical excitability in smoking and not smoking individuals with and without nicotine. Psychopharmacology 229(4): 653-664. 
Monte-Silva K, Kuo MF, Hessenthaler S, Fresnoza S, Liebetanz D, Paulus W, Nitsche MA (2013). Induction of Late LTP-Like Plasticity in the Human Motor Cortex by Repeated Non-Invasive Brain Stimulation. Brain Stimulation 6(3):424-432.

\section{Awards and Recognitions}

2010- Recipient: Certificate of Recognition for an outstanding contribution to the Philippine National Red Cross

2005- Passed the licensure examination for physician given by the Professional Regulation Commission of the Philippines

2000- Recipient: Certificate of Recognition as an Outstanding Officer given by the Biology and Physical Therapy Society, Far Eastern University

1996- Science Investigatory Projects $2^{\text {nd }}$ place award given by the Department of Science and Technology, Philippines

1996- Recipient: Medal as an Outstanding Scout of the Philippines

1992-1996- Consistent honor student - Barcenaga National High School 